\title{
INTERPRETING THE EVIDENCE ON LIFE CYCLE SKILL FORMATION
}

\author{
FLAVIO CUNHA \\ University of Chicago \\ JAMES J. HECKMAN \\ University of Chicago, University College London and The American Bar Foundation \\ LANCE LOCHNER \\ University of Western Ontario \\ DIMITRIY V. MASTEROV \\ University of Michigan
}

\section{Contents}

Abstract

$\begin{array}{ll}\text { Keywords } & 699\end{array}$

1. Introduction 700

2. A summary of the empirical evidence on life cycle skill formation 709

$\begin{array}{ll}\text { 2.1. Human capital accumulation } & 709\end{array}$

$\begin{array}{ll}\text { 2.2. Early test score differentials } & 711\end{array}$

2.3. The evidence on the importance of noncognitive skills 717

2.4. Critical periods, sensitive periods, and socioemotional bases of skill formation and remediation 719

2.5. Interpreting the role of family income: The evidence on credit constraints 729

2.5.1. Family income and enrollment in college $\quad 732$

2.5.2. Racial and family income gaps: Long-term family factors vs. short-term credit constraints

2.5.3. Borrowing constraints as determinants of family investment in children

2.5.4. High rate of return to schooling compared to the return on physical capital

2.5.5. Are rates of return to investment higher for persons from low-income families?

2.5.6. The role of ability in returns to schooling and in choice of post-school investment 
2.6. What is known about specific policies to foster ability and skill? 750

2.6.1. Early interventions $\quad 750$

2.6.2. Intervention in the adolescent years $\quad 771$

2.6.3. The effectiveness of late adolescent and young adult remediation programs $\quad 775$

3. Using the technology of skill formation to explain the evidence 780

$\begin{array}{ll}\text { 3.1. A model of skill formation } & 780\end{array}$

3.2. The technology of skill formation in overlapping generations economies 793

$\begin{array}{ll}\text { 3.2.1. Generational structure and the human capital production function } & 794\end{array}$

3.2.2. Formalizing the problem of the agent 794

3.3. The technology of skill formation in a model with credit constraints 795

3.4. The technology of skill formation in a model with market incompleteness 796

$\begin{array}{ll}\text { 4. Summary and conclusions } & 799\end{array}$

$\begin{array}{ll}\text { Acknowledgements } & 802\end{array}$

$\begin{array}{ll}\text { Appendix A } & 802\end{array}$

$\begin{array}{ll}\text { A.1. The general technology of skill formation } & 802\end{array}$

A.2. Relationship with the Ben-Porath (1967) model 804

$\begin{array}{ll}\text { References } & 805\end{array}$

\begin{abstract}
This paper presents economic models of child development that capture the essence of recent findings from the empirical literature on skill formation. The goal of this essay is to provide a theoretical framework for interpreting the evidence from a vast empirical literature, for guiding the next generation of empirical studies, and for formulating policy. Central to our analysis is the concept that childhood has more than one stage. We formalize the concepts of self-productivity and complementarity of human capital investments and use them to explain the evidence on skill formation. Together, they explain why skill begets skill through a multiplier process. Skill formation is a life cycle process. It starts in the womb and goes on throughout life. Families play a role in this process that is far more important than the role of schools. There are multiple skills and multiple abilities that are important for adult success. Abilities are both inherited and created, and the traditional debate about nature versus nurture is scientifically obsolete. Human capital investment exhibits both self-productivity and complementarity. Skill attainment at one stage of the life cycle raises skill attainment at later stages of the life cycle (self-productivity). Early investment facilitates the productivity of later investment (complementarity). Early investments are not productive if they are not followed up by later investments (another aspect of complementarity). This complementarity explains why there is no equity-efficiency trade-off for early investment. The returns to investing early in the life cycle are high. Remediation of inadequate early investments is difficult and very costly as a consequence of both self-productivity and complementarity.
\end{abstract}




\section{Keywords}

skill formation, education, government policy, educational finance

JEL classification: J31, I21, I22, I28 


\section{Introduction}

The most valuable of all capital is that invested in human beings; and of that capital the most precious part is the result of the care and influence of the mother. Marshall (1890, paragraph VI.IV.11)

The study of human skill formation is no longer handicapped by the taboo that once made it impermissible to discuss differences among people. It is well documented that individuals are very diverse in a variety of abilities, that these abilities account for a substantial amount of the interpersonal variation in socioeconomic outcomes, and that this diversity is already apparent at an early age. The family plays a powerful role in shaping these abilities, contributing both genetic endowments and pre- and post-natal environments, which interact to determine the abilities, behavior and talents of children. Some families do this task poorly, with detrimental consequences for their children. From a variety of intervention studies, we know that it is possible to partially compensate for exposure to adverse environments if high-quality interventions are made sufficiently early in children's lives. The remediation efforts that appear to be most effective are those that supplement family resources for young children from disadvantaged environments. Since the family is the fundamental source of inequality in American society, programs that target children from disadvantaged families can have substantial economic and social returns.

This chapter presents formal models of skill formation that distill the essence of recent empirical findings from the literature on child development. The goal is to provide a theoretical framework for interpreting the evidence from a large empirical literature, for guiding the next generation of empirical studies, and for formulating policy.

Recent empirical research has substantially improved our understanding of how skills and abilities are formed over the life cycle. The early human capital literature [Becker (1964)] viewed human capital as a rival explanation for human ability in explaining earnings. It emphasized that acquired human capital could explain many features of earnings distributions and earnings dynamics that models of innate and invariant cognitive ability could not. This point of view still underlies many recent economic models of family influence [e.g., Aiyagari, Greenwood and Sechadri (2002), Becker and Tomes $(1979,1986)]$. Related work [Ben-Porath (1967), Griliches (1977)] emphasized that invariant innate ability was an input into the production of human capital, although its effect on human capital accumulation was ambiguous. More innate ability could lead to less schooling if all schooling does is to teach what an able person could learn without formal instruction. On the other hand, more innate ability might make learning easier and promote schooling. The signaling literature [Spence (1973), Stiglitz (1975)] focused on the latter interpretation in developing models of education where higher levels of schooling signal higher innate ability. In its extreme form, this literature suggested that there was no learning content in schooling.

The entire literature assumed that ability is an innate, scalar, age-invariant measure of cognitive skill. This early point of view still prevails in most quarters of economics. 
Except for work by Marxist economists [see, e.g., Bowles and Gintis (1976), Edwards (1976)], noncognitive traits like motivation, persistence, time preference, and self control were neglected in empirical research and treated as "soft skills," peripheral to educational and labor market outcomes.

In contrast to the wisdom of Marshall (1890), as encapsulated in the quotation that begins this chapter, the recent economic literature on family influence on child outcomes focuses on family income constraints and heritability as the principal sources of parental influence on child development. Becker and Tomes $(1979,1986)$ initiated a large literature that emphasized the importance of credit constraints and family income on the schooling and earnings of children. Important developments of this work by Benabou (2000, 2002), Aiyagari, Greenwood and Seshadri (2002), Caucutt and Kumar (2003), Hanushek, Leung and Yilmaz (2004), and Seshadri and Yuki (2004), emphasize the role of credit constraints and altruism in forming the skills of children. In this work, ability is treated as determined by genetic factors. The life cycle of the child at home is collapsed into a single period so that there is no distinction between early and late investments in children. Becker and Tomes (1986) show that there is no trade-off between equity and efficiency in making government transfers directed toward credit-constrained families because the return to human capital investment in children from such families is high due to the presence of credit constraints. We show that their insight holds true for early period investments in a multi-period model of child investment, but not for investments in later periods. We also generalize their discussion of credit constraints to a multiperiod setting following work by Caucutt and Lochner (2004), Cunha (2004), and Cunha and Heckman (2004, 2006).

Recent research, summarized in Heckman (2000) and Carneiro and Heckman (2003), presents a richer picture of schooling, life cycle skill formation and earnings determination. It recognizes the importance of both cognitive and noncognitive abilities in explaining schooling and socioeconomic success. These abilities are produced by the family and by personal actions. The role of the mother is especially important, as anticipated in the quote by Marshall that begins this chapter. Both genes and environments are involved in producing these abilities. Environments affect genetic expression mechanisms [see, e.g., Turkheimer et al. (2003)]. This interaction has important theoretical and empirical implications for skill policies. It suggests an important role for environmentenriching policies in fostering human skills.

In the light of a substantial body of recent research, the traditional sharp distinction between acquired skills and genetically determined cognitive ability maintained in the human capital literature is no longer tenable. Abilities are multiple in nature. They are both cognitive and noncognitive. Measured cognitive ability is susceptible to environmental influences, including in utero experiences. So is measured noncognitive ability. There are genetic components to both. ${ }^{1}$ We have come to understand that achievement tests used to monitor performance in school and to determine acceptance

1 See Robinson, Grozinger and Whitfield (2005) for a summary of recent research on primates and other animals. See Knudson et al. (2006). 
into the military are not the same as IQ tests. Achievement test scores are determined by IQ, noncognitive inputs and by environmental factors. Even IQ can be affected by environmental interventions at least up to age 10 or so. ${ }^{2}$ It is hard to change IQ after this age. In the popular literature, achievement tests and IQ tests are often confused. ${ }^{3}$ Achievement test scores are affected by IQ, schooling inputs, and noncognitive skills, and are malleable over a much greater range of ages than is IQ. Noncognitive abilities such as motivation, self-discipline, and time preference - associated with the development of the prefrontal cortex - are also affected by environmental influences. They are more malleable at later ages than IQ. Achievement test outcomes can be influenced until very late ages and are affected by both cognitive and noncognitive skills. Noncognitive abilities and cognitive abilities affect schooling attainment and performance, and a wide array of behaviors [Heckman, Stixrud and Urzua (2006)]. Abilities have an acquired character although they differ in their malleability at different ages.

We characterize the human skill formation process in the following fashion. Skills and abilities are used interchangeably throughout this chapter because both are affected by environments, investment and genes. Agents possess a vector of abilities at each age. These abilities - or skills - are multiple in nature and range from pure cognitive abilities (e.g., IQ) to noncognitive abilities (patience, self control, temperament, time preference). Achievement test scores are affected by cognitive, noncognitive and environmental inputs. These abilities are used with different weights in different tasks in the labor market and in social life more generally.

The human skill or ability formation process is governed by a multistage technology. Each stage corresponds to a period in the life cycle of a child. Inputs or investments at each stage produce outputs at that stage. Unlike the Ben-Porath (1967) model, in our models qualitatively different inputs can be used at different stages and the technologies may be different at different stages. ${ }^{4}$ The outputs at each stage are the levels of each skill achieved at that stage. Some stages of the technology may be more productive in producing some skills than other stages, and some inputs may be more productive at some stages than at other stages. Those stages that are more productive in producing certain skills are called "sensitive periods" for those skills. If one stage alone is effective in producing a skill (or ability) it is called a "critical period" for that skill.

An important feature of this technology is that the skills produced at one stage augment the skills attained at later stages. This is termed self-productivity. It embodies the

\footnotetext{
${ }^{2}$ Until age 4 or 5, measures of IQ do not predict adult IQ very well. Using parental IQ actually yields a better prediction of the child's score at age 15 than any test given before age 5 . After age 10, however, IQ becomes stable within the constraints of psychometric measurement error. See Jensen (1980) for a discussion.

3 See, e.g., Herrnstein and Murray (1994).

${ }^{4}$ Heckman, Lochner, and Taber (1998) generalize and estimate the Ben-Porath model by allowing the technology producing schooling human capital to be different from the technology producing post-school investment. Su (2004) and Cardak and Givon (2004) develop multistage models of secondary and postsecondary schooling choices focusing on determinants of progression through school. However, their emphasis is on later stages of the life cycle, not the early years.
} 
idea that skills acquired in one period persist into future periods. It also embodies the idea that skills are self-reinforcing. For example, self-control and emotional security may reinforce intellectual curiosity and promote more vigorous learning of cognitive skills. A second key feature of skill formation is complementarity. Skills produced at one stage raise the productivity of investment at subsequent stages. In a multistage technology, complementarity also implies that levels of skill investments at different ages bolster each other. They are synergistic. Complementarity also implies that early investment has to be followed up by later investment in order for the early investment to be productive. Together, complementarity and self-productivity produce multiplier effects which explain how skills beget skills and abilities beget abilities.

Complementarity, self-productivity of human capital and multiplier effects imply an equity-efficiency trade-off for late child investments but not for early investments. These features of the technology of skill formation have consequences for the design and evaluation of public policies toward families. In particular, the returns to late childhood investment and remediation for young adolescents from disadvantaged backgrounds are low, while the returns to early investment in children from disadvantaged environments are high.

Our analysis demonstrates the quantitative insignificance of credit constraints in the college-going years in explaining child college enrollment. Controlling for cognitive ability, under meritocratic policies currently in place in American society, family income during the child's college-going years plays only a minor role in determining child college participation, although much public policy is predicated on precisely the opposite point of view. Abilities (and skills) are formed over time, and the early periods in a child's life cycle are crucial for development. Augmenting family income only in the time period when a child goes to college will not make up for suboptimal investment in the 18 years before. Permanent family income plays an important role in explaining educational choices, insofar as it is a proxy for the high level of investment in abilities and skills that wealthier families provide, but it is not synonymous with family income in the adolescent years, nor with tuition and fees.

Carneiro and Heckman $(2002,2003)$ present evidence for the United States that only a small fraction (at most $8 \%$ ) of the families of American adolescents are credit constrained in making their college decisions. The quantitatively important constraints facing disadvantaged children are the ones determining their early environments - parental background, and the like. The empirically important market failure in the life cycle of child skill formation is the inability of children to buy their parents or the lifetime resources that parents provide, and not the inability of families to secure loans for a child's education when the child is an adolescent. Our analysis has major implications for the way policies should be designed in order to help low income and disadvantaged populations. Evidence from disadvantaged populations demonstrates that enriched early interventions can raise measured ability and other skills.

Ours is an unusual survey. The standard approach to survey writing in empirical economics is to compile lists of facts and "treatment effects" from various empirical studies. Instead, in this chapter, we develop a comprehensive model of the skill forma- 
tion process that is grounded in the best available empirical evidence. We distill general theoretical principles that can guide skill formation policy. We present economic models that focus on basic principles. Any study of skill formation policy grounded in economic and scientific fundamentals improves on a purely empirical approach to policy evaluation that relies on evaluations of the programs and policies in place or those previously experienced. Although economic policy analysis should be grounded in data, it is important to recognize that those policies that can be evaluated empirically are only a small subset of the policies that might be tried. ${ }^{5}$ If we base speculation about economic policies on economic fundamentals, rather than solely on estimated "treatment effects" that are only weakly related to those fundamentals, we are in a better position to think beyond what has been tried to propose more innovative answers to skill formation questions. We investigate the study of skill formation policy by placing it in the context of economic models of life cycle learning and skill accumulation rather than focusing exclusively on which policies have "worked" in the past. The current literature on childhood skill formation abounds in facts and figures, but lacks a clear interpretive framework that is faithful to the evidence. If a picture (graph) is worth a thousand words, then a model is worth a thousand pictures (graphs). Our models summarize the existing evidence succinctly and point the way to future developments.

Any model that is faithful to the evidence summarized in this paper must recognize that (a) parental influences are key factors governing child development; (b) early child investments must be distinguished from late child investments and that an equityefficiency trade-off exists for late investments, but not for early investments; (c) abilities are created, not solely inherited, and are multiple in variety; and (d) the traditional ability-skills dichotomy is obsolete. These insights change the way we interpret evidence and design policy. Point (a) is emphasized in many papers. Point (b) is ignored by models that consider only one period of childhood investment. Points (c) and (d) have received scant attention in the formal literature on child investment.

The central concept in this paper is the production function for skills. Since both skills and abilities can be acquired, we do not distinguish between these two concepts. Both skills and abilities are affected by genes, environments and personal actions. ${ }^{6} \mathrm{We}$ use a skill production technology to interpret the evidence on the life cycle evolution of skills and abilities, developing the technology and its implications more formally in Section 3.

Here, we provide an intuitive summary of the main theoretical ideas that organize the evidence presented in this paper. Assume, for the sake of simplicity, that there are two stages in the life cycle of the child prior to attaining adulthood. Adulthood is a third and

\footnotetext{
5 See Heckman and Vytlacil (2005, 2007a, 2007b) for comprehensive discussions of econometric policy evaluation.

6 One possible distinction between abilities and skills is that the latter are acquired by personal actions while the former are acquired by external influences. This distinction is not sharp since personal actions may affect the operation of the environment on the individuals, and personal actions (self help programs) may alter abilities.
} 
final stage. Denote investment in a child during period $t$ as $I_{t}$, and the skill produced from that investment as $S_{t}$ for $t=1,2$. Both $I_{t}$ and $S_{t}$ may be vectors (e.g., cognitive and noncognitive skills), and they may be of different dimensions. The $S_{t}$ are different levels of the same skills or abilities at different stages. Thus $S_{t}$ could contain a variety of abilities and skills, ranging from pure IQ to noncognitive skills like motivation. It could also include cognitive skills as measured in achievement tests that are affected by IQ, motivation and self-control. $I_{t}$ is a vector of investments at stage $t$. These may be stage-specific investments (e.g., phonics lessons) or general investments that are not stage-specific. Some stages may be uniquely suited to the formation of some skills. These are the critical or sensitive periods.

Let $S_{0}$ be the vector of initial skills of the child, say at birth. These skill levels may be influenced by in utero experiences and genetics. ${ }^{7}$ We define the technology of skill formation at stage $t$ in a recursive fashion:

$$
S_{t}=f_{t}\left(I_{t}, S_{t-1}\right)
$$

where $f_{t}(\cdot)$ is increasing in $\left(I_{t}, S_{t-1}\right)$ and is concave in $I_{t}$. For simplicity, we assume differentiability, except in special cases. Each stage of the life cycle may have a different production technology using different inputs. ${ }^{8}$

Different adult tasks $j=1, \ldots, J$ require skills that can be combined in different ways to produce task-specific output at period $t$ in adult life, $T_{j, t}$. The tasks correspond to the outputs in the $J$ different occupations (e.g., lawyer, ditch digger, full time mother, athlete):

$$
T_{j, t}=T_{j, t}\left(S_{t}\right) \quad \text { for } j=1,2, \ldots, J .
$$

In some tasks, components of $S_{t}$ can substitute for each other. In other tasks, those same components may be strongly complementary. For example, to be a good mother requires many skills. To be a good ditch digger requires fewer skills.

Appendix A presents a more general discussion of our specification of the technology of skill formation and compares it to the conventional Ben-Porath (1967) model which is a very special case of our framework. Throughout much of this paper, we focus on technology (1), and for simplicity we assume that there is one task in the economy. However, task function (2) reminds us that remediation for early disadvantage may take two forms: (a) through later investments or (b) through subsidy and technical change in the tasks that disadvantaged children can perform in adulthood. ${ }^{9}$

Given the technology of skill formation (1), the concept of universal self-productivity is captured by the assumption that $\frac{\partial S_{2}}{\partial S_{1}}=\frac{\partial f_{2}}{\partial S_{1}}>0 .{ }^{10}$ More generally, some components

7 As emphasized in the studies in Keating and Hertzman (1999) these endowments are influenced by parental genes and environment.

8 This technology and its properties are developed more formally in Appendix A.

${ }^{9}$ For example, remediation through technological change might involve automatic change machines for cashiers who are innumerate.

10 A better terminology would be "recursive productivity," where the output from one stage is the input in the next stage because $S_{1}$ and $S_{2}$ can be vectors. 
of $S_{1}$ may be productive for $S_{2}$ while others may not or may even have a negative effect. This formulation is sufficiently general to allow cross effects of knowledge of one skill (or ability) on another skill (or ability). ${ }^{11}$ The concept of universal direct complementarity of investments in stage 2 technology is that

$$
\frac{\partial^{2} f_{2}\left(I_{2}, S_{1}\right)}{\partial I_{2} \partial S_{1}^{\prime}}>0 \text {. }
$$

For the vector case, this says that higher levels of the stocks of all skills increase the productivity of period 2 investment. More generally, $\frac{\partial^{2} f_{2}\left(I_{2}, S_{1}\right)}{\partial I_{2} \partial S_{1}^{\prime}} \geqslant 0$, since some inputs may not be complementary with stocks of past skills or abilities. Even more generally, some skills may have a negative effect on the productivity of some investments. ${ }^{12}$

In addition to the notions of direct complementarity and self-productivity in skill production, there is the notion of complementarity or substitution of period $t$ skills in each task, as determined by the task function (2). The story of the tortoise and the hare tells us that it is sometimes possible to compensate with effort for what one lacks in pure athletic skill. In the general case with $J$ different task functions corresponding to different adult jobs or occupations, tasks will have different degrees of substitution among the skills, and some components of skills are irrelevant for certain tasks, so it is possible in some tasks to compensate for skill deficits while for other tasks it may not be. A failure to acquire one skill can be offset by choosing to do tasks that do not require it or else by compensating for investments in other skills.

The structure of complementarity or substitutability in investments over time as governed by equation (1) is crucial in determining whether or not there is an equityefficiency trade-off for late investments. ${ }^{13}$ To see this, consider two children, $A$ and $B$, with $S_{0}^{A}=S_{0}^{B}$ but who differ, for whatever reason, in their level of period 1 investment, $I_{1}$. We assume that there is only one investment good. Suppose that $A$ comes from

11 In capital theory, the "Crusonia vine" of Knight (1944) is a pure version of a self productive process. His vine grows at a fixed rate of $g$ per year, independently of any inputs once the seed is sown. In our notation, for a scalar $S_{t}$ this would be $S_{t}=(1+g) S_{t-1}$, so that $S_{t}=(1+g)^{t} S_{0}$ and $\partial f_{t} / \partial I_{t} \equiv 0$ for $t>0$. Our notation is more general because we allow for multiple inputs that may interact synergistically.

12 In capital theory, Hayek's (1941) stages of production of capital entail investments at each stage that are stage-specific. His theory encompasses both self-productivity and direct complementarity.

13 Complementarity has multiple definitions in economics and these definitions are not equivalent [Samuelson (1974)]. The two polar cases, perfect substitutes and perfect complements, have been a part of the economist's toolkit at least since Fisher (1982). A production function for output, $g(x, y)$, defined in terms of inputs $(x, y)$ is said to exhibit perfect substitution among the inputs if the output $g(x, y)$ is

$$
g(x, y)=g(a x+(1-a) y), \quad 0<a<1 .
$$

Thus $x$ and $y$ substitute perfectly in the sense that one unit of $y$ produces exactly the same output as $(1-a) / a$ units of $x$ for all levels of $x$ and $y$. If $x$ is an early input and $y$ is a late input, technically one can always remediate for a low $x$ input by a compensation in terms of $y$. If $a=1$, this is not possible. The closer $a$ is to 1 , the greater the required remediation in $y$. As we note in this chapter, it may not be economically feasible or efficient to remediate. 
a deprived environment whereas $B$ does not so $\bar{I}_{1}^{A}<\bar{I}_{1}^{B} \cdot{ }^{14}$ Given period 1 investments, what is the appropriate investment allocation for period 2? If there is one skill, and the goal is to maximize the sum of adult skills in society, the problem is

$$
\max \left(S_{2}^{A}+S_{2}^{B}\right) \quad \text { given } I_{1}^{A}=\bar{I}_{1}^{A}, I_{1}^{B}=\bar{I}_{1}^{B} \cdot 15
$$

This is the "social planner's" problem.

\section{Perfect complementarity characterizes $g(x, y)$ if}

$$
g(x, y)=g(\min (x, y)) .
$$

This is an "O ring" technology where output is limited by the weakest link (the lowest level of input). Thus if $x$ is an early input, a low level of $x$ cannot be remediated by any investment in $y$. Another implication of this technology is that if $x$ is big, a low level of $y$ undoes the early investment.

A second definition of complementarity and substitution, sometimes called direct substitution or complementarity, for a twice differentiable $g(x, y)$ is that $(x, y)$ are direct complements if

$$
\partial^{2} g(x, y) / \partial x \partial y>0,
$$

while $(x, y)$ are direct substitutes if

$$
\partial^{2} g(x, y) / \partial x \partial y<0 .
$$

Inputs $(x, y)$ are independent if

$$
\partial^{2} g(x, y) / \partial x \partial y=0 .
$$

What is confusing is that the two definitions do not always agree. Suppose that $g(x, y)=a x+(1-a) y$. Then $(x, y)$ are perfect substitutes under the first definition, but they are independent inputs under the second definition. Note further that if $(x, y)$ are perfect complements under the first definition, $g$ is not everywhere differentiable. However, if $g$ is strictly concave and differentiable, $(x, y)$ are perfect substitutes under either definition. To make matters worse if $g(x, y)$ is homogeneous of degree one and $\partial^{2} g(x, y) / \partial x^{2}<0$, then it is a consequence of Euler's Theorem that

$$
\partial^{2} g(x, y) / \partial x \partial y>0
$$

so that inputs are direct complements.

The CES technology for two inputs,

$$
g(x, y)=\left[a x^{\sigma}+(1-a) y^{\sigma}\right]^{1 / \sigma},
$$

nests the two polar cases subsumed in the first definition $(\sigma=1$ perfect substitutes; $\sigma=-\infty$ for perfect complements). The parameter $\sigma$ is a measure of substitution or complementarity. However for $0<a<1$ and $-\infty<\sigma<1$,

$$
\partial^{2} g(x, y) / \partial x \partial y>0,
$$

so that $(x, y)$ are direct complements for all values of the substitution/complementarity parameter $\sigma$. In the general case with more than 2 inputs, direct complementarity is not imposed as a consequence of assumptions about substitution or complementarity in the CES case. In the example, we use the two polar cases because they are intuitive.

14 Plausibly $S_{0}^{A}<S_{0}^{B}$, but we abstract from this.

15 This criterion is the same as maximizing human capital if adult skill is the same as adult human capital. 
Assume that the resources available for investment are $M .{ }^{16}$ We assume that the social planner is free to impose taxes and lump sum transfers. For large enough $M$ (i.e., assuming that investment is feasible), this problem yields the interior solution

$$
\frac{\partial f_{2}\left(I_{2}^{A}, S_{1}\left(\bar{I}_{1}^{A}\right)\right)}{\partial I_{2}^{A}}=\frac{\partial f_{2}\left(I_{2}^{B}, S_{1}\left(\bar{I}_{1}^{B}\right)\right)}{\partial I_{2}^{B}} .
$$

The marginal return to second period investment should be equated across persons. ${ }^{17}$

Consider the role of complementarity and substitutability by first studying the polar case in which inputs are perfect substitutes in the intuitive [Fisher (1982)] sense of the term. If $I_{2}$ and $S_{1}$ are perfect substitutes, the second period technology can be written as $S_{2}=f_{2}\left(\gamma S_{1}+(1-\gamma) I_{2}\right)$ for $0 \leqslant \gamma \leqslant 1$. The parameter $\gamma$ determines the relative productivity of investment in the different periods. For interior solutions, the problem of maximizing social output yields the first order condition:

$$
f_{2}^{\prime}\left(\gamma \bar{S}_{1}^{A}+(1-\gamma) I_{2}^{A}\right)=f_{2}^{\prime}\left(\gamma \bar{S}_{1}^{B}+(1-\gamma) I_{2}^{B}\right),
$$

which implies that adult skill levels are equated. Specifically, second period investments are fully equalizing:

$$
I_{2}^{A}=I_{2}^{B}+\frac{\gamma}{1-\gamma}\left(\bar{S}_{1}^{B}-\bar{S}_{1}^{A}\right)
$$

so there is full compensation for adverse early environments.

If $S_{1}$ and $I_{2}$ are strong complements in the intuitive sense of that term, we obtain a very different result. Consider the polar opposite case of perfect complementarity (i.e., the so-called "Leontief case") with

$$
S_{2}=f_{2}\left(\min \left\{S_{1}, I_{2}\right\}\right) .
$$

It takes a unit of $S_{1}$ and a unit of $I_{2}$ together to produce $S_{2}$. In the Leontief case, efficiency dictates that lower first period investments in $A$ relative to $B$ be followed by lower second period investments in $A$ relative to $B\left(\bar{I}_{1}^{A}<\bar{I}_{1}^{B}\right.$ implies $\left.I_{2}^{A}<I_{2}^{B}\right)$. Efficiency in this case dictates a policy that perpetuates the initial inequality of inputs due to disadvantaged environments. Attempts to remediate early deficits are not possible due to the structure of the technology of skill formation. There is an efficiency-equity trade-off for period 2 investments, but not for period 1 investments. With this production technology, the skill level attained in period 2 is restricted by the skill level attained earlier. Period 1 is a bottleneck period. Efficient period 2 investment can be no larger than period 1 investment. This example is a bit artificial because we have postulated only a single skill. More generally, there may be some skills (abilities) that are essential for making investment in the second period productive.

\footnotetext{
16 This may include social and private resources.

17 Low $M$ may imply zero investment for one or both persons unless Inada conditions (which guarantee infinite marginal product at zero levels of input) are imposed on the production function.
} 
Complementarity has a dual face. Investments in the young are essential and cannot easily be substituted for by later investments. At the same time, later investments are needed to make the early investments pay off. On efficiency grounds, the Leontief example shows that early disadvantages will be perpetuated and compensatory investments at later ages may be inefficient if complementarity is sufficiently strong.

On the other hand, a technology with perfect substitutes and equal productivity of investments at all ages implies that the timing of investment is irrelevant for producing a given level of human capital. Indeed, with discounting and common unit investment costs across periods, common productivity in both periods (i.e., $\gamma=1 / 2$ ), and $S_{1}=I_{1}$, later investments are preferred to early investments because it is cheaper to defer costs. Second period compensation for adverse environments will be efficient. Delaying all investments to the second period is optimal. However, if $\gamma$ is close to 1 it may be very costly to remediate deficient first period investments. When $\gamma=1$, it is impossible.

We develop some implications of complementarity and age-specific productivity in this paper for the general vector case in Appendix A. We organize the evidence we present in this chapter around the concepts of self-productivity and complementarity. We introduce the notion of a skill multiplier in Section 3.1. The available empirical evidence on human skill formation is consistent with both self-productivity and complementarity. These features of the technology of human skill formation explain why early interventions targeted towards disadvantaged young children are more effective than interventions given to older disadvantaged children, and why later investments yield higher returns for the more able.

The plan of this chapter is as follows. Section 2 presents the evidence. Section 3 presents simple formal models that summarize the evidence by using economic theory, applying the concepts of complementarity, self-productivity, and the derived investment multiplier. Section 4 concludes the paper.

\section{A summary of the empirical evidence on life cycle skill formation}

\subsection{Human capital accumulation}

Skill formation is a dynamic process. The skills and abilities acquired in one stage of the life cycle affect the productivity of learning in the next stage. Human capital, as we define it in this chapter, consists of different types of skills and abilities. It is now well established that cognitive ability is an important determinant of schooling and labor market outcomes [see Heckman (1995)]. At the same time, noncognitive abilities, although harder to measure, play an important role as well [see the evidence in Heckman, Stixrud and Urzua (2006). As emphasized in recent studies of child development [e.g., Shonkoff and Phillips (2000)], different abilities are formed and shaped at different stages of the life cycle. Empirical evidence from human and animal species tells us that when the opportunities for formation of these abilities are missed, remediation can 
be costly, and full remediation prohibitively costly [Cameron (2004), Knudsen (2004), Knudsen et al. (2006)]. These findings highlight the need for economists to take a comprehensive view of skill formation over the life cycle.

The dynamic feature of human capital accumulation has implications for how investments in human skills should be distributed over the life cycle. Figure 1A summarizes the major finding of an entire literature. It plots the rate of return to human capital at different stages of the life cycle for a person of given abilities. The horizontal axis represents age, which is a surrogate for the agent's stage in the life cycle of skill formation. The vertical axis represents the rate of return to investment assuming the same amount of investment is made at each age. This is an out-of-equilibrium productivity curve. $\mathrm{Ce}$ teris paribus, the rate of return to a dollar of investment made while a person is young is higher than the rate of return to the same dollar invested at a later age. Optimal investment profiles equate the marginal rate of return to investment with the opportunity cost of funds in all periods and for all persons, assuming that these investments are feasible. For an externally specified constant opportunity cost of funds $r$ (represented by the horizontal line with intercept $r$ in Figure 1A), an optimal investment strategy is to invest relatively less when a person is old and more at younger ages (see Figure 1B). For persons with higher "innate" ability (higher $S_{0}$ in the production technology of Section 1 ), both curves shift to the right.

Cognitive ability is only one aspect of $S_{0}$. It is necessary for success in life, but for many aspects of performance in social life, it is not sufficient. Noncognitive abilities also matter for success both in the labor market and in schooling. Even when early childhood

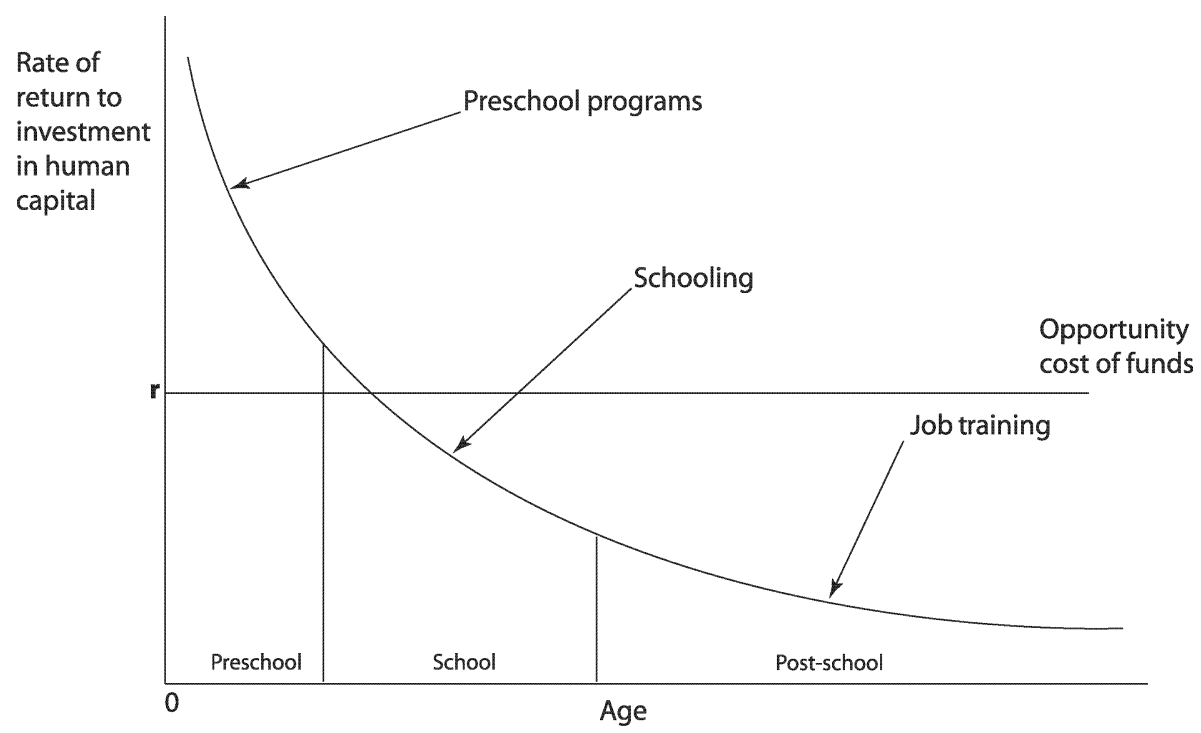

Figure 1A. Rates of return to human capital investment initially setting investment to be equal across all ages. 


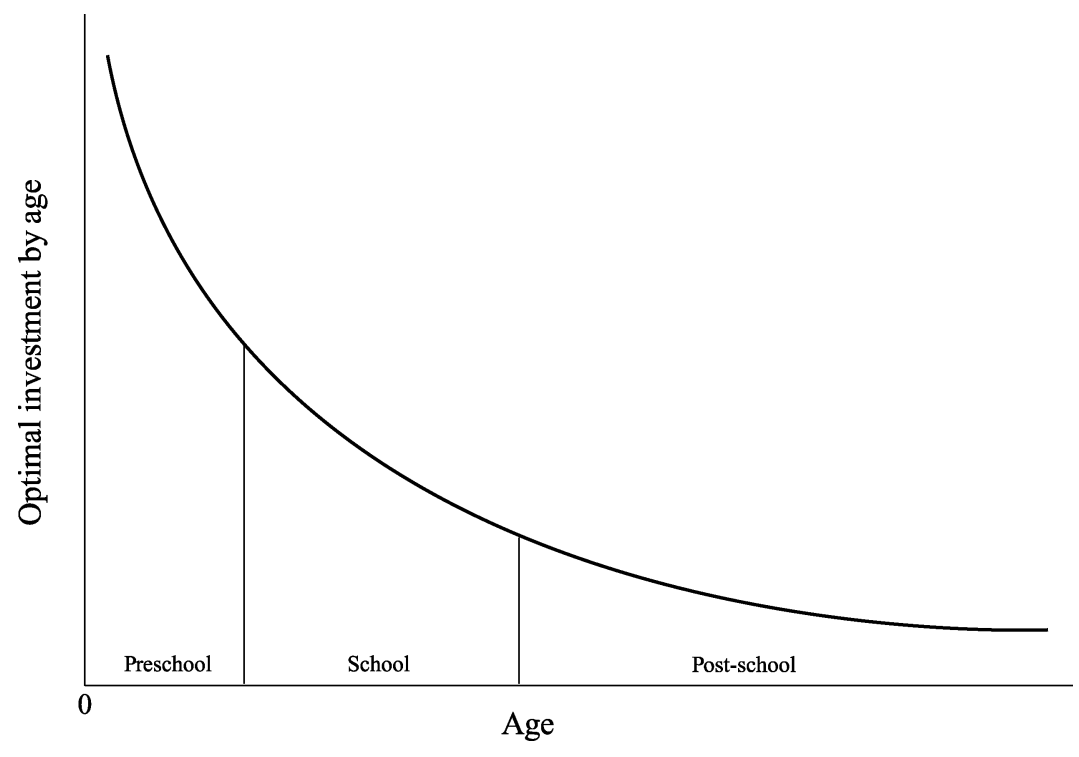

Figure 1B. Optimal investment levels.

interventions do not boost IQ, they improve noncognitive skills, with substantial effects on schooling, labor market outcomes, and behavioral outcomes such as teenage pregnancy and participation in criminal activities. They raise achievement test scores, which can be influenced by schooling (and other inputs), even when they do not boost IQ. In light of this evidence, the neglect of noncognitive ability in evaluating human capital interventions, and in formalizing the skill formation process, is unwarranted. We summarize the evidence on the importance of noncognitive skills in Section 2.3. For now, it will suffice to say that both types of skills or abilities are affected by families and schools, but they differ in their malleability over the life cycle. Differences in levels of cognitive and noncognitive skills by family income and family background emerge early and persist. If anything, schooling widens these early differences, but the main gaps in these skills that are found in adulthood emerge before schooling begins.

\subsection{Early test score differentials}

Important differences in the ability of children across family types appear at early ages and persist. Figure $2 \mathrm{~A}$ plots average percentile ranks ${ }^{18}$ on the Peabody Individual

18 In constructing the graph in Figure 2A, we computed each individual's position in the distribution of test scores at each age. Then we divided individuals into different quartiles of permanent family income and computed the average percentile rank at each age. Because the scale of test scores is arbitrary, an analysis of test scores can only determine how the factors being studied shift people in the overall distribution of ability. 
Achievement Test in Math (PIAT Math) by age for different quartiles of family income. This test is a measure of age-appropriate math knowledge. There are large gaps by the time children enter school. The gaps in ranks across income quartiles remain relatively stable as children develop. Such gaps also appear in other test scores, although for some test scores they widen slightly. ${ }^{19}$ Just as income gradients in schooling participation rates are evident, racial differences in early test scores also emerge. Figure 2B presents evidence on the emergence of racial gaps in ranks on the PIAT Math Test.

Ability affects schooling participation and affects wages as we document below. It is shaped early in life. The available evidence indicates that IQ is relatively more malleable early in the life cycle than in later years [see Shonkoff and Phillips (2000), and Carneiro and Heckman (2003)]. Having access to more and higher-quality resources that contribute to improving cognitive ability early in life affects skill acquisition later in life. IQ is not the same as what is measured by achievement tests. Achievement tests are affected by schooling and other environmental influences into adolescence even if IQ is not [see Hansen, Heckman and Mullen (2004), Heckman, Stixrud and Urzua (2006)].

Figures 3A and 3B present the gaps in PIAT Math from the previous two figures after controlling for some main features of the child's family background. The gaps across racial and income groups are significantly reduced when we control for maternal education and cognitive ability, ${ }^{20}$ and for family structure. Measured long-term family factors

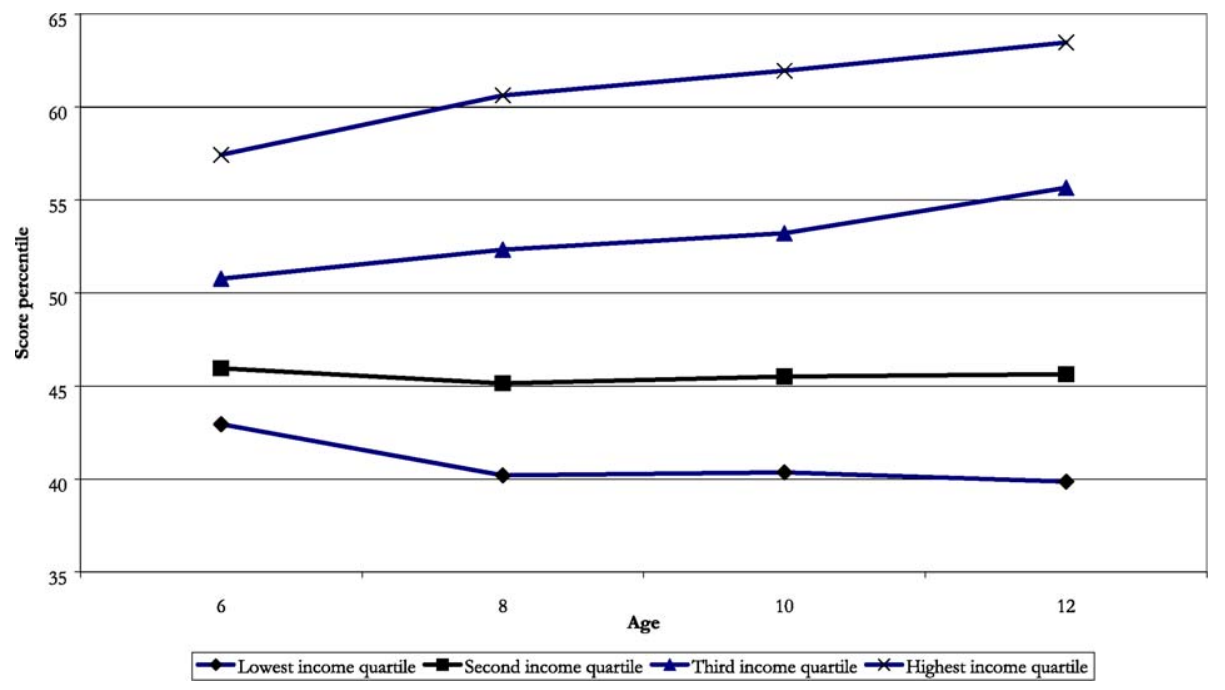

Figure 2A. Children of NLSY79. Average percentile rank on PIAT Math score, by income quartile.

* Income quartiles are computed from average family income between the ages of 6 and 10.

19 For evidence on other tests, see Carneiro, Heckman and Masterov (2005).

${ }^{20}$ Cognitive ability is measured using the Armed Forces Qualifications Test, corrected for the effect of schooling using the methodology of Hansen, Heckman and Mullen (2004). 


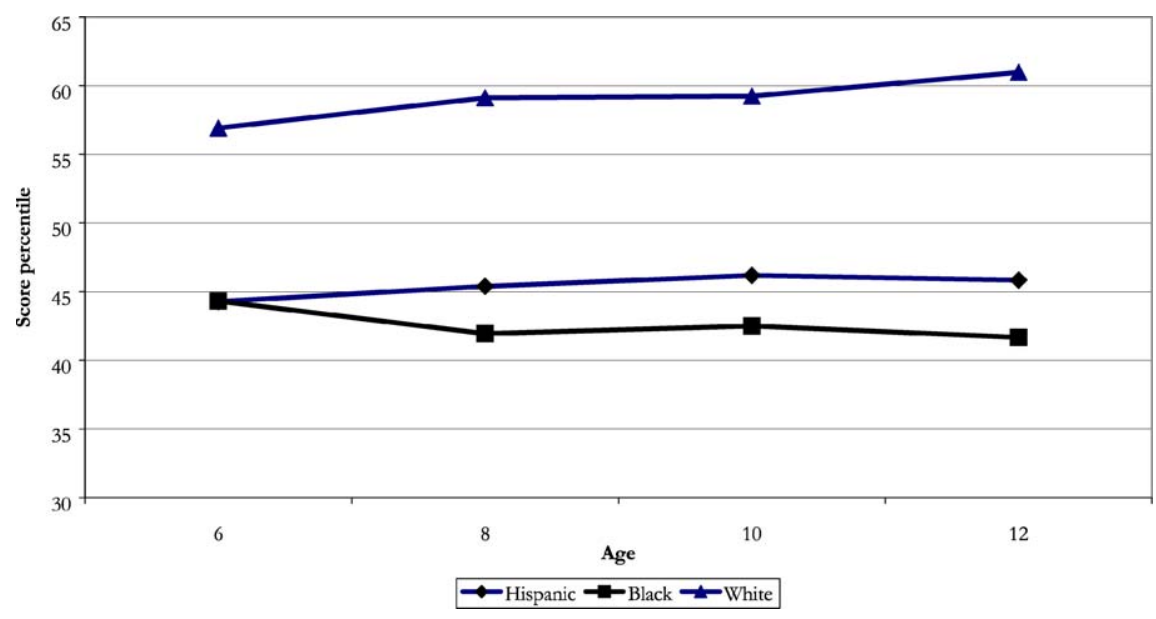

Figure 2B. Average percentile rank on PIAT Math score, by race.

play a powerful role in a correlational sense. The gaps at age 12 do not disappear entirely, however, when we compare the highest and lowest income quartiles or whites with blacks. The evidence from early intervention programs with randomized assignment that we discuss in Section 2.6 shows that these correlational results have a causal basis. When disadvantaged children are given enriched early environments, the gaps in academic achievement test scores between advantaged and disadvantaged children can be partially remedied.

The emergence of early test score gradients is not limited to cognitive measures. At early ages, differences in children's behavior across income and racial groups are also evident, as Figures 4A and 4B illustrate. These figures present differences in ranks on an index of Anti-Social Behavior across different income and racial groups. The AntiSocial Behavior index is based on exhibiting age-specific behaviors like cheating and telling lies, bullying and cruelty to others, not feeling sorry for misbehaving, breaking things deliberately, disobedience at school, and trouble getting along with teachers. High values of the index correspond to a higher prevalence of behavioral problems. As we discuss further in Section 2.3, understanding the gaps in these behavioral skills across different income and racial groups and how to eliminate them is important for understanding the determinants of economic success. Figures 5A and 5B present AntiSocial Behavior index adjusted for mother's ability, mother's score on the Armed Forces Qualification Test (AFQT), and broken home. ${ }^{21}$ Adjusting for early family background

21 We first regress the Anti-Social score on mother's education, mother's AFQT, and broken home at the same age at which the score is measured. We then rank individuals on the residuals of this regression and construct percentiles. We then include family income in the regression as well as the other variables mentioned above before taking the residuals and constructing the ranks. 


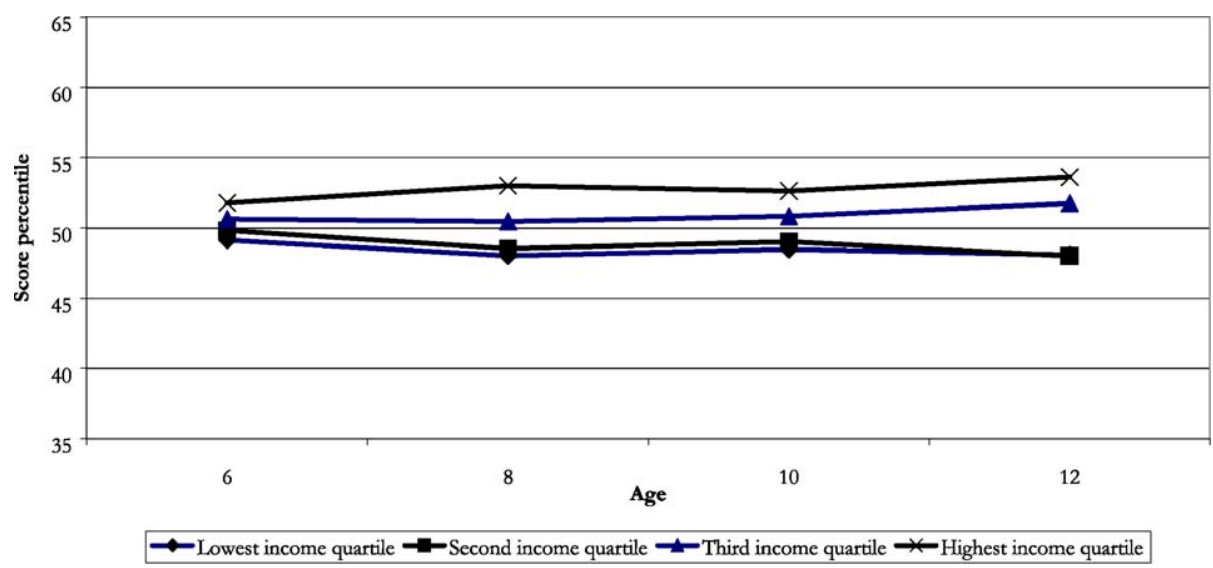

Figure 3A. Children of NLSY79. Adjusted average PIAT Math score percentiles by income quartile." * Adjusted by maternal education, maternal AFQT (corrected for the effect of schooling) and broken home at each age.

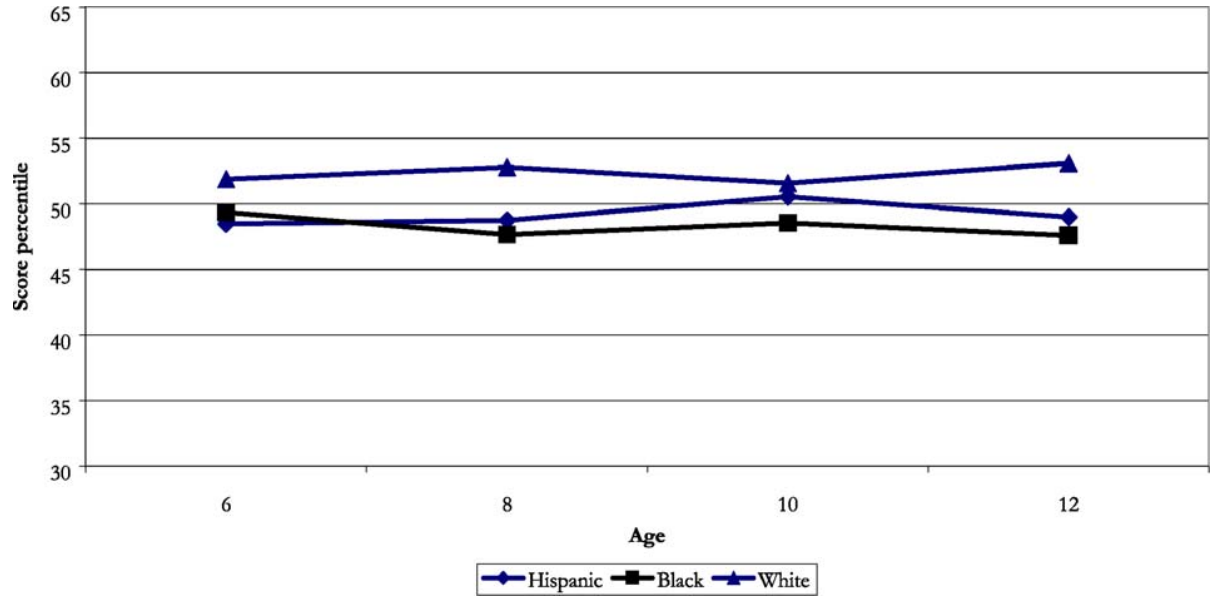

Figure 3B. Adjusted average PIAT Math score percentile by race. ${ }^{*}$

* Adjusted by maternal education, maternal AFQT (corrected for the effect of schooling) and broken home at each age.

factors substantially reduces gaps in ranks in noncognitive skills across income and racial groups. Comparing adjusted cognitive and noncognitive test scores reveals the importance of long-term factors in reducing the gaps in behavioral scores across these groups. Although noncognitive ability gaps across income and racial groups cannot be fully eliminated by a regression adjustment, controlling for mother's ability and education, family income, and family structure significantly reduces the gaps in noncognitive 


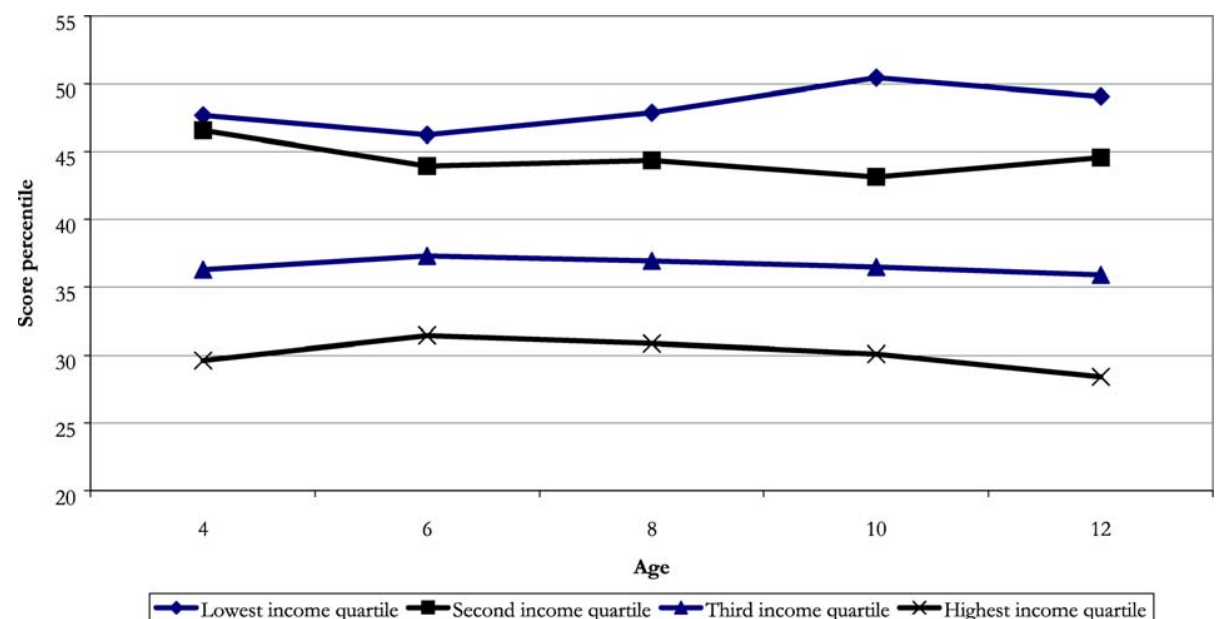

Figure 4A. Children of NLSY79. Average percentile rank on anti-social behavior score, by income quartile.

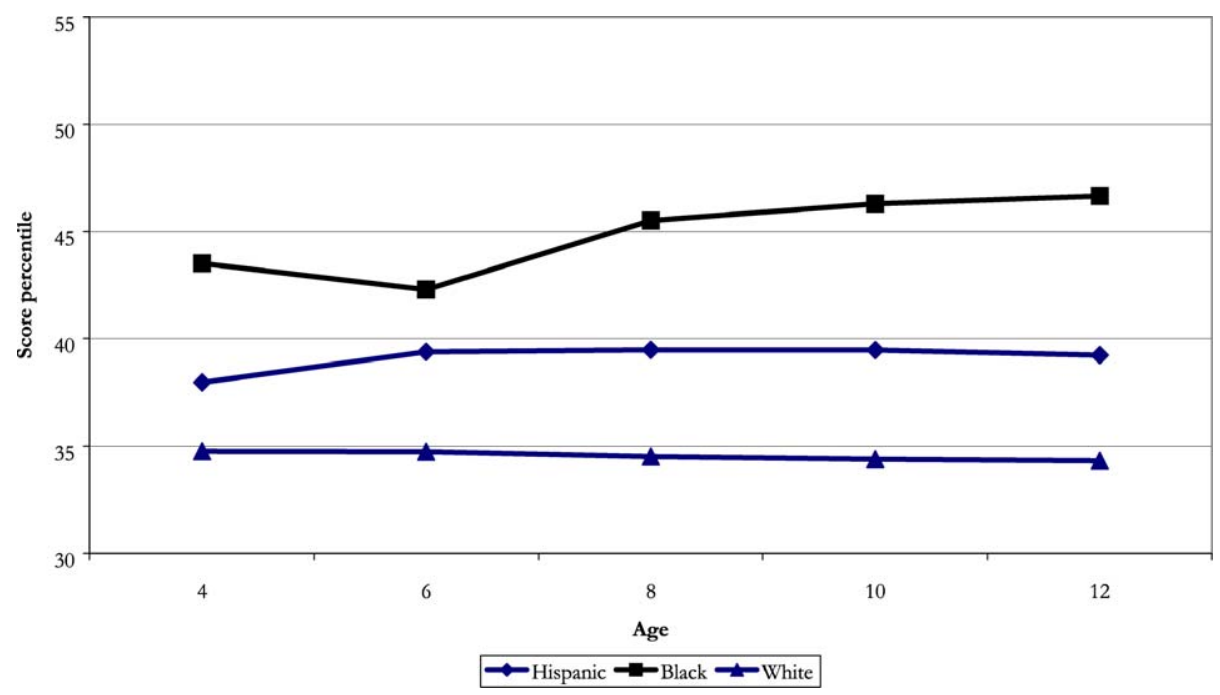

Figure 4B. Average percentile rank on anti-social behavior score, by race.

abilities across these groups at both early and later ages. The experimental evidence discussed in Section 2.6 confirms that these findings on noncognitive skills have a causal basis. Indeed, the evidence across a variety of studies suggests that early childhood interventions affect motivation and other noncognitive skills.

This evidence suggests that strong families (those with enriched parental environments) promote cognitive, social, and behavioral skills. Weak families do not. This 


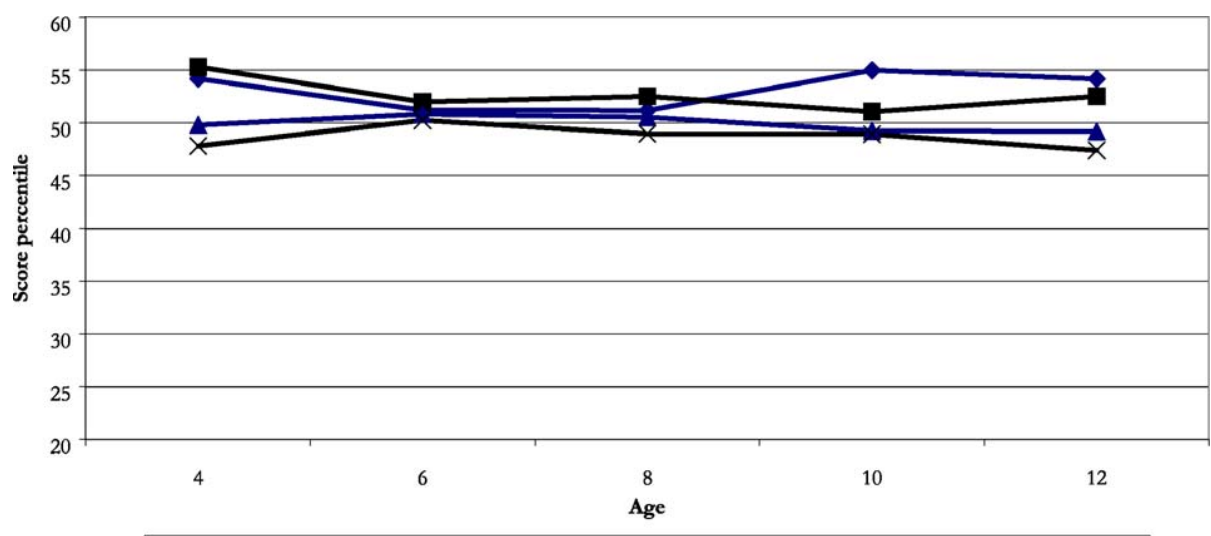

Lowest income quartile

Figure 5A. Children of NLSY79. Adjusted average anti-social behavior score percentile by income quartile. * Adjusted by maternal education, maternal AFQT (corrected for the effect of schooling) and broken home at each age.

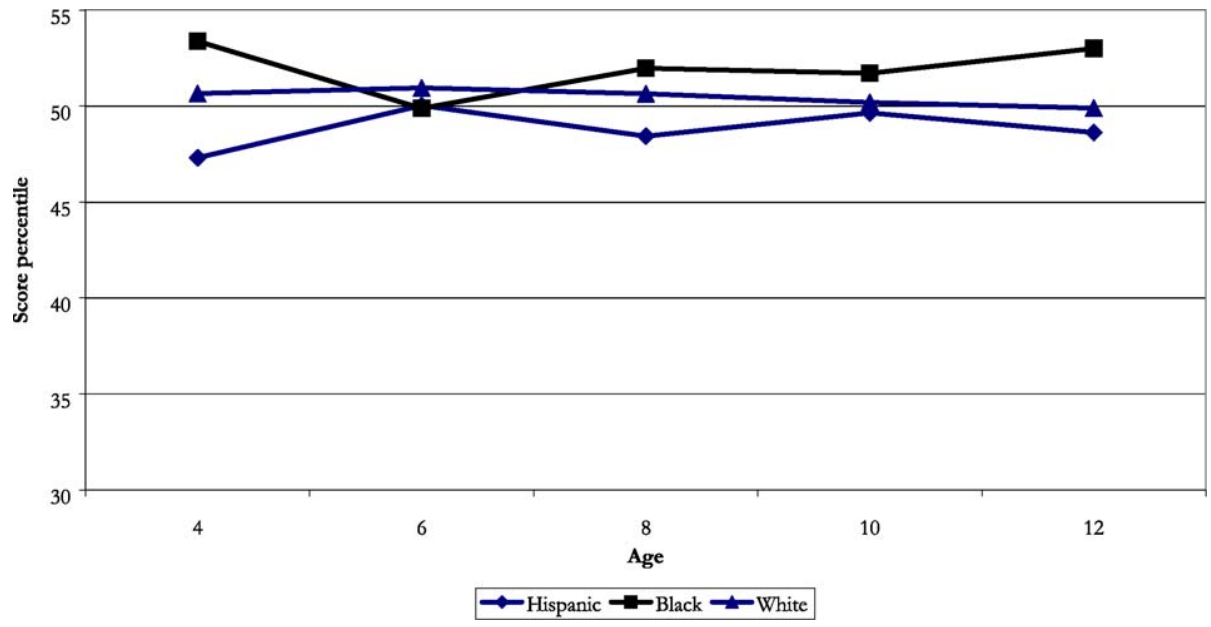

Figure 5B. Adjusted average anti-social behavior score percentile by race."

* Adjusted by maternal education, maternal AFQT (corrected for the effect of schooling) and broken home at each age.

evidence is consistent with a large body of evidence in sociology and economics [see, e.g., Duncan and Brooks-Gunn (1997b)]. The relevant policy issue is to determine what interventions in dysfunctional families, if any, are successful. The evidence presented in Section 2.6 addresses this question. 


\subsection{The evidence on the importance of noncognitive skills}

Much of the neglect of noncognitive skills in analyses of earnings, schooling, and other life outcomes is due to the lack of any reliable means of measuring them. Many different personality traits are lumped into the category of noncognitive skills. Psychologists have developed batteries of tests to measure these skills [Sternberg (1985)]. Companies use these tests to screen workers, but they are not yet widely used to ascertain college readiness or to evaluate the effectiveness of schools or reforms of schools. The literature on cognitive tests ascertains that one dominant factor $(g)$ summarizes cognitive tests and their effects on outcomes. No single factor has emerged as dominant in the literature on noncognitive skills and it is unlikely that one will ever be found, given the diversity of traits subsumed under the category of noncognitive skills. Heckman, Stixrud and Urzua (2006), test and reject the $g$ theory of noncognitive skills.

Studies by Bowles and Gintis (1976), Edwards (1976), and Klein, Spady and Weiss (1991) demonstrate that job stability and dependability are the traits most valued by employers as ascertained by supervisor ratings and questions of employers, although they present no direct evidence of the effects of these traits on wages and educational attainment. Perseverance, dependability and consistency are the most important predictors of grades in school [Bowles and Gintis (1976)].

Self-reported measures of persistence, self-esteem, optimism, future orientedness, and the like are now collected in major data sets, and some recent papers discuss estimates of the effects of these measures on earnings and schooling outcomes [see Bowles and Gintis (1976), Duncan, Claessens and Engel (2004)]. These studies shed new light on the importance of noncognitive skills for success in social life. Yet these studies are not without controversy. For example, ex post assessments of self-esteem may be as much the consequence as the cause of the measures being investigated.

Heckman and Rubinstein (2001) avoid the problems inherent in these ex post assessments by using evidence from the GED testing program in the United States to demonstrate the quantitative importance of noncognitive skills in determining earnings and educational attainment. The GED program is a second-chance program that administers a battery of cognitive tests to self-selected high school dropouts to determine whether or not their level of academic attainment is equivalent to that of high school graduates.

The GED examination is successful in psychometrically equating GED test takers with ordinary high school graduates who do not go on to college. Recipients are as smart as ordinary high school graduates who do not go on to college, where cognitive ability is measured by an average of cognitive components of the AFQT or by the first principal component $(g)$ derived from the components. According to these same measures, GED recipients are smarter than other high school dropouts who do not obtain a GED [see Heckman and Rubinstein (2001)]. In the raw data, GED recipients earn more than ordinary high school dropouts, have higher hourly wages, and finish more years of high school before they drop out. This is entirely consistent with the literature that emphasizes the importance of cognitive skills in determining labor market outcomes. 
When measured ability is controlled for, however, GED recipients earn the same as or less than other dropouts. Heckman and Rubinstein (2001) note that noncognitive skills play an important role in this gap. GEDs have higher cognitive skills than dropouts but exhibit the same problems of self control and self discipline exhibited by dropouts, and on some behaviors are worse than other dropouts.

Heckman, Stixrud and Urzua (2006) and Urzua (2006) present evidence that both cognitive and noncognitive skills affect schooling and the returns to schooling. ${ }^{22}$ They analyze the changes in the probabilities of various outcomes that arise from changing cognitive or noncognitive abilities. Figures 6A and 6B, taken from their 2006 study, shows that both higher levels of cognitive and noncognitive skills are associated with lower rates of attrition from high school. For many outcome measures, increasing noncognitive ability over the same decile range as cognitive ability has a greater effect on outcomes than increasing cognitive ability over the same decile range. These effects are not always uniform across genders. ${ }^{23}$

Increasing noncognitive ability to the highest level reduces the probability of being a high school dropout to virtually zero for females with average cognitive ability (see Figure 6B). ${ }^{24}$ This effect is especially pronounced at the bottom of the distribution (going up from the bottom fifth). The effect is less strong for males. Both cognitive and noncognitive skills are strong predictors of who graduates from a four year college but the effects of noncognitive skills are stronger for females (see Figures $6 \mathrm{C}$ and 6D). Increases in both types of ability have the same effect on reducing the likelihood of spending time in jail by age 30 for males (see Figure 6E). ${ }^{25}$ Figures $6 \mathrm{~F}$ and $6 \mathrm{G}$ show strong effects of both cognitive and noncognitive skills on smoking. Here there is a larger effect for males of increasing noncognitive ability. Figure $6 \mathrm{H}$ shows the strong effect of both cognitive and noncognitive skills on non-marital

\footnotetext{
22 Cognitive and noncognitive abilities are estimated using a two-factor model and the NLSY79 data. The cognitive skill is identified by using a subset of five Armed Forces Vocational Aptitude Battery (ASVAB) tests (word knowledge, paragraph comprehension, numerical operations, coding speed and mathematics knowledge). The noncognitive factor is identified using the Rosenberg Self-Esteem and Rotter Locus of Control scales. The Rosenberg scale contains ten statements of self-approval and disapproval with which respondents are asked to strongly agree, agree, disagree or strongly disagree. A high score indicates a high self-approval rating. The Rotter scale is based on four questions about the extent to which respondents believe themselves to have control over the various domains of their lives. A higher score indicates more control over one's life. All tests were administered in 1979-1981, when the respondents were 14-24 years old. The estimation of the model is carried out using an MCMC routine. Heckman, Stixrud and Urzua use only the young sample to analyze the data (the scores are measured at least 3-4 years before the outcomes). They also show results from other data sets where the separation between the age of the test and the outcome is more substantial, and they find very similar results. They apply the method developed in Hansen, Heckman and Mullen (2004) to account for spurious feedback between outcomes and test scores.

23 Heckman, Stixrud and Urzua (2006) show how this nonuniformity in the effects of cognitive and noncognitive skills on outcomes across genders can explain the differential effectiveness of early intervention programs across genders.

24 Heckman, Stixrud and Urzua (2006) show the same patterns apply to college attendance.

25 Incarceration is not an important phenomenon for females.
} 
pregnancy. For this outcome both cognitive and noncognitive ability are important. ${ }^{26}$ Higher levels of noncognitive skills promote success on achievement tests even when they do not affect IQ. This effect operates because noncognitive skills affect schooling and schooling raises measured achievement [Hansen, Heckman and Mullen (2004), Heckman, Larenas and Urzua (2004)]. Responses to changes in cognitive and noncognitive skills are not always uniform across genders.

Current systems of evaluating educational reforms are based predominantly on changes in scores on cognitive tests. These tests capture only one of the many skills required for a successful life [see Heckman (1999)]. A more comprehensive evaluation of educational systems would account for their effects on producing the noncognitive traits that are also valued in the market. There is substantial evidence that mentoring and motivational programs oriented toward disadvantaged teenagers are effective. We review this evidence in Section 2.6.

Much of the effectiveness of early childhood interventions comes from boosting noncognitive skills and from fostering motivation. ${ }^{27}$ While IQ is fairly well set after the first decade of life, motivation and self-discipline are more malleable at later ages [Heckman (2000)]. More motivated children are more likely to stay in school and have higher achievement tests. Our analysis suggests that social policy should be more active in attempting to alter noncognitive traits, including values, especially for children from disadvantaged environments who receive poor discipline and little encouragement at home. This more active social policy approach would include mentoring programs and stricter enforcement of discipline in the schools. Although such programs are controversial, they are likely to be effective and to produce substantial saving to society from reduced pathological behavior (see Section 2.6).

We now turn to some evidence from animal and human populations that bolsters our case that early factors matter and socioemotional skills, shaped at an early age, also matter.

\subsection{Critical periods, sensitive periods, and socioemotional bases of skill formation and remediation}

Early experience exerts a profound influence on socioemotional outcomes directly, but it also interacts with genetic endowments, with consequences that are at least as important for development. ${ }^{28}$ Experimental studies using animals have produced several suggestive findings that enhance our understanding of the evidence on human behavior.

26 Heckman, Stixrud and Urzua (2006) show the same pattern for other reproductive outcomes, such as marital childbearing.

27 See Karoly et al. (1998), Currie and Blau (2006), and Heckman (2000) for comprehensive reviews of the literature.

28 A twins study by Turkheimer et al. (2003) found that in poor families, $60 \%$ of the variance in IQ is accounted for by the shared environments, and the contribution of genes is close to zero, whereas in wealthy families a nearly opposite result is found. 

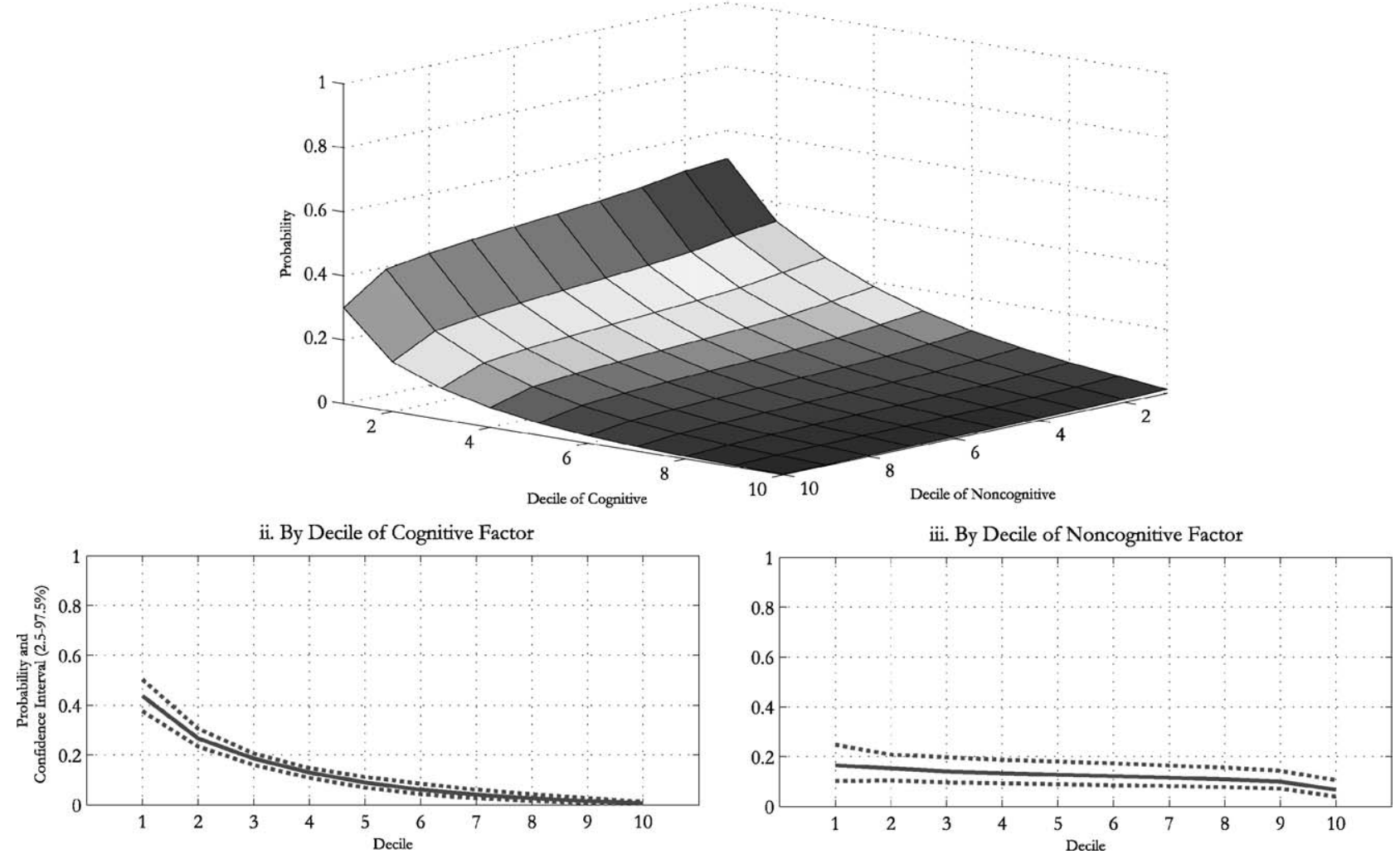

Figure 6A. Probability of being a high school dropout by age 30 - males.

Notes: The data are simulated from the estimates of the model and our NLSY79 sample. We use the standard convention that higher deciles are associated with higher values of the variable. The confidence intervals are computed using bootstrapping (200 draws). Source: Heckman, Stixrud and Urzua (2006). 


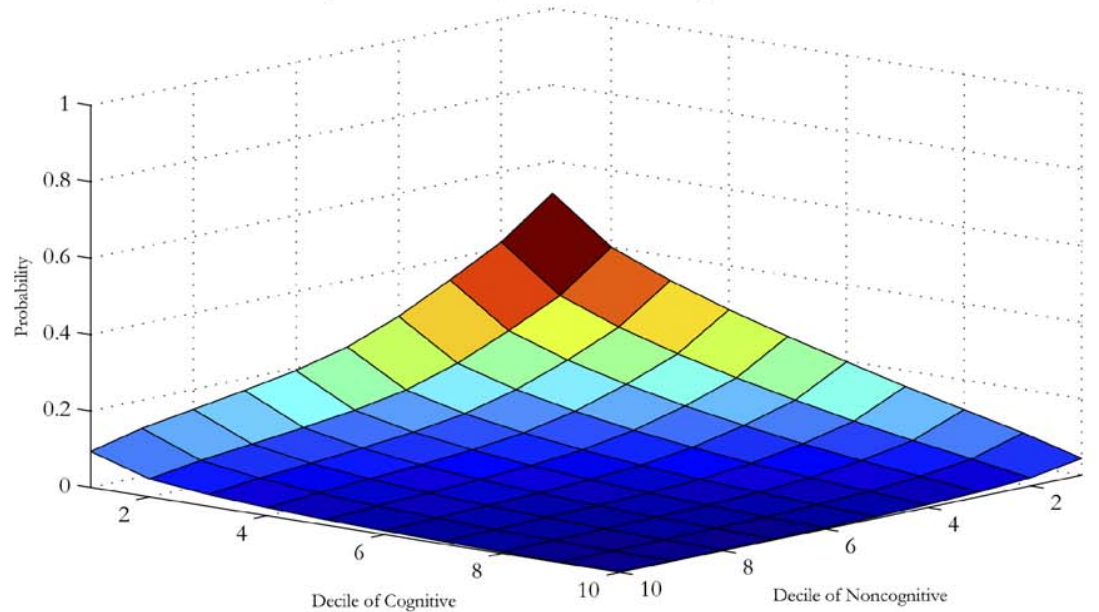

ii. By Decile of Cognitive Factor

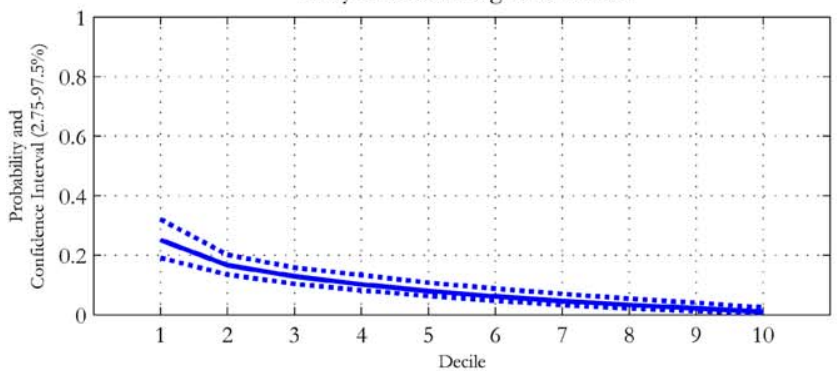

iii. By Decile of Noncognitive Factor

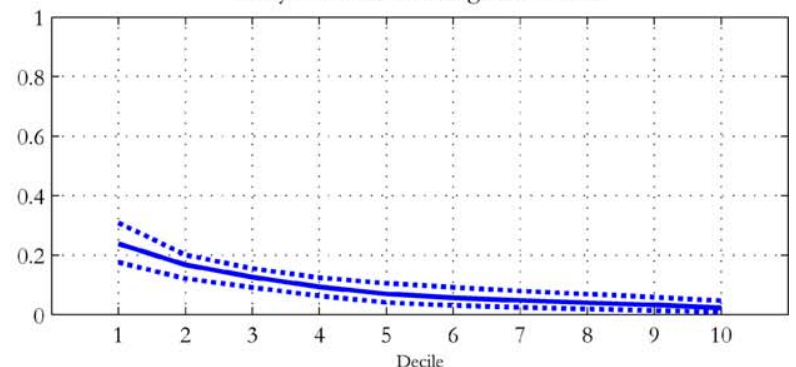

Figure 6B. Probability of being a high school dropout by age 30 - females.

Notes: The data are simulated from the estimates of the model and our NLSY79 sample. We use the standard convention that higher deciles are associated with higher values of the variable. The confidence intervals are computed using bootstrapping (200 draws). Source: Heckman, Stixrud and Urzua (2006). 
i. By Decile of Cognitive and Noncognitive Factors
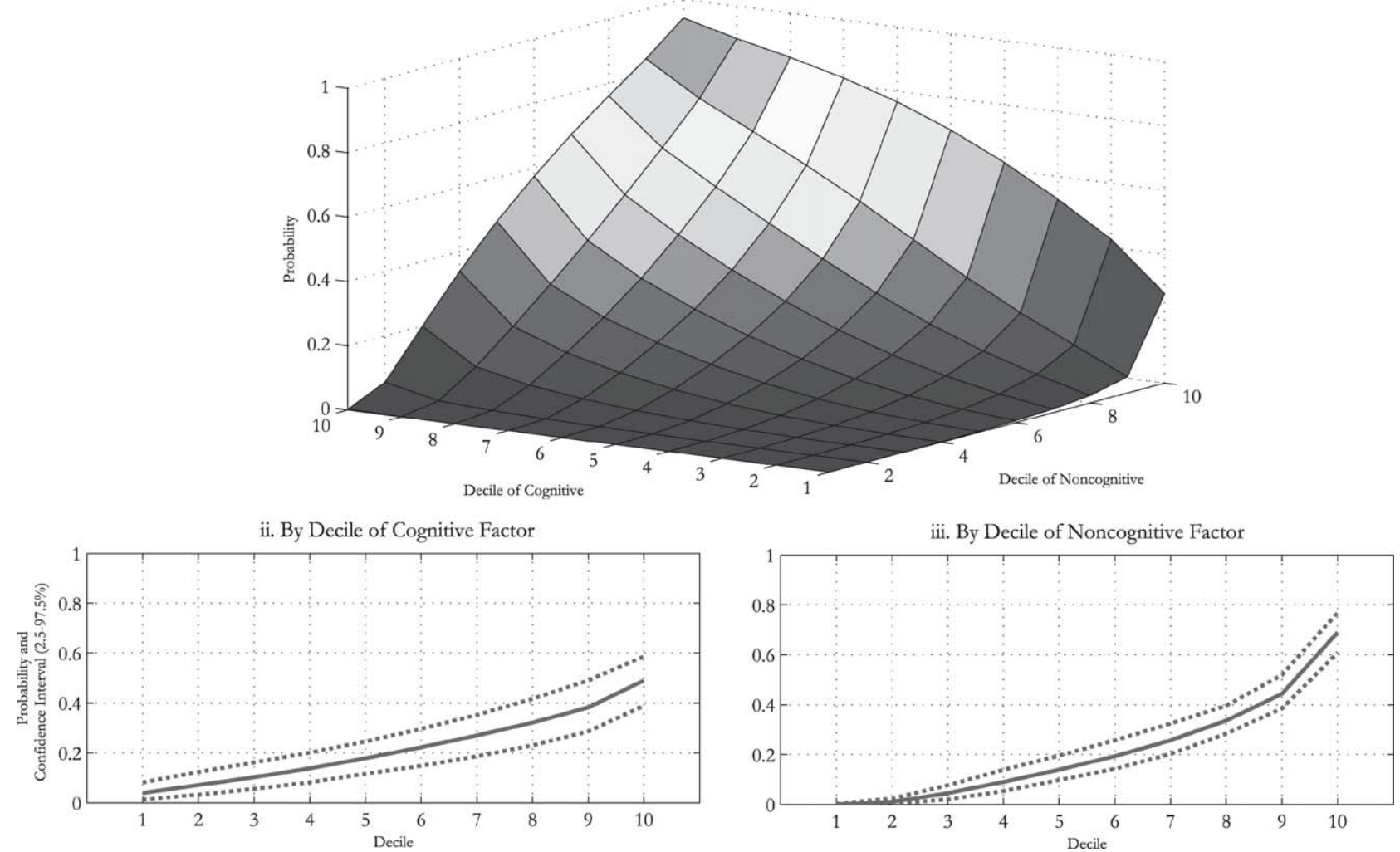

Figure 6C. Probability of being a 4-yr college graduate by age 30 - males.

Notes: The data are simulated from the estimates of the model and our NLSY79 sample. We use the standard convention that higher deciles are associated with higher values of the variable. The confidence intervals are computed using bootstrapping (200 draws). Source: Heckman, Stixrud and Urzua (2006). 


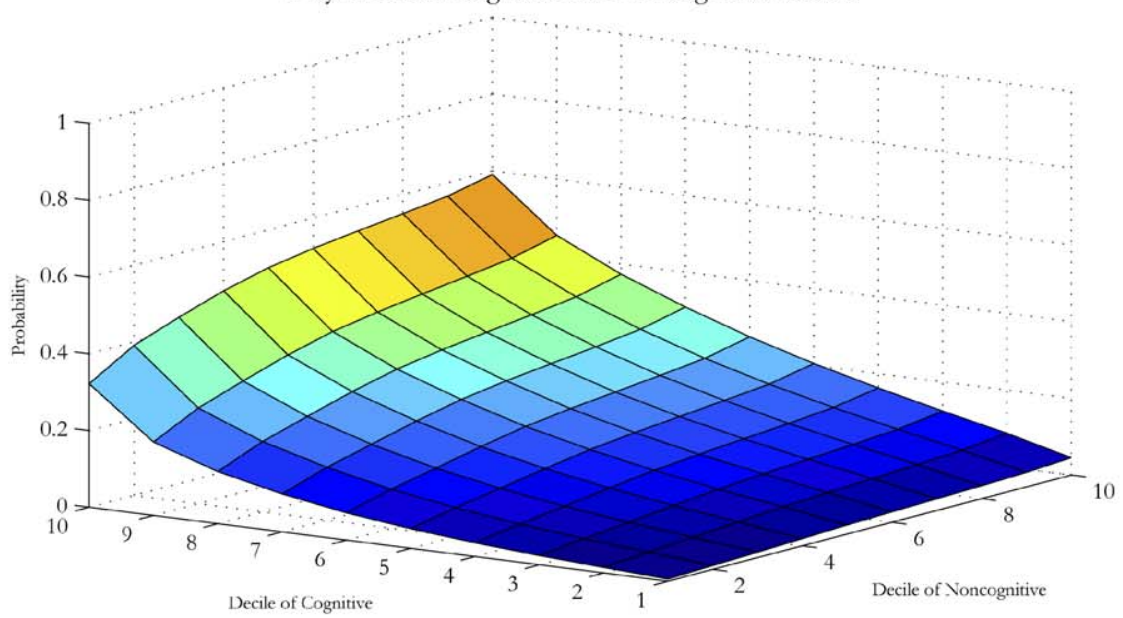

ii. By Decile of Cognitive Factor

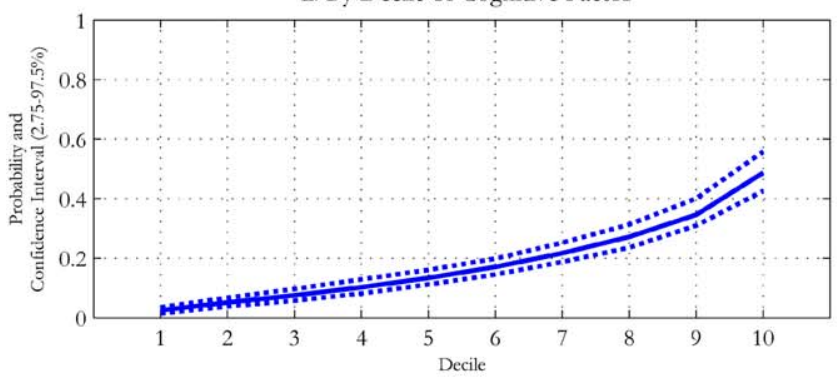

iii. By Decile of Noncognitive Factor

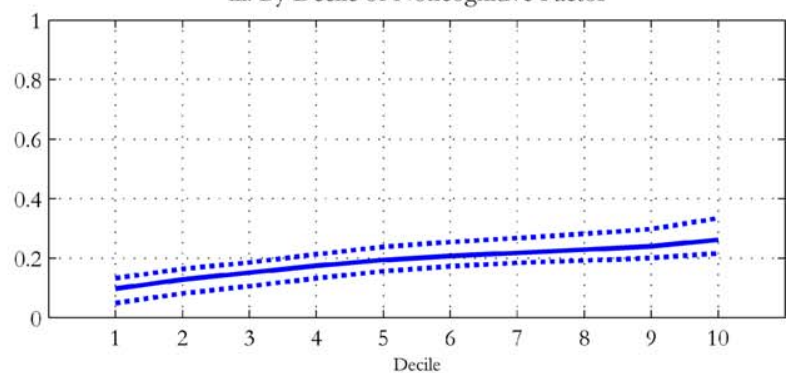

Figure 6D. Probability of being a 4-yr college graduate by age $30-$ females

Notes: The data are simulated from the estimates of the model and our NLSY79 sample. We use the standard convention that higher deciles are associated with higher values of the variable. The confidence intervals are computed using bootstrapping (200 draws). Source: Heckman, Stixrud and Urzua (2006). 
i. By Decile of Cognitive and Noncognitive Factor
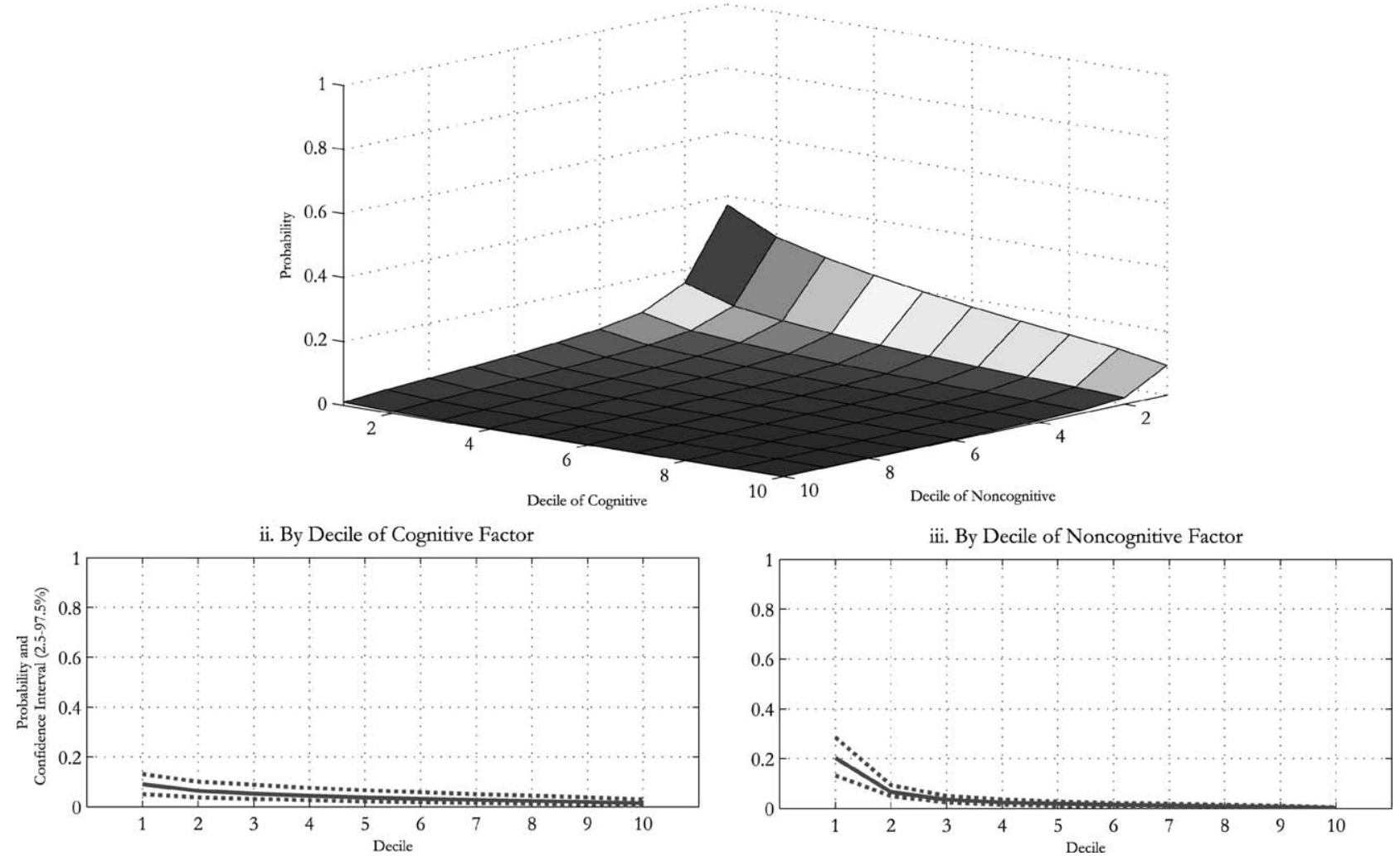

Figure 6E. Probability of incarceration by age 30 - males.

Notes: The data are simulated from the estimates of the model and our NLSY79 sample. We use the standard convention that higher deciles are associated with higher values of the variable. The confidence intervals are computed using bootstrapping (200 draws). Source: Heckman, Stixrud and Urzua (2006). 


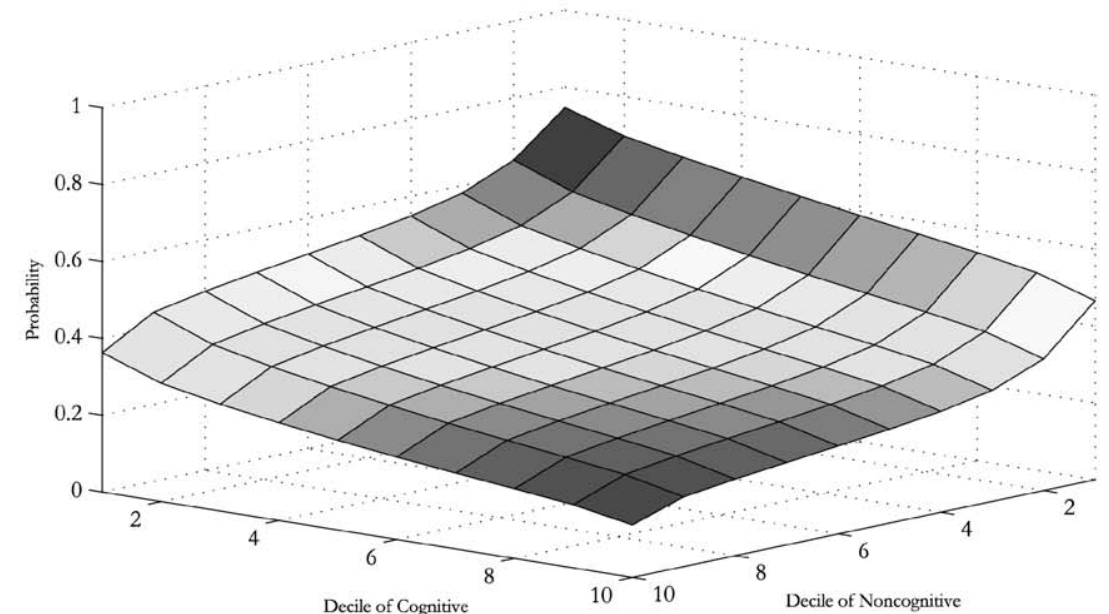

ii. By Decile of Cognitive Factor

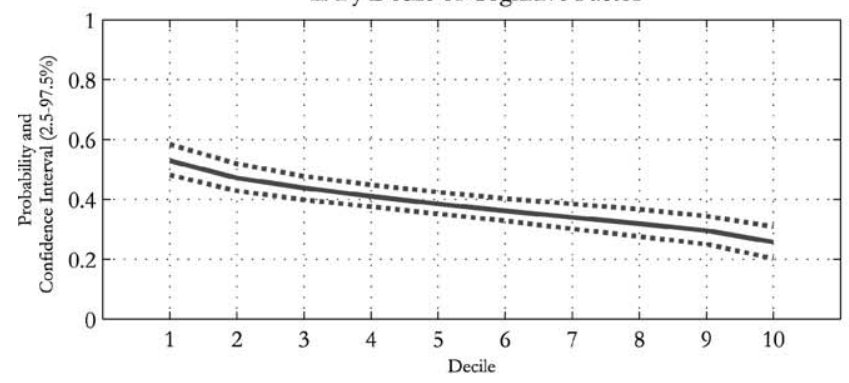

iii. By Decile of Noncognitive Factor

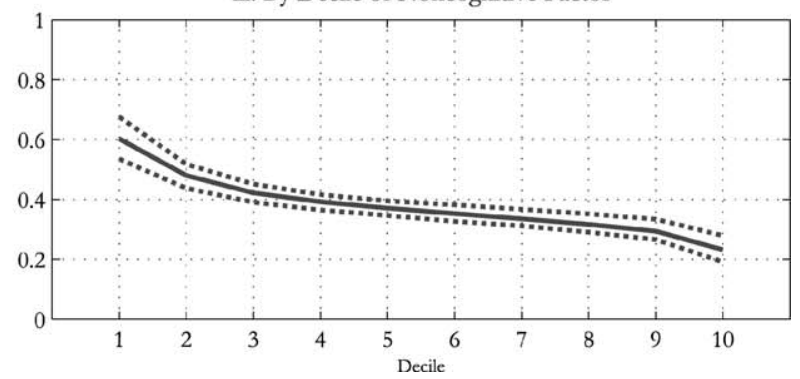

Figure 6F. Probability of daily smoking by age 18 - males.

Notes: The data are simulated from the estimates of the model and our NLSY79 sample. We use the standard convention that higher deciles are associated with higher values of the variable. The confidence intervals are computed using bootstrapping (200 draws). Source: Heckman, Stixrud and Urzua (2006). 
i. By Decile of Cognitive and Noncognitive Factor
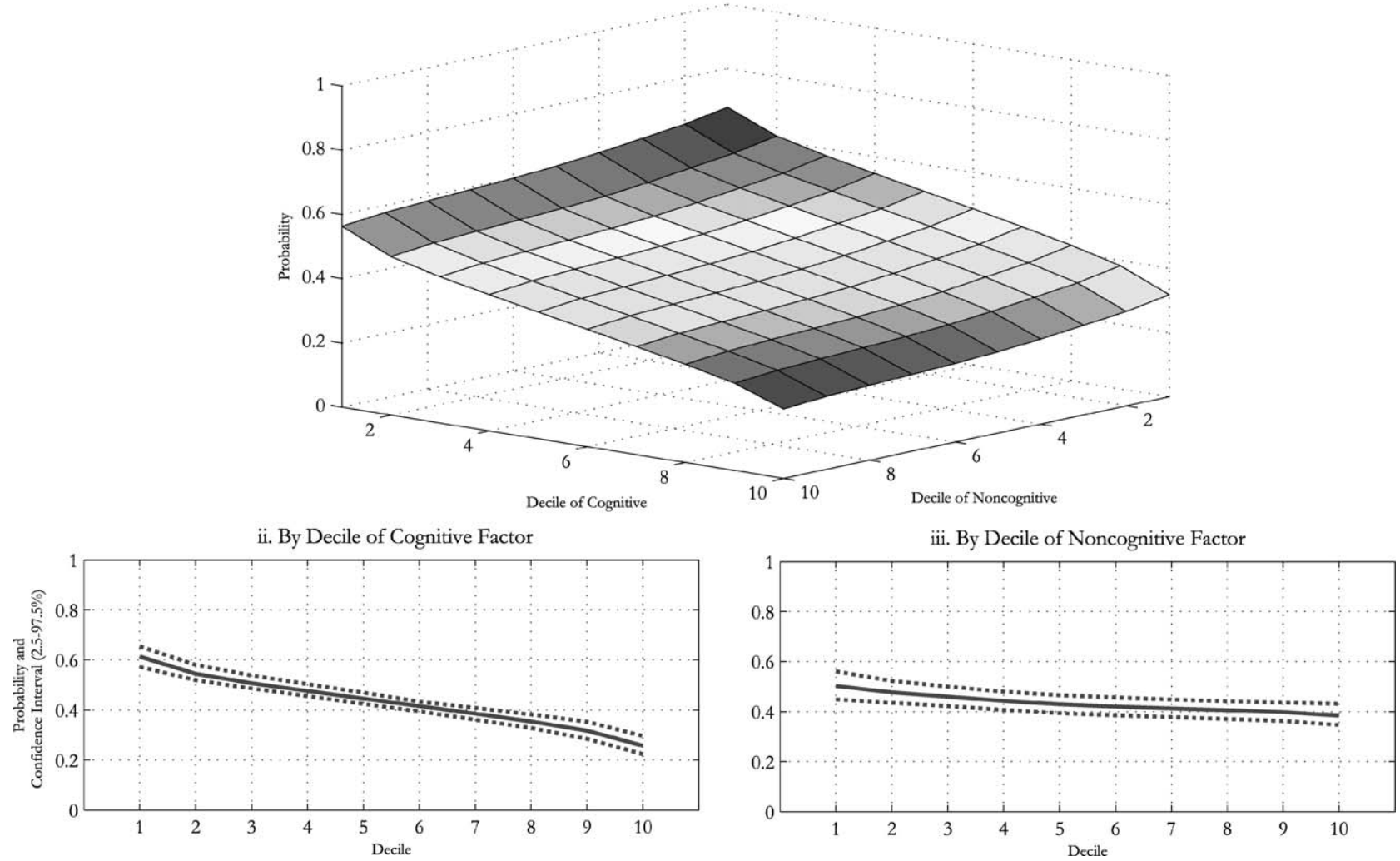

Figure 6G. Probability of daily smoking by age 18 - females.

Notes: The data are simulated from the estimates of the model and our NLSY79 sample. We use the standard convention that higher deciles are associated with higher values of the variable. The confidence intervals are computed using bootstrapping (200 draws). Source: Heckman, Stixrud and Urzua (2006). 

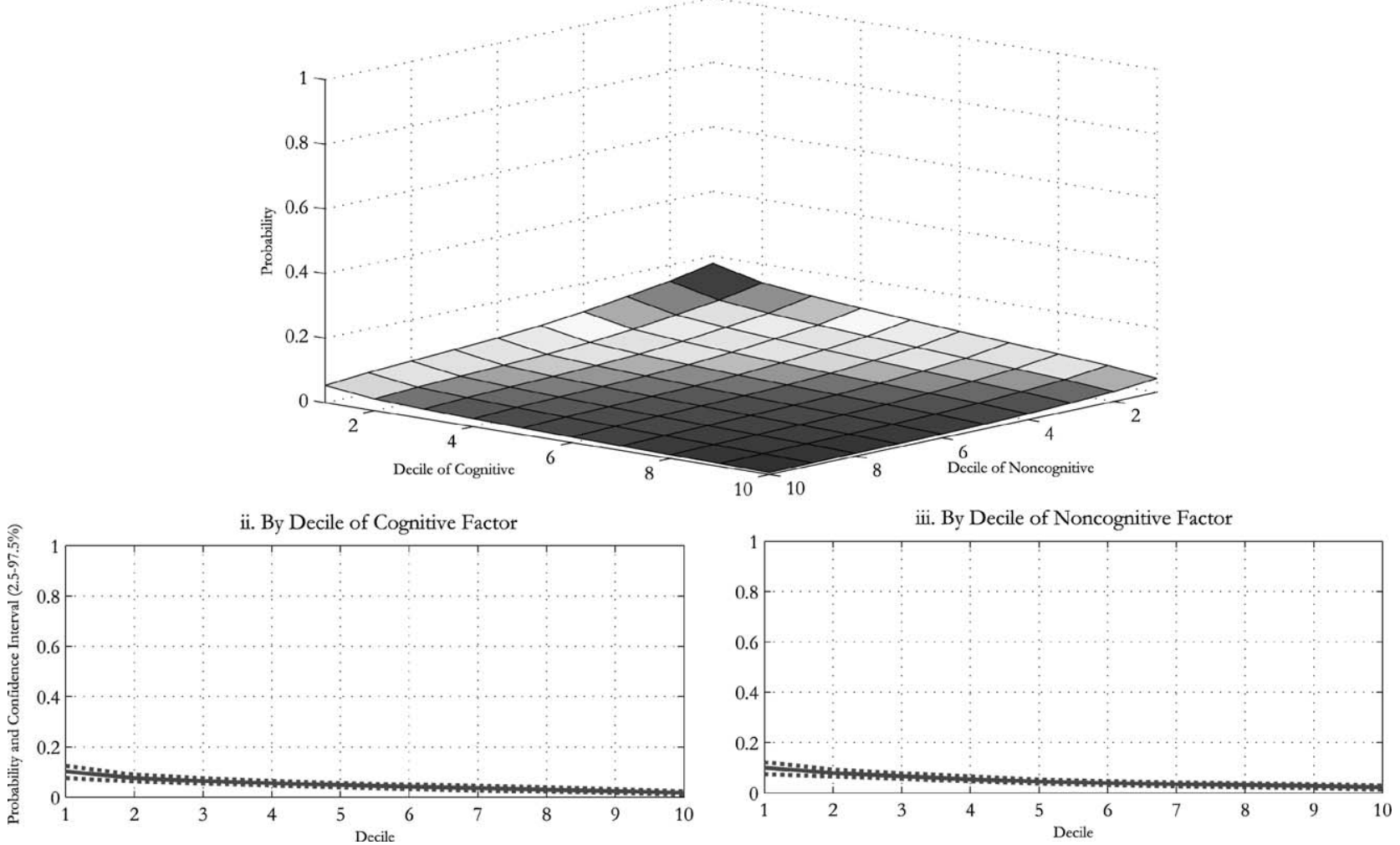

Figure $6 \mathrm{H}$. Probability of being single with child at age 18 - females.

Notes: The data are simulated from the estimates of the model and our NLSY79 sample. We use the standard convention that higher deciles are associated with higher values of the variable. The confidence intervals are computed using bootstrapping (200 draws). Source: Heckman, Stixrud and Urzua (2006). 
Suomi (1999) provides a summary of his research on the malleability of temperament. He and his colleagues selectively bred rhesus monkeys to be highly fearful. They then reassigned some of these infants to nurturing mothers, while pairing some infants of normal mothers with fearful adoptive mothers. Their results suggest that normal infants take on their foster mother's fearful characteristics. Infants born to fearful mothers assigned to nurturing mothers become even more socially precocious than their normal counterparts. They engage in autonomous exploration of their environment earlier and more frequently, and they do not display disproportionate responses to minor alarming stimuli. When they are moved into larger social groups, they are able to recruit allies and attain higher positions in the monkey hierarchy. Regardless of their genetic background, young females acquired the nurturing style of their adoptive mother with their own offspring rather than the style predicted by their genetic profile or own biological mother's behavior. These results suggest that positive early experiences can dramatically modify genetic tendencies, as expressed in behavior. Knudson et al. (2006) review the evidence from animal and human studies.

Knudsen (2004) shows that early experience can modify the biochemistry and architecture of neural circuits. When such experiences operate within a limited time frame in the life cycle, that period is termed "sensitive." During a sensitive period, certain patterns of connectivity among neurons become stable as a result of environmental influence. This stability is environmentally adaptive. ${ }^{29}$ These pathways can be altered after the sensitive period, but their plasticity is limited by the structure created during the sensitive period, i.e., it is less efficient to invest in later periods. When experience in a given period is crucial for normal development, that period is called "critical." We formally define sensitive and critical periods in Section 3. Intuitively, if late investment is a good substitute for early investment, the early years are not critical. If it is not a good substitute, then the early period is critical.

Critical periods have been extensively documented in the development of binocular vision in the cortex of mammals, auditory space processing in the midbrain of barn owls, filial imprinting in the forebrain of ducks and chickens, and song learning in the forebrain of songbirds [see Knudsen (2004)]. For our purposes, the most relevant example is language acquisition and the fact that children tend to perform better in acquiring language skills than do adults, despite being more limited in most cognitive domains. Age of exposure to a language is negatively related to ultimate proficiency achieved in that language [see Newport (2002), for a summary of the evidence]. The decline in proficiency begins as early as 4 and 6 , and continues until a plateau is reached in adulthood. This pattern is evident for many aspects of language proficiency, such as control over sounds as well as grammatical structure, and has been shown for both first

29 Knudsen (2004) argues that experience provides information about the individual and his environment that cannot be predicted accurately and, therefore, cannot be encoded genetically. This may explain why the early experience of deprivation may result in maladaptive development and corresponding behavior. In some sense, the adaptation may only be adaptive locally, rather than globally. 
and second languages. ${ }^{30}$ However, not all aspects of language acquisition are equally sensitive. Newport (2002) cites evidence that the acquisition of vocabulary and semantic processing can be accomplished relatively easily even in adulthood, while the more formal dimensions of language (such as syntax, phonology, and morphology) are less easily acquired. These differences are apparent even on a neurological level. In short, both critical and sensitive periods are features of language learning.

Other types of social behavior are characterized by sensitive and critical periods. Independent research by Cameron (2004) suggests that development of normal social behavior in infant rhesus monkeys can be disrupted by removing the mother from the social group. When mothers and infants are separated when the infants are one week old, their subsequent adult behavior is profoundly antisocial, anxious, and aggressive. When the disruption takes place at a later age, the effects are qualitatively different and their severity declines with age at separation. The impact on the youngest monkeys can be offset by pairing them with an experienced mother, but the degree of catchup decreases with the age at which the "foster" placement takes place. Remediation is possible, though its timing is crucial.

The monkeys who are emotionally secure explore more and learn more. This evidence shows how noncognitive skills feed into the formation of cognitive skills. It helps to explain how the Perry Preschool Program, discussed in Section 2.6, which did not raise IQ but raised noncognitive skills, affected achievement test outcomes. We formalize the notion of critical and sensitive periods in Section 3 and in Appendix A to this paper. Closely related is the concept of a "bottleneck" period. If skills at one stage of the life cycle are not formed at a sufficiently high level, it is difficult to proceed to excellence at the next stage. The Leontief technology discussed in Section 3.1 crystallizes this point.

It is important to understand how families invest in their children and why many youth do not pursue a higher education despite the purportedly high returns. As we discuss next, children from disadvantaged families often reach college-going ages without adequate preparation or skills to make college attendance worthwhile. We turn to a discussion of the importance of credit constraints and other long-term family factors on adolescent schooling decisions.

\subsection{Interpreting the role of family income: The evidence on credit constraints}

There is a strong relationship between family income and college attendance. Figure 7 displays aggregate time series of college participation rates for eighteen- to twenty-fouryear-old American males classified by their parental income measured in the child's late adolescent years. There are substantial differences in college participation rates across family income classes in each year. The cross sectional pattern of schooling attendance by family income levels that is evident in this figure is found in many other

30 The age-of-exposure effect appears even in the grammatical skills of deaf adults who learn sign language. See Pinker (1994) and Newport (2002) for more on this topic. 
countries [see the essays in Blossfeld and Shavit (1993)]. In the late 1970s or early 1980s, college participation rates began to increase in response to increasing economic rates of return to schooling, but only for youth from the top family income groups. With a lag, children from other groups also responded, but the gaps in rates did not close. This differential educational response by income class threatens to perpetuate or widen income inequality across generations and among racial and ethnic groups. See Figure 8 for the time-series evidence on college attendance rates by race.

There are two different, but not necessarily mutually exclusive, interpretations of this evidence. The common and more influential one is the most obvious one. Credit constraints facing families in a child's adolescent years affect the resources required to finance a college education. A second interpretation emphasizes the long-run factors associated with higher family income. It notes that family income is strongly correlated over a child's life cycle. Families with high income in a child's adolescent years are more likely to have high income before that period. Higher levels of family resources in a child's formative years are associated with higher quality education and better environments that foster cognitive and noncognitive skills.

Both interpretations of the evidence are consistent with a form of credit constraint. The first, more common interpretation, is clearly compatible with this point of view. But the second interpretation is consistent with another type of credit constraint: the inability of a child to buy the parental environments and genes (or their substitutes) that form the

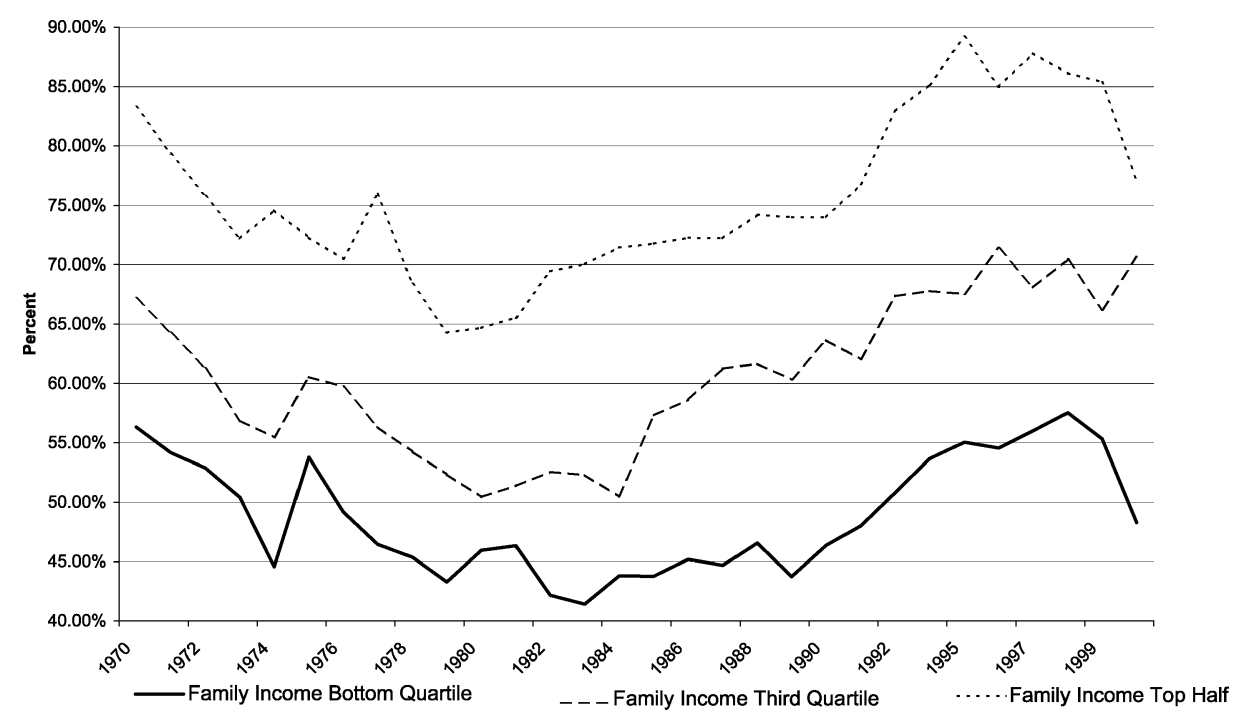

Figure 7. College participation, 18 to 24 yrs, HS graduates and GED holders. Dependent ${ }^{*}$ White Males. Source: These number were computed from the CPS P-20 School Reports and the October CPS.

* Dependent is living at parental home or supported by parental family while at college. 
cognitive and noncognitive abilities required for success in school. Some parents may never earn enough to provide the best developmental environments for their children.

Carneiro and Heckman $(2002,2003)$ argue on quantitative grounds that the inability of a child to acquire the family resources provided to children by wealthy families is the most important factor underlying Figure 7. After controlling for the ability formed by the early teenage years, they show that parental income in the adolescent years plays only a minor role in explaining college enrollment decisions. The evidence from the U.S. presented in their research suggests that at most 8 percent of American adolescents are affected by short-term liquidity constraints that inhibit their participation in postsecondary schooling. Most of the family income gap in enrollment is due to long-term factors that produce the abilities needed to benefit from participation in college.

The evidence reviewed here suggests that the first-order explanation for gaps in enrollment in college by family income is long-run family factors that are crystallized in ability. Short-run income constraints affecting families during the child's college-going years play a role in creating these gaps, albeit a quantitatively minor one. There is scope for intervention to alleviate these short-term constraints and the returns to carefully targeted interventions are potentially high. One should not expect to reduce the enrollment gaps evident in Figure 7 substantially by eliminating such constraints.

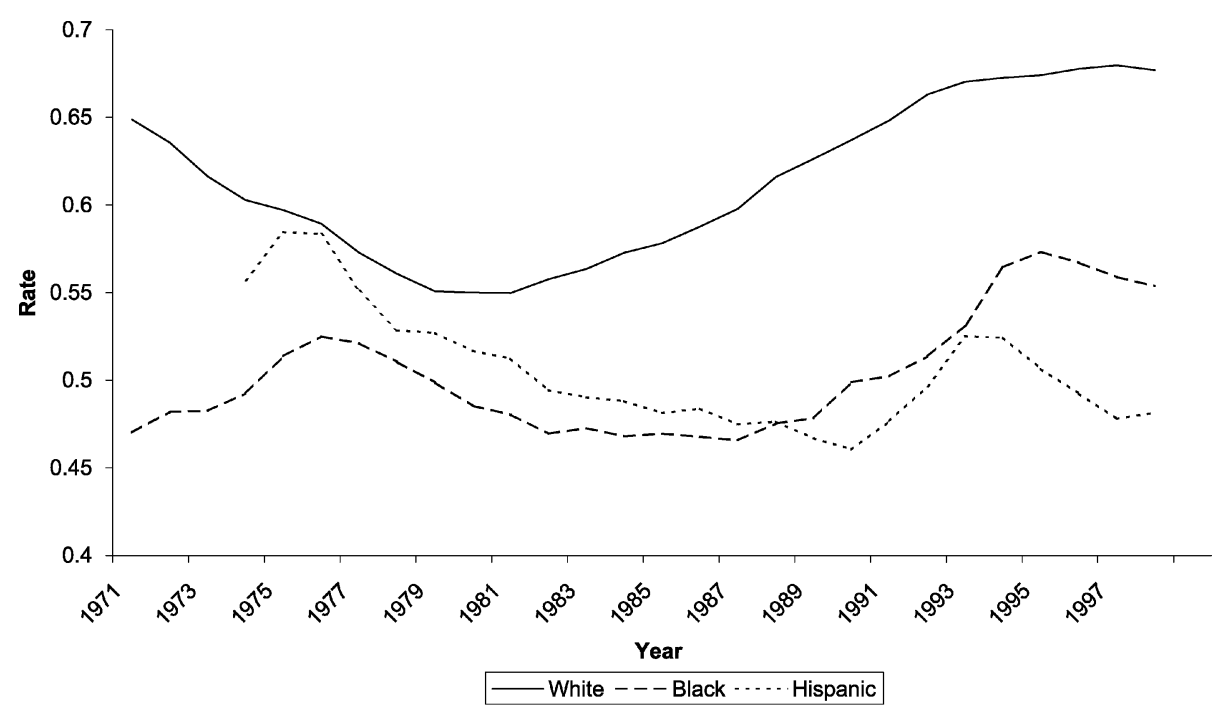

Figure 8. College participation by race. Dependent ${ }^{*}$ high school graduates and GED holders. Males, ages 18-24.

Note: Three-year moving averages are shown. Source: These number were computed from the CPS P-20

School Reports and the October CPS.

* Dependent is living at parental home or supported by parental family while at college. 


\subsubsection{Family income and enrollment in college}

The argument that short-term family credit constraints are the most plausible explanation for the relationship depicted in Figure 7 starts by noting that human capital is different from physical capital. There is no asset market for human capital. People cannot sell rights to their future labor earnings to potential lenders to secure financing for their human capital investments in the way that indentured servants once financed the cost of travel to the New World with their labor. Even if they could, there would be substantial problems in enforcing performance of contracts on future earnings given that persons control their own labor supply and the effort and quality of their work. The lack of collateral on the part of borrowers and the inability to monitor effort by lenders are widely cited reasons for current large-scale government interventions to finance education.

If people had to rely on their own resources to finance all of their schooling costs the level of educational attainment in society would be much lower. To the extent that subsidies do not cover the full costs of college tuition, persons are forced to raise funds to pay tuition through private loans, through work while in college, or through foregone consumption [see Keane and Wolpin (2001)]. Such constraints may affect the choice of college quality, the content of the educational experience, the decision of when to enter college, the length of time it takes to complete schooling, and even graduation from college. Children from families with higher incomes have access to resources that are not available to children from low-income families; although children from higher-income families still depend on the good will of their parents to gain access to these resources. Limited access to credit markets means that the costs of funds are higher for the children of the poor, and this limits their enrollment in college. ${ }^{31}$ Proponents of this view argue the reductions in real income among parents in the bottom half of the family income distribution, coupled with a growth in real tuition costs, has prevented low income whites and minorities from taking advantage of the rising education premium.

An alternative interpretation of the same evidence is that long-run family and environmental factors play a decisive role in shaping the ability and expectations of children. Families with higher levels of resources produce higher-quality children who are better able to perform in school and take advantage of the new market for skills.

Children whose parents have higher incomes have access to better-quality primary and secondary schools. Children's tastes for education and their expectations about their life chances are shaped by those of their parents. Educated parents are better able to develop scholastic aptitude in their children by assisting and directing their studies. We

31 Evidence on educational responses to tuition subsidies is sometimes mistakenly interpreted as evidence on credit constraints. The purchase of education is governed by the same principles that govern the purchase of other goods: the lower the price, the more likely are people to buy the good. Dynarski (2000) presents recent evidence about the strength of tuition effects on college participation that is consistent with a long line of research. In addition, there is, undoubtedly, a consumption component to education. Families with higher incomes may buy more of the good for their children and may buy higher quality education as well. This will contribute to the relationship displayed in Figure 7. 
have reviewed the evidence that ability gaps open up early and are strongly related to family characteristics. The influences of family factors present from birth through adolescence accumulate to produce ability and college readiness. By the time individuals finish high school and their scholastic ability is largely determined, the scope of tuition policy for promoting college attendance is greatly diminished.

The interpretation that stresses the role of family and the childhood environment in producing college readiness does not necessarily rule out short-term borrowing constraints as a partial explanation for the patterns revealed in Figure 7. However, if the finances of poor but motivated families hinder them from providing high quality elementary and secondary schooling for their children, and produce a low level of college readiness, government policy aimed at reducing the short-term borrowing constraints for the college expenses of those children during their college-going years is unlikely to be effective in substantially closing the gaps evident in Figure 7. In these circumstances, policies that improve the early environments that shape ability will be more effective in the long run.

The following experiment captures the essence of the distinction we are making. Suppose two poor families participate in lotteries that are adjusted to have the same expected present value (at age zero of the child) but have different award dates. Markets are assumed to be imperfect in the sense that families cannot borrow against the future awards. Compare a family that wins the lottery in the child's adolescent years with a family that wins in the child's early formative years. The former child would lack all of the benefits of investment during the early childhood years that the child from the family that wins early would receive. The child from the late-winning family would be likely to have lower levels of cognitive and noncognitive abilities than the child from the earlywinning family. To the extent that investments are complementary and self-productive, the children of the early winner will be much more likely to attend college. Although none of the data we possess are as clean as the data generated by this hypothetical experiment, taken as a whole, they point in this direction.

\subsubsection{Racial and family income gaps: Long-term family factors vs. short-term credit constraints}

A simple approach to testing the relative importance of long-run factors versus short-run credit constraints in accounting for the evidence in Figure 7 is to condition on long-run factors and examine if there is any additional role for short-run credit constraints.

Cameron and Heckman $(1998,1999,2001)$ compare the estimated effects of family background and family income on college attendance, controlling for scholastic ability (as measured by the Armed Forces Qualifying Test, or AFQT). Measured scholastic ability is influenced by long-term family and environmental factors, which are in turn produced by long-term family factors. To the extent that the influence of family income on college attendance is diminished by the inclusion of scholastic ability in an analysis of college attendance, one would conclude that long-run family factors crystallized in AFQT scores are the driving force behind schooling attainment, and not short-term 
credit constraints. Fitting a life cycle model of schooling to a subsample of the National Longitudinal Survey of Youth (NLSY79) data with AFQT measured before high school graduation, Cameron and Heckman examine what portion of the gap between minority youth and whites in school attendance at various levels is due to family income, to tuition costs, and to family background. ${ }^{32}$ They find that when they do not control for ability measured at an early age, about half (five points) of the eleven-point gap between black and white college attendance rates is due to family income; more than half (four points) of the seven-point difference between Hispanics and whites is due to family income. When scholastic ability is accounted for, only one half of one point of the eleven-point black-white gap is explained by family income. The gap between Hispanics and whites actually widens when family income is included in the empirical model. Adjusting for ability at the age people enter college more than accounts for minority-majority college attendance gaps. Cameron and Heckman obtain comparable results when they adjust for parental education and family structure. ${ }^{33}$ The effects of tuition on college entry are greatly weakened when measures of ability are included. This analysis suggests that it is long-run factors that determine college attendance, not short-term borrowing constraints, that explain the evidence in Figure 7.

It is sometimes claimed that enrollment responses to tuition should be larger for constrained (low-income) persons [see Kane (1994), and the survey in Ellwood and Kane (2000)], although there is no theoretical basis for this. ${ }^{34}$ Cameron and Heckman (1999) address this issue empirically. Even without adjusting for AFQT, they find no pattern in the estimated tuition response by family income level. When conditioning on ability, tuition effects become smaller for everyone (in absolute value) and the influence of family income becomes negligible. In a separate study of the HOPE Scholarship program in Georgia [Dynarski (2000)], the tuition elasticity for youth from middle- and highincome families is as high as other estimates found in the literature for lower income youth.

Based on NLSY79 data, Figures 9 and 10 illustrate the relative importance of family income and academic ability in determining a number of college-related outcomes. ${ }^{35}$ Classifying white males by ability (as measured by AFQT scores) results in a clear ordering that shows that more able people are more likely to go to college than those who are less able. Within test score terciles, we further display college enrollment rates by family income measured in the child's adolescent years. Inspecting the graphs on the left (panels A, C, and E), we observe a clear ordering by family income within ability

\footnotetext{
32 See Bureau of Labor Statistics (2001) for a description of the NLSY data.

33 Cameron and Heckman condition on an early measure of ability not contaminated by the feedback from schooling to test scores. Such feedback is documented in Hansen, Heckman and Mullen (2004).

34 Mulligan (1997) shows in the context of a Becker-Tomes model that tuition elasticities for human capital accumulation are greater (in absolute value) for unconstrained people. His proof easily generalizes to more general preferences. Carneiro and Heckman (2002) use a discrete choice schooling framework to demonstrate that constrained persons may respond less than unconstrained persons.

35 See Carneiro and Heckman (2002) for details.
} 
groups - persons from families with higher income are more likely to enroll in college. However, this does not necessarily mean that short-run credit constraints are operative in the college-going years. Family income in the adolescent years is strongly correlated with family income throughout the life cycle, and long-run family resources are likely to produce many skills that are not fully captured by a single test score. When we control for early family background factors (parental education, family structure, and place of residence), the relationship between family income and school enrollment is greatly weakened for all college outcomes as the graphs in the right-hand side (panels B, D, and E) reveal. Adjusted gaps are much smaller than the unadjusted ones.

Most of the analysis in the literature focuses on college enrollment and much less on other dimensions of college attendance, such as completion, quality of school, and delay of entry into college. ${ }^{36}$ When we perform a parallel analysis for completion of four-year college, we find no evidence of constraints for white males and, in fact, overadjust the gaps in college enrollment. Figures $9(\mathrm{C})$ and (D) present the raw and adjusted gaps respectively, for completion of four-year college. Figures $9(\mathrm{E})$ and (F) show the raw and adjusted gaps for delay of entry into college. There is no evidence of short-run credit constraints in these measures. Carneiro and Heckman (2003) present evidence of short-run credit constraints among the least able poor in completing two years of college, but not for the brightest poor.

Using the difference in each outcome between the highest income category and the lower income categories as a rough measure of the fraction of persons constrained, Carneiro and Heckman $(2002,2003)$ find that there is weak evidence among certain subgroups for short-term credit constraints in years of entry delay and for choice of twoyear versus four-year colleges, a measure of school quality. Depending on the measure of college participation selected, the estimated percentage of white males constrained ranges from 0 to 8 percent. Comparable results hold for other demographic groups.

The strongest evidence for short-term credit constraints is for Hispanic males. This is not surprising since those in the country illegally are not eligible for the same schooling aid as legal residents. The weakest evidence for credit constraints is for black males. On many measures, the effective constraint for this group is zero [see Carneiro and Heckman (2002, 2003)].

Many of the variables used to control for long-term family factors also predict family income in the adolescent years. Does the preceding analysis simply project family income in adolescent years onto other long term family factors? Carneiro and Heckman (2002) claim it does not. Independent variation in family income remains even after controlling for other family factors. When they reverse the roles of family income and family background - e.g., examining how differences in family background affect college enrollment rates after conditioning on family income levels - a strong long-run family background effect remains. As Figure 9 shows, adjusting for family income in

36 Work while attending school is studied in Keane and Wolpin (2001). Delay in entry is studied in Kane (1996). 
A. Percentage Enrolled in 2-Year and 4-Year Colleges

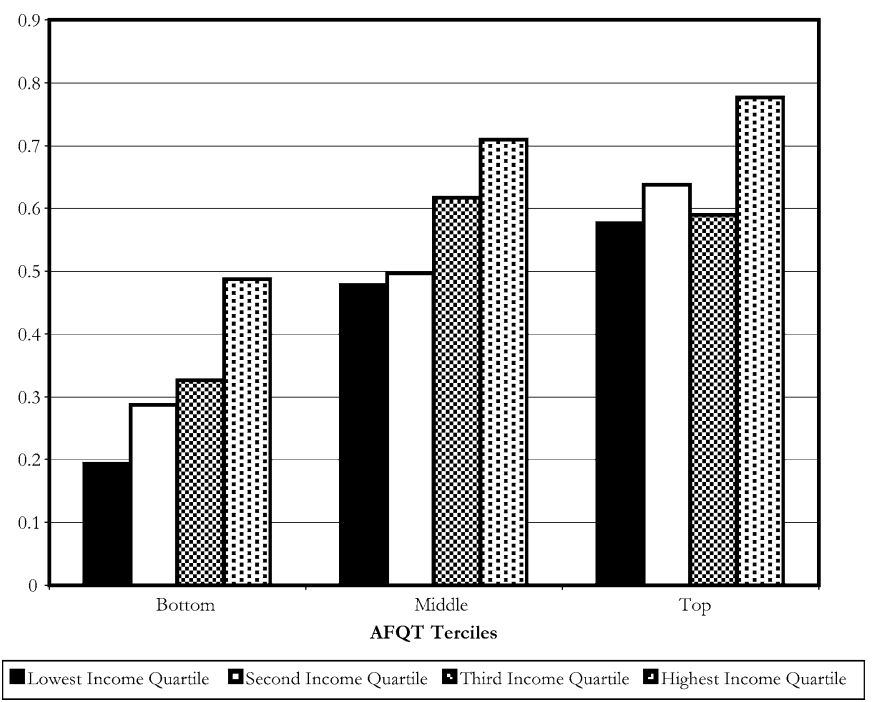

B. Adjusted Percentage Enrolled in 2-Year and 4-Year Colleges

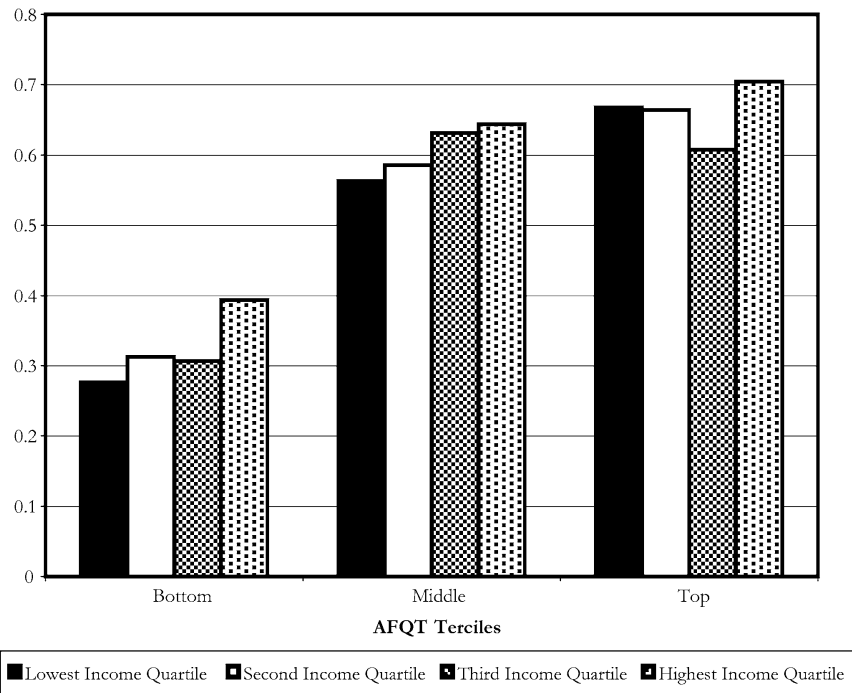

Figure 9. Enrollment, completion and no delay rates by family income quartiles and age-adjusted AFQT terciles white males, NLSY79.

Note: To draw these graphs we performed the following steps. (1) Within each AFQT tercile, we regress percentage enrolled, completion rate, and percentage with no delay on family background: $y=\alpha+F \gamma+Q_{1} \beta_{1}+Q_{2} \beta_{2}+Q_{3} \beta_{3}$, where $y$ is percentage enrolled, completion rate, or percentage with no delay, $F$ is a vector of family background variables (southern origin, broken home, urban origin, mother's education and father's education), $Q_{1}$ is a dummy for being in the first quartile of the distribution of family income at 17, $Q_{2}$ is for being in the second quartile and $Q_{3}$ is for being in the third quartile. (2) Then, within each AFQT tercile, the height of the first bar is given by $\alpha+\bar{F} \gamma+\beta_{1}$, the second is given by $\alpha+\bar{F} \gamma+\beta_{2}$, the third by $\alpha+\bar{F} \gamma+\beta_{3}$ and the fourth by $\alpha+\bar{F} \gamma$ (where $\bar{F}$ is a vector of the mean values for the variables in $F$ ). The coefficients for the regression are given in the Appendix Table B-3 of Carneiro and Heckman (2003). 
C. 4-Year College Completion Rate

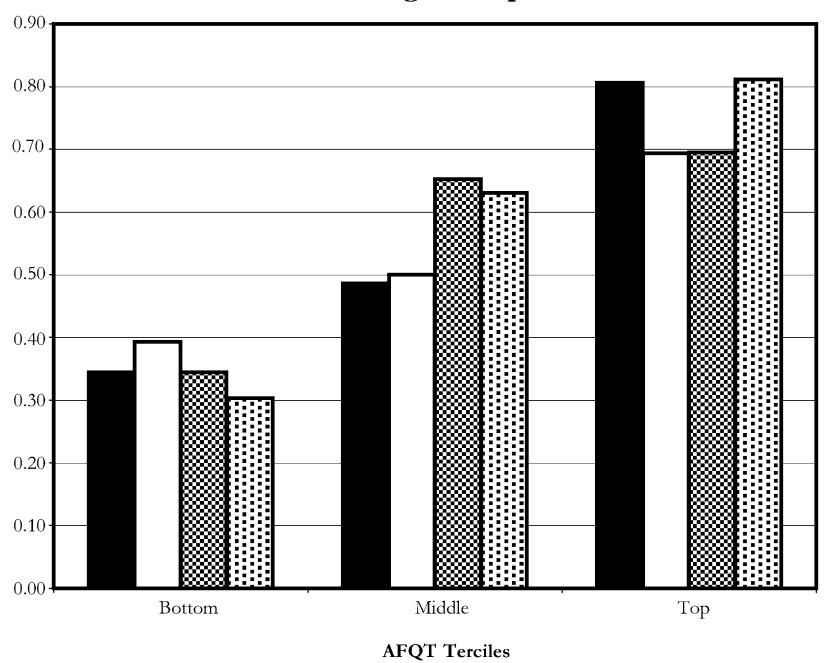

Lowest Income Quartile
AFQT Terciles

- Second Income Quartile $\mathbf{D}$ Third Income Quartile UHighest Income Quartile
D. Adjusted 4-Year College Completion Rate

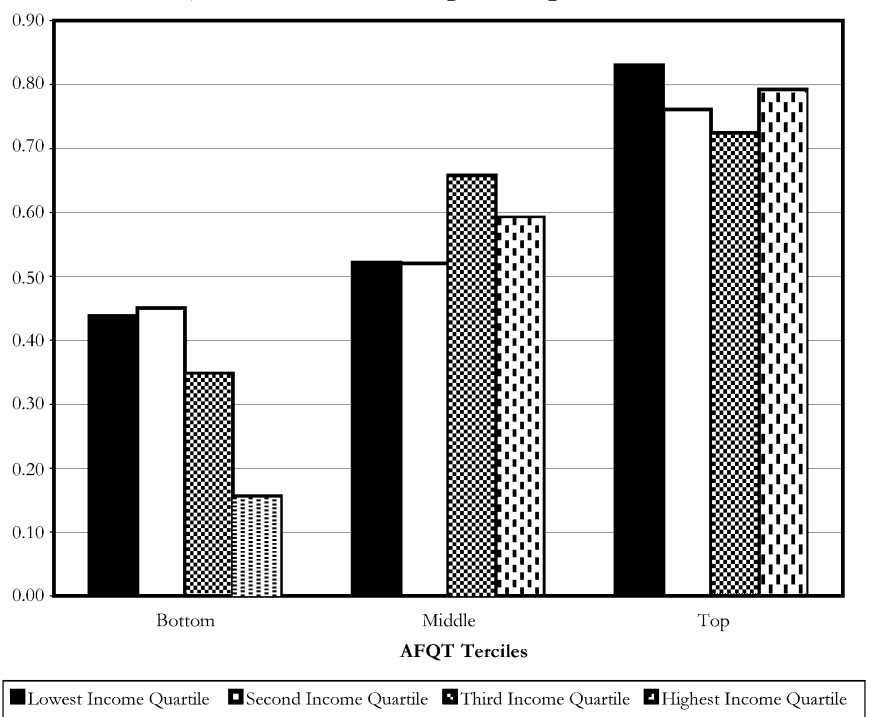

Figure 9. (Continued.)

Note: To draw these graphs we performed the following steps. (1) Within each AFQT tercile, we regress percentage enrolled, completion rate, and percentage with no delay on family background: $y=\alpha+F \gamma+Q_{1} \beta_{1}+Q_{2} \beta_{2}+Q_{3} \beta_{3}$, where $y$ is percentage enrolled, completion rate, or percentage with no delay, $F$ is a vector of family background variables (southern origin, broken home, urban origin, mother's education and father's education), $Q_{1}$ is a dummy for being in the first quartile of the distribution of family income at $17, Q_{2}$ is for being in the second quartile and $Q_{3}$ is for being in the third quartile. (2) Then, within each AFQT tercile, the height of the first bar is given by $\alpha+\bar{F} \gamma+\beta_{1}$, the second is given by $\alpha+\bar{F} \gamma+\beta_{2}$, the third by $\alpha+\bar{F} \gamma+\beta_{3}$ and the fourth by $\alpha+\bar{F} \gamma$ (where $\bar{F}$ is a vector of the mean values for the variables in $F$ ). The coefficients for the regression are given in the Appendix Table B-3 of Carneiro and Heckman (2003). 
E. Percentage with No Delay in College Entry

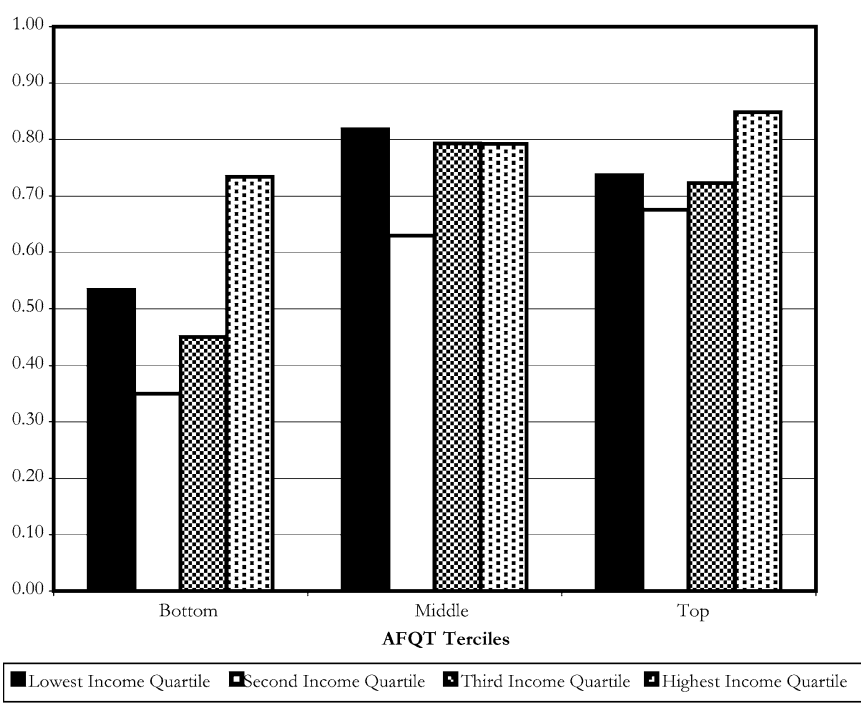

F. Adjusted Percentage with No Delay in College Entry

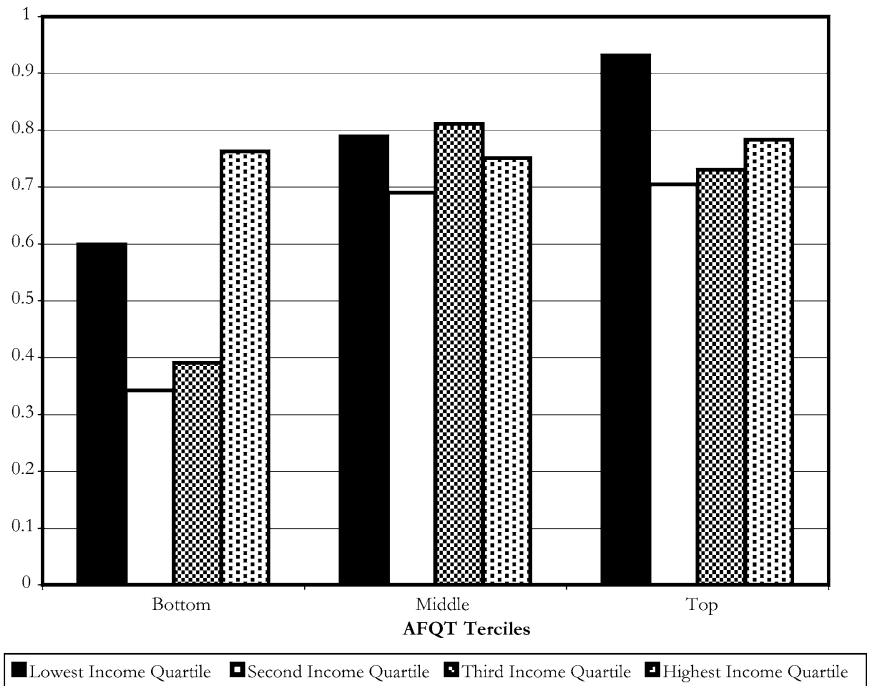

Figure 9. (Continued.)

Note: To draw these graphs we performed the following steps. (1) Within each AFQT tercile, we regress percentage enrolled, completion rate, and percentage with no delay on family background: $y=\alpha+F \gamma+Q_{1} \beta_{1}+Q_{2} \beta_{2}+Q_{3} \beta_{3}$, where $y$ is percentage enrolled, completion rate, or percentage with no delay, $F$ is a vector of family background variables (southern origin, broken home, urban origin, mother's education and father's education), $Q_{1}$ is a dummy for being in the first quartile of the distribution of family income at $17, Q_{2}$ is for being in the second quartile and $Q_{3}$ is for being in the third quartile. (2) Then, within each AFQT tercile, the height of the first bar is given by $\alpha+\bar{F} \gamma+\beta_{1}$, the second is given by $\alpha+\bar{F} \gamma+\beta_{2}$, the third by $\alpha+\bar{F} \gamma+\beta_{3}$ and the fourth by $\alpha+\bar{F} \gamma$ (where $\bar{F}$ is a vector of the mean values for the variables in $F$ ). The coefficients for the regression are given in the Appendix Table B-3 of Carneiro and Heckman (2003). 

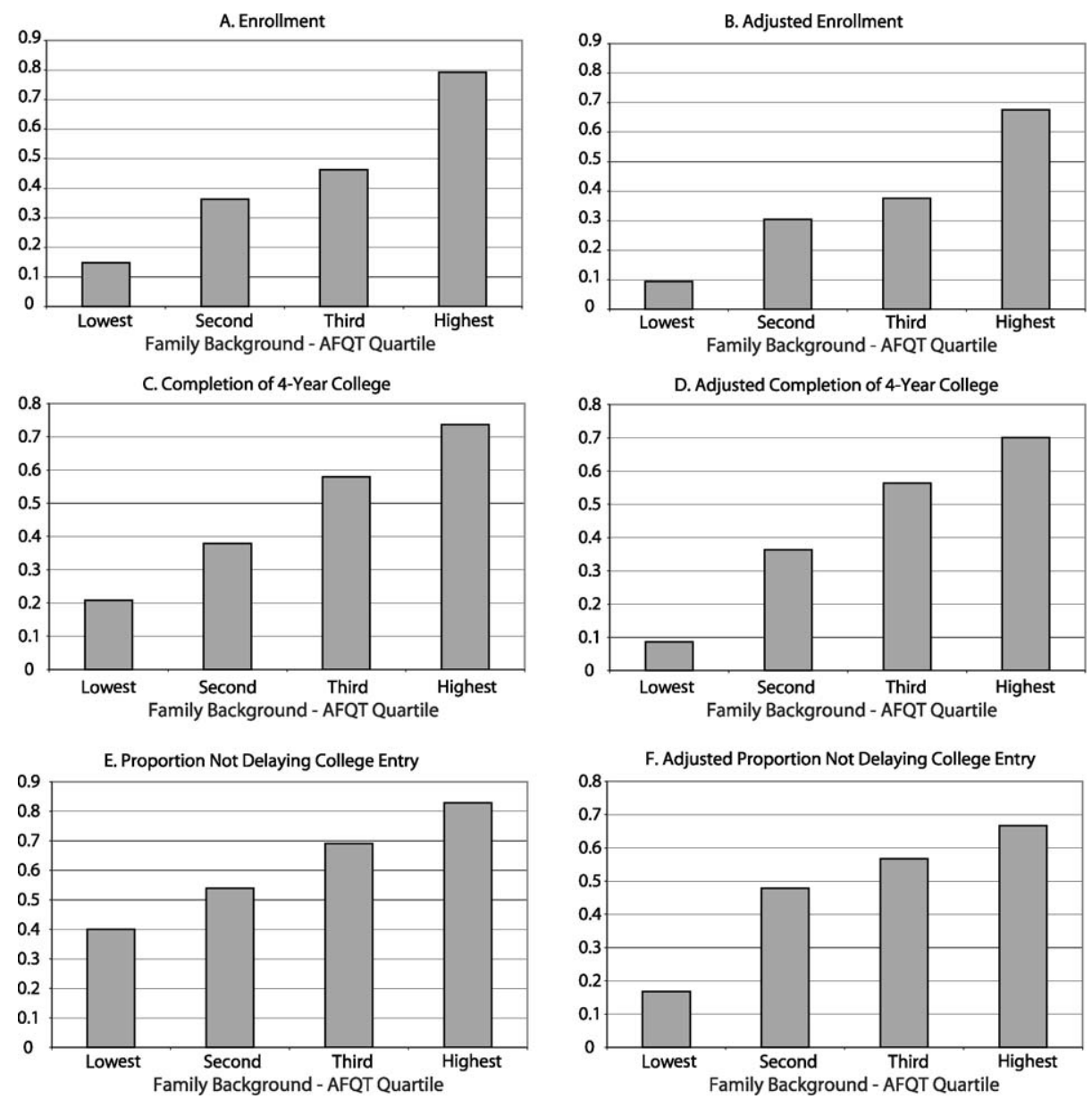

Figure 10. Enrollment, completion and delay by family background-AFQT Quartiles. NLSY79 white males. We correct for the effect of schooling at the test date on AFQT. The family background-AFQT index is based on a linear combination of south, broken home, urban, mother's education, father's education and AFQT. For the residual plots, we condition on family income at age 17. See Table B-4 in the appendix to Carneiro and Heckman (2003) for the coefficients of the linear combination of the variables forming this index.

adolescent years does not substantially affect differences in college decisions by family background.

Tables 1A and 1B report further evidence on the unimportance of short-run credit constraints on college attendance. Using data from the Children of the NLSY79 (CNLSY79) survey, they present estimates of child enrollment in college on family per capita permanent income and on family per capita income flows received at various stages of the life cycle (transitory income). Permanent income is formed as an average 
Table $1 \mathrm{~A}$

Regression of college enrollment on various measures of family income and PIAT math at age 12

\begin{tabular}{|c|c|c|c|c|}
\hline & $\begin{array}{l}\text { (1) } \\
\text { College } \\
\text { enrollment }\end{array}$ & $\begin{array}{l}\text { (2) } \\
\text { College } \\
\text { enrollment }\end{array}$ & $\begin{array}{l}(3) \\
\text { College } \\
\text { enrollment }\end{array}$ & $\begin{array}{l}(4) \\
\text { College } \\
\text { enrollment }\end{array}$ \\
\hline Permanent family income at ages $0-18$ (in $10 \mathrm{~K}$ ) & $\begin{array}{c}0.0839^{*} \\
(0.0121)\end{array}$ & $\begin{array}{c}0.0747^{*} \\
(0.0184)\end{array}$ & $\begin{array}{r}0.0902^{*} \\
(0.0185)\end{array}$ & $\begin{array}{c}0.0779^{*} \\
(0.0284)\end{array}$ \\
\hline PIAT math at age 12 & $\begin{array}{c}0.0077^{*} \\
(0.0017)\end{array}$ & $\begin{array}{c}0.0076^{*} \\
(0.0018)\end{array}$ & $\begin{array}{c}0.0076^{*} \\
(0.0018)\end{array}$ & $\begin{array}{l}0.0075^{*} \\
(0.0018)\end{array}$ \\
\hline Permanent family income at ages $0-5$ (in $10 \mathrm{~K}$ ) & - & $\begin{array}{c}0.0158 \\
(0.0238)\end{array}$ & - & $\begin{array}{c}0.0149 \\
(0.0261)\end{array}$ \\
\hline Permanent family income at ages $16-18$ (in $10 \mathrm{~K}$ ) & $\begin{array}{l}- \\
-\end{array}$ & - & $\begin{array}{r}-0.0069 \\
(0.0177)\end{array}$ & $\begin{array}{c}-0.0023 \\
(0.0194)\end{array}$ \\
\hline Constant & $\begin{array}{c}0.1447^{*} \\
(0.0264)\end{array}$ & $\begin{array}{c}0.1404^{*} \\
(0.0272)\end{array}$ & $\begin{array}{c}0.1410^{*} \\
(0.0268)\end{array}$ & $\begin{array}{c}0.1380^{*} \\
(0.0273)\end{array}$ \\
\hline Observations & 863 & 863 & 861 & 861 \\
\hline$R$-squared & 0.1 & 0.1 & 0.11 & 0.11 \\
\hline
\end{tabular}

Standard errors in parentheses. Permanent family income is discounted to age 0 using a $5 \%$ rate.

* Significant at $1 \%$.

discounted income flow to the family over the life of the child at home (ages 0 to 18). ${ }^{37}$ Two features are clear from these tables: (a) permanent income matters a lot for college enrollment and (b) given permanent income, transitory income flows matter little. This result is robust whether or not one controls for ability at age 12: compare Table 1A with Table 1B which does not control for ability at age 12. We discuss other studies on the importance of the timing of family income in Section 2.5.3.

Policies that improve the educational financing of identified constrained subgroups in the college-going years will increase their human capital and may well be justified on objective cost-benefit criteria. The potential economic loss from delay in entering college can be substantial. If $V$ is the economic value of attending school, and schooling is delayed one year, then the costs of delaying schooling by one year and not earning any income, are $\frac{r V}{1+r}$, where $r$ is the rate of return. For $r=0.10$, which is not out of line with estimates in the literature, this delay is 9 percent of the lifetime value of schooling (roughly \$20,000 in 2004 dollars). For the identified constrained subgroups, the benefits to reducing delay and promoting earlier college completion, higher college quality and graduation are likely to be substantial even when earnings net of disutility costs of work in the year of delay are taken into account.

Stinebrickner and Stinebrickner (2004) examine the role of credit constraints in determining college attrition at a small liberal arts college in Kentucky. Since the probability

37 We obtain the same empirical patterns reported in the text whether or not we use per capita income measures. 
Table 1B

Regression of college enrollment on various measures of family income

\begin{tabular}{lcccc}
\hline & $\begin{array}{l}\text { (1) } \\
\text { College } \\
\text { enrollment }\end{array}$ & $\begin{array}{l}\text { (2) } \\
\text { College } \\
\text { enrollment }\end{array}$ & $\begin{array}{l}\text { (3) } \\
\text { College } \\
\text { enrollment }\end{array}$ & $\begin{array}{l}\text { l) } \\
\text { College } \\
\text { enrollment }\end{array}$ \\
\hline Permanent family income at ages 0-18 (in 10K) & $0.0942^{*}$ & $0.0829^{*}$ & $0.1031^{*}$ & $0.0887^{*}$ \\
& $(0.0108)$ & $(0.0170)$ & $(0.0169)$ & $(0.0270)$ \\
Permanent family income at ages 0-5 (in 10K) & - & 0.0259 & - & 0.0233 \\
& - & $(0.0220)$ & - & $(0.0246)$ \\
Permanent family income at ages 16-18 (in 10K) & - & - & -0.0108 & -0.0048 \\
Constant & - & - & $(0.0170)$ & $(0.0188)$ \\
& $0.1367^{*}$ & $0.1179^{*}$ & $0.1329^{*}$ & 0.1158 \\
Observations & $(0.0243)$ & $(0.0251)$ & $(0.0246)$ & $(0.0252)$ \\
$R$-squared & 1015 & 987 & 1013 & 985 \\
\hline & 0.07 & 0.08 & 0.07 & 0.08 \\
\hline
\end{tabular}

Standard errors in parentheses. Permanent family income is discounted to age 0 using a 5\% rate.

* Significant at $1 \%$.

of dropping out of college differs substantially by family income in their sample, it is natural to ask whether this may be the result of borrowing constraints. They utilize a unique set of questions asked of all survey respondents to infer the role played by borrowing constraints in determining college attrition and the relationship between family income and attrition. The survey asks whether students would like to borrow more money for school if they could and, if so, how much they would like to borrow. They find that only $20 \%$ of the sample would like to borrow more for school, and the median amount those individuals would like to borrow is only $\$ 500$. Based on these findings, they estimate that the inability to borrow plays little role in attrition decisions.

A few other studies have attempted to model borrowing constraints and schooling decisions more explicitly. Cameron and Taber (2004) examine the empirical importance of borrowing constraints in a model that incorporates the insight that borrowing constraints will influence both schooling choices and returns to schooling. Using a variety of methods, they find no evidence that borrowing constraints in the adolescent years play a role in explaining the years of schooling attained by recent cohorts of American youth. Keane and Wolpin (2001) estimate a more formally explicit sequential dynamic model and reach the same conclusion. Students are estimated to be constrained in the short-run, but alleviate the constraints they face by working while in college. Relaxing the budget constraint barely affects schooling decisions but affects work while in school. Neither study looks at delay or quality effects, which have been found to be quantitatively important.

In designing policies to alleviate short-term constraints, it is important to specifically target the interventions toward the constrained in ways that previous programs have not. 
Broad-based policies generate deadweight. For example, Dynarski (2003) and Cameron and Heckman (1999) estimate that 93 percent of President Clinton's Hope Scholarship funds, which were directed toward middle-class families, were given to children who would have attended school even without the program. Stanley (2003) studies the impact of the GI Bill on the college-going decisions of Korean War veterans and finds that most college subsidies under the bill were used by veterans from families in the top half of the socioeconomic distribution. In an analysis of Georgia's HOPE Scholarship program, Dynarski (2000) finds that most of the funds went to middle- and high-income students. These studies all suggest that previous government attempts to finance college have primarily benefited the most well-off with little impact on those most likely to be constrained. This conclusion is further supported by simulations from the model of dynamic schooling choices in Keane and Wolpin (2001).

While targeting those identified as constrained may be good policy, it is important not to lose sight of the main factors accounting for differences in schooling attainment. Family background factors crystallized in ability are the first-order factors explaining college attendance and completion gaps. Differences in ability by family income groups appear at early ages and persist. They affect schooling decisions and wages. A major conclusion of the studies reviewed in this section is that the abilities decisive in producing differentials in college attendance are shaped early in life.

Lochner and Monge (2004) argue that the current structure of the student lending system in the U.S. minimizes the effect of liquidity problems on college attendance decisions, even though it may severely distort consumption patterns. This is because the student loan system directly links borrowing limits to schooling expenditures, a feature neglected in most studies of credit constraints and schooling. That is, students who spend more on college can borrow more as long as their total borrowing remains below an upper limit set by government lending programs. While Stafford loan limits for dependent students are limited to a cumulative amount of $\$ 23,000$, students from poorer families can borrow up to an additional $\$ 40,000$ from the Perkins loan program in addition to any direct transfers from the Pell Grant program. Finally, parents can borrow up to the student's determined need from the PLUS loan program. ${ }^{38}$ Thus, the effective constraint on family borrowing for many college students is simply the amount needed for tuition, fees, books, and room and board at the institution of choice. In this sense, college costs can be fully covered by student loans. ${ }^{39}$ While students cannot borrow

38 PLUS take-up rates are low relative to the roughly 50\% take-up rates of other student loans. It is difficult to know whether this reflects a reluctance of parents to take on debt when students would choose to do so themselves if they could or whether it reflects the fact that other lending and grants satisfy the needs of most students. Parents are not eligible for PLUS loans if they have a bad credit rating (they are eligible with no credit rating or a good one), but students with ineligible parents are able to borrow considerably more (at the levels set for independent students) from the Stafford loan program than other dependent students.

39 While loans cannot be taken out to cover foregone earnings, room and board does not, strictly speaking, represent a cost of college. To the extent that these roughly offset each other for individuals who work a few hours a week during the school year and full-time during the summer, the full costs of college, including direct and indirect costs, can be borrowed. 
above and beyond the costs of college to buy fancy cars or expensive apartments (even if their future prospects are bright and they would like to consume more while in college), the constraints embodied in the federal student loan system tend not to distort schooling decisions. ${ }^{40}$ The analysis of Lochner and Monge (2004) is consistent with the analysis and evidence in Keane and Wolpin (2001). ${ }^{41}$

\subsubsection{Borrowing constraints as determinants of family investment in children}

While many recent studies have analyzed the importance of borrowing constraints among college-age students, very little attention has been given to the role played by borrowing constraints in determining family investments in younger children. Two conceptually distinct types of constraints may limit family investments in their younger children. First, parents may be unable to borrow against their children's future income even if they can borrow against their own future income. This suggests that bright children born to poor parents may not receive the efficient amount of investment because their parents may never earn enough to pay for those investments. The timing of income receipts for the parents is assumed to be irrelevant in this case. Only the discounted present value of their income matters. A second, more severe, constraint on parents may limit them from borrowing fully against their own future income. This is the constraint most commonly associated with the notion of borrowing constraints, and it implies that the timing of a parent's income matters for child investment decisions. Parents who earn a smaller share of their lifetime income when their children are young are likely to invest less in their young children. Two families with the same lifetime income may make different early investment decisions. These early investment decisions may affect later decisions about college attendance.

While it seems likely that the first form of constraint is relevant for most families, the empirical importance of the second is a matter of some controversy. The obvious test for the second borrowing constraint examines whether the timing of family income matters for child achievement and schooling outcomes. Only a few studies speak to

\footnotetext{
40 Furthermore, the option for students to default on their student loans after leaving school may actually encourage some of the least able to attend low quality colleges that offer little net return. While this may sound farfetched, cohort default rates reached $20 \%$ in the early 1990 s. Many institutions had default rates above $50 \%$.

41 The take-up rate on Pell Grants and Perkins Loans targeted toward students from low-income families is low [Orfield (1992)]. Many more people are eligible for support than those who claim it. Binding borrowing constraints are not a plausible explanation for the lack of utilization of these potential resources. Kane (1999) suggests that nonmonetary costs of applying for financial aid may be high, especially for low-income people, because the application process is complex. He argues that decreasing these costs may be a more promising avenue for relaxing financing constraints for low-income people than expanding existing programs. He provides no evidence, however, in support of this conjecture. An alternative explanation consistent with our evidence is that many eligible persons perceive that even with a substantial tuition subsidy, the returns to college education for them are too low to pay for the foregone earnings required to attend school. Risk aversion due to the uncertainty of income flows may also reduce the returns relative to the benefits.
} 
this issue. Duncan and Brooks-Gunn (1997b) use PSID data to estimate the effects of family income earned at different stages of a child's life (ages 0-5, 6-10 and 1115) on final schooling outcomes. Both standard cross-sectional OLS and sibling fixed effects models reveal that early income (ages 0-5) has a significantly larger impact on years of completed schooling and high school graduation rates than does income at later ages. Levy and Duncan (2000) report similar results using the PSID and siblings fixed effects models. Carneiro and Heckman (2003) argue that these findings do not necessarily imply that timing matters, since one should discount income in all stages back to the same base year. Otherwise, the income earned when a child is young is worth more than when the child is older, simply because the latter needs to be discounted. When they control for the discounted present value of lifetime income over the child's ages $0-18$, they do not find any significant additional effect of early income on college enrollment decisions using data from the Children of the NLSY79 (recall our discussion of Tables 1A and 1B). They conclude that the timing of parental income within the life cycle of the child is unimportant.

Caucutt and Lochner (2004) use the Children of NLSY79 to conduct three tests for determining whether the timing of (discounted) family income affects adolescent math and reading achievement levels. Their estimates suggest that (i) income earned at earlier ages has a slightly larger (and statistically significant) impact on adolescent test scores than does income earned at later ages, (ii) future income has less of an effect on current outcomes than does past income and (iii) the slope of a family's income profile is negatively related to test scores, even after controlling for the discounted present value of family income taken over a twenty-year period. While most of their findings are consistent with the presence of constraints on parental borrowing against their own income, none of them suggest that the timing of parental income within the life cycle of the child plays a large role in determining child outcomes. Consistent with Carneiro and Heckman (2003), their results suggest a strong effect of permanent lifetime income on child development outcomes.

Overall, the evidence on whether the timing of income matters on children's outcomes is mixed. While some of the evidence suggests that timing does matter, some does not. Even those studies that suggest a role for timing do not find large effects. Because it is necessary to observe individuals over a long time period in order to examine the role of income timing, most studies are based on a fairly small number of individuals and are forced to make strong assumptions about the dynamic process by which income may affect achievement and schooling outcomes. Additional studies of this issue are certainly warranted to explore the robustness of the findings to alternative specifications.

\subsubsection{High rate of return to schooling compared to the return on physical capital}

Least squares estimates of the rate of return to schooling, based on the Mincer earnings function, are often above 10 percent and sometimes are as high as 17 to 20 percent. Estimates based on instrumental variables are even higher. [See, for example, the evidence 
surveyed by Card $(1999,2001)$, and the discussion of the quality of the instruments used in this literature presented in Carneiro and Heckman (2002)]. It is sometimes claimed that the returns to schooling are very high relative to the returns to physical capital, and therefore people are credit-constrained or that some other market failure is present.

The cross-sectional Mincer rate of return to schooling does not, in general, estimate the marginal internal rate of return to schooling, and the internal rate of return is not well-defined in sequential dynamic programming models. ${ }^{42}$ Willis (1986) and Heckman, Lochner and Todd (2006) state the conditions under which the Mincer rate of return will equal the marginal internal rate of return to schooling. The latter paper shows that these assumptions are at odds with U.S. earnings data. Even if these conditions are satisfied, implicit comparisons are usually made against a risk-free interest rate. However, this is not the relevant comparison for evaluating schooling decisions. Carneiro, Hansen and Heckman (2001, 2003), Cunha, Heckman and Navarro (2005), and Navarro (2005) estimate that agents face considerable uncertainty in their returns to schooling. The illiquidity and irreversibility of human capital investments drive the premium on human capital far above the safe interest rate [see Judd (2000)]. Consequently, comparisons of Mincer returns and returns to capital are intrinsically uninformative about the existence of credit constraints or the need for intervention in human capital markets. See Carneiro and Heckman (2002), Cunha, Heckman and Navarro (2005), and Navarro (2005) for further discussion of this point.

\subsubsection{Are rates of return to investment higher for persons from low-income families?}

If low-income families are credit-constrained, under conditions specified in Carneiro and Heckman (2002), at the margin, the returns to schooling for children from constrained families should be higher, since they are investing less than the efficient amount. ${ }^{43}$ We develop this analysis formally in Section 3. Carneiro and Heckman (2002) establish that if choices are made at the margin of schooling quality, the estimated Mincer return may be lower for constrained persons, unless adjustments for schooling quality are made in the estimated returns. The empirical literature on this topic, which does not adjust for quality, finds that returns to secondary schooling and post-secondary schooling are higher for high-ability people than for low-ability people. [See, for example, Cawley et al. (2000), Meghir and Palme (1999), Tabler (2001), or the evidence presented in Section 2.5.6.] Family income and child ability are positively correlated, so one would expect higher returns to schooling for children of high-income families for this reason alone. Altonji and Dunn (1996) find in their preferred empirical specification that the returns to schooling are higher for children from more-educated

\footnotetext{
42 See Heckman, Lochner and Todd (2006) and Heckman, Lochner and Taber (1998) for examples in which cross-sectional rates of return are uninformative about the return to schooling that any person experiences.

43 Carneiro and Heckman (2002) show that for this prediction to be valid, it is necessary to assume that all families face the same technology of schooling (relating inputs to outputs) and that there be no comparative advantage in the labor market. Cameron and Taber (2004) derive a different set of conditions.
} 
families than for children of less-educated families. This effect operates in part through higher schooling participation rates and hence higher earnings. There is no evidence that rates of return to secondary and postsecondary schooling are higher for children from low-income families than for children from high-income families. Indeed all of the evidence points to returns in the later stages of child schooling being higher for high ability children from more advantaged environments. This is consistent with complementarity and self-productivity as discussed in Section 1 . We elaborate on this point in Section 3.

Interventions at very early ages, however, have higher returns for the most disadvantaged. This empirical pattern holds across many studies. For example, this holds true for a nurse home visitation program in Elmira, NY [Olds (2002)], where there was no statistically significant effect of the program on child socioeconomic outcomes for the sample as a whole, but modest effects were found for the disadvantaged subsample of unmarried, young, and poor white mothers and their children. The nurse home visitation program in Memphis replicated this pattern of results, though the overall effects of treatment were much weaker. ${ }^{44}$ The IHDP $^{45}$ study of low-birth weight babies by Brooks-Gunn et al. (1992) finds that the increase in IQ is higher among children of poorly educated mothers. ${ }^{46}$ Non-experimental studies of preschool by Magnuson et al. (2004); Magnuson, Ruhm and Waldfogel (2004) and the Gormley et al. (2004) study of Oklahoma universal pre-K program find the effect of preschool on achievement test scores to be higher among the disadvantaged children.

By the late adolescent years, the pattern is reversed and returns are lower for low ability and disadvantaged children. An equity-efficiency trade-off becomes evident. This is clear in the higher returns to the most able in job training and in the military AFQT studies, both of which we summarize below. This reversal in the pattern of returns to investment in disadvantaged persons is a consequence of the technology of skill formation that we formalize in Section 3 of this paper. Distinguishing returns from early investment from returns to late investment reveals the value of self-productivity and complementarity as useful conceptual tools for organizing the evidence on child development.

\footnotetext{
44 We discuss the evidence on other visitation programs in Section 2.6.1.4.

45 The Infant Health and Development Program was a randomized study of low-birthweight infants conducted at 8 sites around the country. The treatment group received home visits by program staff, child attendance at a child development center, and parent group meetings. Both treatment and control children received medical, developmental, and social assessments, with referral for pediatric care and other services. All services were provided at no cost to the families. The intervention lasted until children were 36 months of age, adjusted for prematurity.

46 However, any cognitive effect of IHDP are almost entirely attenuated by age 8 [see McCarton et al. (1997)].
} 
Table 2

Average marginal effect on participation in company training (the probability of participating in training)

\begin{tabular}{|c|c|c|c|c|c|c|}
\hline & \multicolumn{6}{|c|}{ Average marginal effect } \\
\hline & \multicolumn{2}{|c|}{ White males } & \multicolumn{2}{|c|}{ Black males } & \multicolumn{2}{|c|}{ Hispanic males } \\
\hline & (1) & $(2)$ & (1) & $(2)$ & (1) & (2) \\
\hline \multirow[t]{2}{*}{ Age-adjusted AFQT } & 0.0149 & - & 0.0182 & - & 0.0066 & - \\
\hline & $(0.0024)$ & - & $(0.0033)$ & - & $(0.0037)$ & - \\
\hline \multirow{2}{*}{$\begin{array}{l}\text { Family income in } 1979 \\
\quad \text { (in } \$ 10,000)\end{array}$} & -0.0021 & -0.0005 & -0.0047 & -0.0019 & 0.0011 & 0.0015 \\
\hline & $(0.0012)$ & $(0.0011)$ & $(0.0024)$ & $(0.0023)$ & $(0.0024)$ & $(0.0023)$ \\
\hline \multirow[t]{2}{*}{ Grade completed } & 0.0382 & - & 0.0060 & - & 0.0036 & - \\
\hline & $(0.001)$ & - & $(0.0014)$ & - & $(0.0014)$ & - \\
\hline \multirow[t]{4}{*}{ Father's education } & -0.0014 & 0.0007 & 0.0003 & 0.0010 & 0.0002 & 0.0008 \\
\hline & $(0.0006)$ & $(0.0005)$ & $(0.0008)$ & $(0.0008)$ & $(0.0007)$ & $(0.0007)$ \\
\hline & \multicolumn{2}{|c|}{ White females } & \multicolumn{2}{|c|}{ Black females } & \multicolumn{2}{|c|}{ Hispanic females } \\
\hline & (1) & $(2)$ & (1) & (2) & (1) & (2) \\
\hline \multirow[t]{2}{*}{ Age-adjusted AFQT } & 0.0076 & - & 0.0169 & - & 0.0159 & - \\
\hline & $(0.0025)$ & - & $(0.0038)$ & - & $(0.0045)$ & - \\
\hline \multirow{2}{*}{$\begin{array}{l}\text { Family income in } 1979 \\
\quad \text { (in } \$ 10,000)\end{array}$} & -0.0007 & 0.0001 & -0.0006 & 0.0014 & -0.0065 & -0.0043 \\
\hline & $(0.0011)$ & $(0.0011)$ & $(0.0024)$ & $(0.0023)$ & $(0.0031)$ & $(0.0029)$ \\
\hline \multirow[t]{2}{*}{ Grade completed } & 0.0027 & - & 0.0014 & - & 0.0013 & - \\
\hline & $(0.0010)$ & - & $(0.0016)$ & - & $(0.0016)$ & - \\
\hline \multirow[t]{2}{*}{ Father's education } & 0.0001 & 0.0009 & 0.0015 & 0.0021 & -0.00001 & 0.0007 \\
\hline & $(0.0006)$ & $(0.0006)$ & $(0.0008)$ & $(0.0008)$ & $(0.0009)$ & $(0.0008)$ \\
\hline
\end{tabular}

The panel data set was constructed using NLSY79 data from 1979-1994. Data on training in 1987 is combined with 1988 in the original dataset. Company training consists of formal training run by employer, and military training excluding basic training. Standard errors are reported in parentheses. Specification (1) includes a constant, age, father's education, mother's education, number of siblings, southern residence at age 14 dummy, urban residence at age 14 dummy, and year dummies. Specification (2) drops age-adjusted AFQT and grade completed. Average marginal effect is estimated using average derivatives from a probit regression.

\subsubsection{The role of ability in returns to schooling and in choice of post-school investment}

Ability is not only a primary determinant of schooling decisions and hence earnings, but it also affects the return per unit of schooling as well as participation in job training. Table 2 gives our evidence on the effect of ability on participation in post-school job training programs. For different demographic groups it shows the effect of measured ability (AFQT) on participation in company training programs. More able people are substantially more likely to participate in company training. Far from remediating credit constraints, as they are sometimes conjectured to do, private-sector post-school investment programs reveal that those who start with higher initial conditions make more investments throughout their lifetimes. 
Table 3

Return to one year of college for individuals at different percentiles of the math test score distribution. White males from High School and Beyond

\begin{tabular}{lccccc}
\hline & $5 \%$ & $25 \%$ & $50 \%$ & $75 \%$ & $95 \%$ \\
\hline Average return in the population & 0.1121 & 0.1374 & 0.1606 & 0.1831 & 0.2101 \\
& $(0.0400)$ & $(0.0328)$ & $(0.0357)$ & $(0.0458)$ & $(0.0622)$ \\
Return for those who attend college & 0.1640 & 0.1893 & 0.2125 & 0.2350 & 0.2621 \\
& $(0.0503)$ & $(0.0582)$ & $(0.0676)$ & $(0.0801)$ & $(0.0962)$ \\
Return for those who do not attend college & 0.0702 & 0.0954 & 0.1187 & 0.1411 & 0.1682 \\
& $(0.0536)$ & $(0.0385)$ & $(0.0298)$ & $(0.0305)$ & $(0.0425)$ \\
Return for those at the margin & 0.1203 & 0.1456 & 0.1689 & 0.1913 & 0.2184 \\
& $(0.0364)$ & $(0.0300)$ & $(0.0345)$ & $(0.0453)$ & $(0.0631)$ \\
\hline
\end{tabular}

Wages are measured in 1991 by dividing annual earnings by hours worked per week multiplied by 52 . The math test score is an average of two 10th grade math test scores. There are no dropouts in the sample and the schooling variable is binary (high school-college). The gross returns to college are divided by 3.5 (average difference in years of schooling between high school graduates that go to college and high school graduates that do not in a sample of white males in the NLSY79). To construct the numbers in the table we proceed in two steps. First we compute the marginal treatment effect using the method of local instrumental variables as in Carneiro, Hansen and Heckman (2001). The parameters in the table are different weighted averages of the marginal treatment effect. Therefore, in the second step we compute the appropriate weight for each parameter and use it to construct a weighted average of the marginal treatment effect (see also Carneiro (2002)). Individuals at the margin are indifferent between attending college or not.

We have already discussed the evidence that the wage returns to schooling are higher for children from the most advantaged environments. This evidence is consistent with complementarity and self-productivity. Ability also affects the economic return to schooling. Carneiro and Heckman (2003) study the economic returns to college for people of different ability (see Table 3 ). Those at the bottom $5 \%$ of the ability distribution get half of the return to college of those at the top $5 \%$ of the ability distribution. Ability also affects wages independently of its effect on schooling, as shown in Carneiro, Heckman and Masterov (2005). This is further evidence on complementarity and selfproductivity.

A strong connection between ability and job performance has been established in a series of studies conducted for the military. The armed services rely heavily on aptitude testing to screen recruits. Aptitude is defined in terms of performance on the Armed Forces Qualification Test (AFQT), which is a subset of the Armed Forces Vocational Aptitude Battery (ASVAB). Category I corresponds to the highest ability level, while V is the lowest, representing scores below the 10th percentile. ${ }^{47}$ Armor and Roll (1994)

47 Recruits whose scores fall in category V are ineligible for enlistment. Category I corresponds to AFQT scores in the 93-99th percentiles, II to 65-92th, IIIA to 50-64th, IIIB to 31-49th, IV to 10-30, and V to 1-9th. 


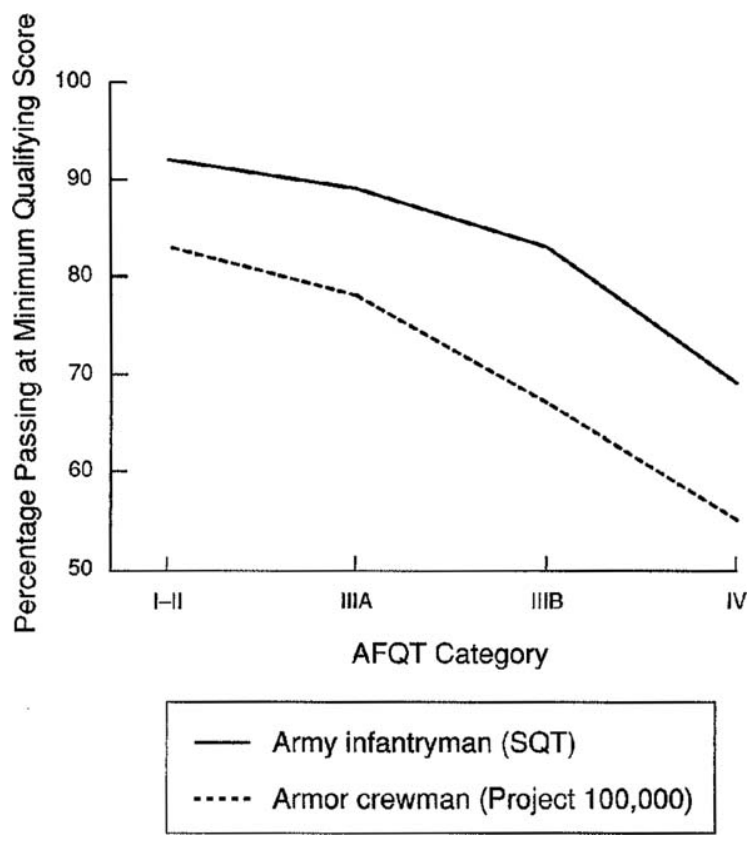

Figure 11A. Military job performance and AFQT. Source: Armor and Roll (1994).

establish that the test is predictive of true productivity and that initial deficits in productivity are not remedied by work experience. Figure 11A shows the relationship between the percentage passing at a minimum qualifying score on two job-performance tests and AFQT for the two largest combat specialties. The two tests are the Skill Qualification Test (SQT) for infantrymen and the Project 100,000 Test for armor crewmen. ${ }^{48}$ The strong positive relationship between AFQT and the measures on job performance tests is unambiguous. Moreover, job experience does not appear to mediate these performance gaps substantially. Remediation through experience, which is sometimes claimed to be effective [Bruer (1999)], is actually ineffective in closing skill gaps. Early disadvantages are not easily remedied by compensatory investments or work experience at later ages.

Figure 11B shows the link between time on the job and the average score on the hands-on performance test developed by the Job Performance Measurement/Enlistment Standards Project (JPM) for first-term soldiers from all branches of the military. While the performance of soldiers at all ability levels improves with experience, the difference

48 The Project 100,000 measure was a field test using real equipment of some task in which performance of each subtask was scored by an officer as correct or incorrect. The passing rate is set at $50 \%$ correct. The SQT includes a hands-on performance test, a job knowledge test, and a certification component (e.g., firing range qualifications). A score of $60 \%$ correct is considered a minimum level of job proficiency. This accounts for the gap between the two lines in the figure. 


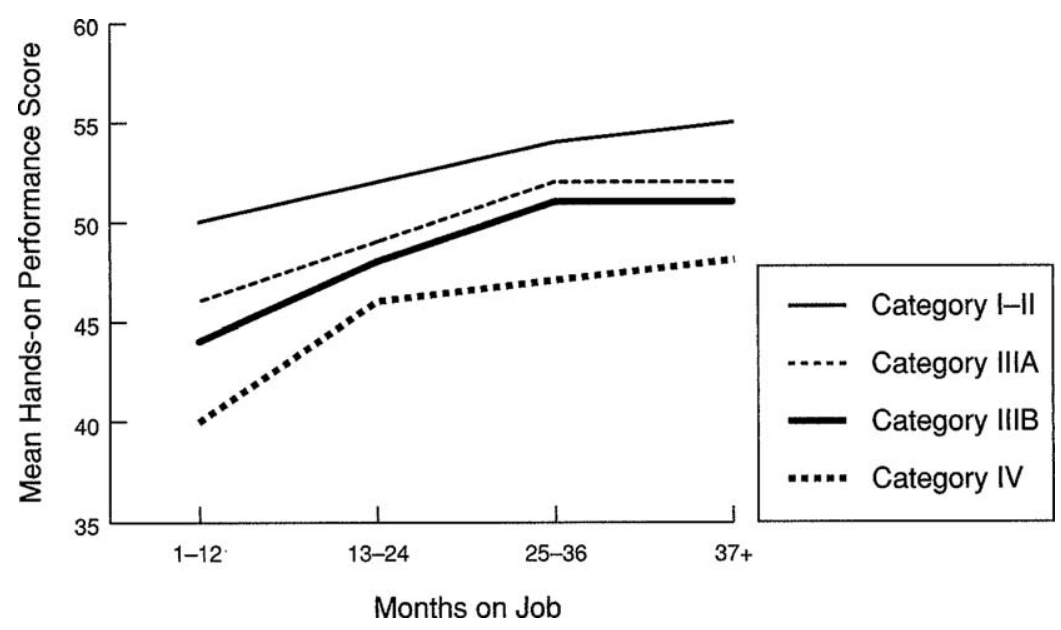

Figure 11B. Military job performance on JPM, AFQT and experience. Source: Armor and Roll (1994).

between categories I-II and IV remains constant at approximately one-half of a standard deviation. To put it differently, the average category IV soldier with three years of experience performs at the level of a category IIIA soldier with one year of service.

Ability formed in the early years is also important in explaining crime, teenage pregnancy and a variety of social pathologies. Figure 12A shows that women with low cognitive ability are more likely to bear children when they are young. Figure 12B shows that men of low cognitive ability are more likely to spend time in jail by the time they are 30 . Figures $12 \mathrm{C}$ and $12 \mathrm{D}$ show that maternal ability is positively associated with how much cognitive and emotional stimulation children receive. Maternal ability is an important ingredient in eliminating test score gaps of children as demonstrated in Section 2.2. Not only do less able women bear children at earlier ages, but they propagate themselves across generations by investing less in their children.

We next turn to an analysis of the evidence on the effectiveness of specific policies in supplementing the environments of disadvantaged children.

\subsection{What is known about specific policies to foster ability and skill?}

\subsubsection{Early interventions}

Karoly et al. (1998), Currie (2001) and Currie and Blau (2006) present comprehensive surveys of numerous preschool intervention programs targeted toward disadvantaged populations and their measured effects. The programs they analyze vary, both in terms of age of enrollment and age of exit. The effects are generally consistent, although in some 


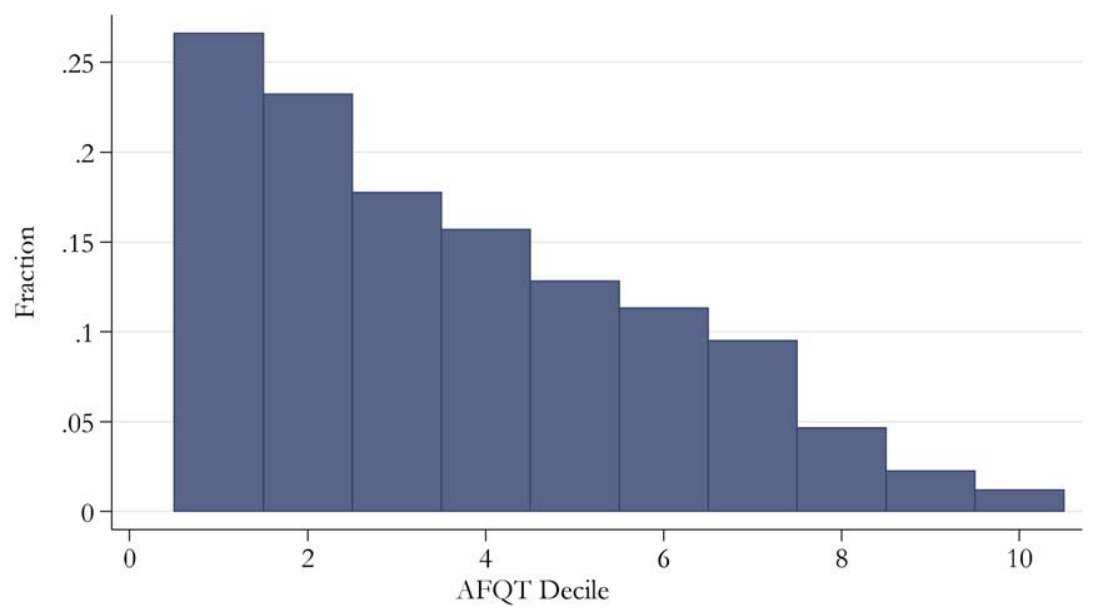

Figure 12A. Fraction of women who gave birth by 18th birthday. Data from NLSY79.

Note: Uses the AFQT calculation procedure as defined by the Department of Defense in 1989. Data used 1979-2000.

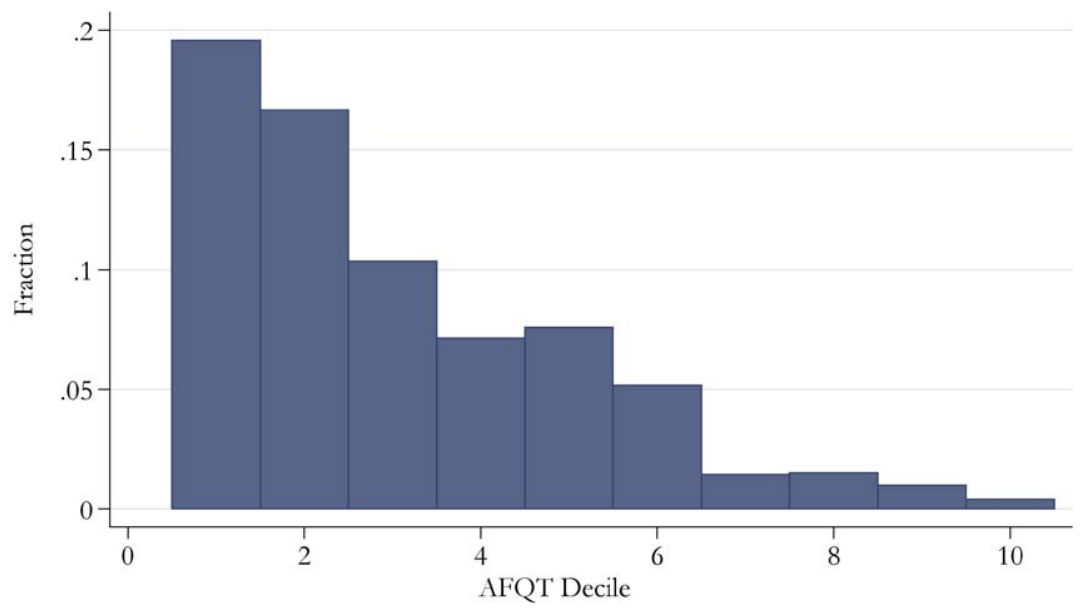

Figure 12B. Fraction of male respondents in jail at age 30 or below. Data from NLSY79.

Note: Uses the AFQT calculation procedure as defined by the Department of Defense in 1989. Data used 1979-2000.

cases they are quite small. ${ }^{49}$ Generally, performance of children in school is improved in terms of less grade repetition, more graduation and higher test scores. Unfortunately,

49 For example, Currie and Thomas (2000) show that test score gains of participants in the Head Start program tend to fade completely for blacks but not for whites. Their paper suggests that one reason may be that 


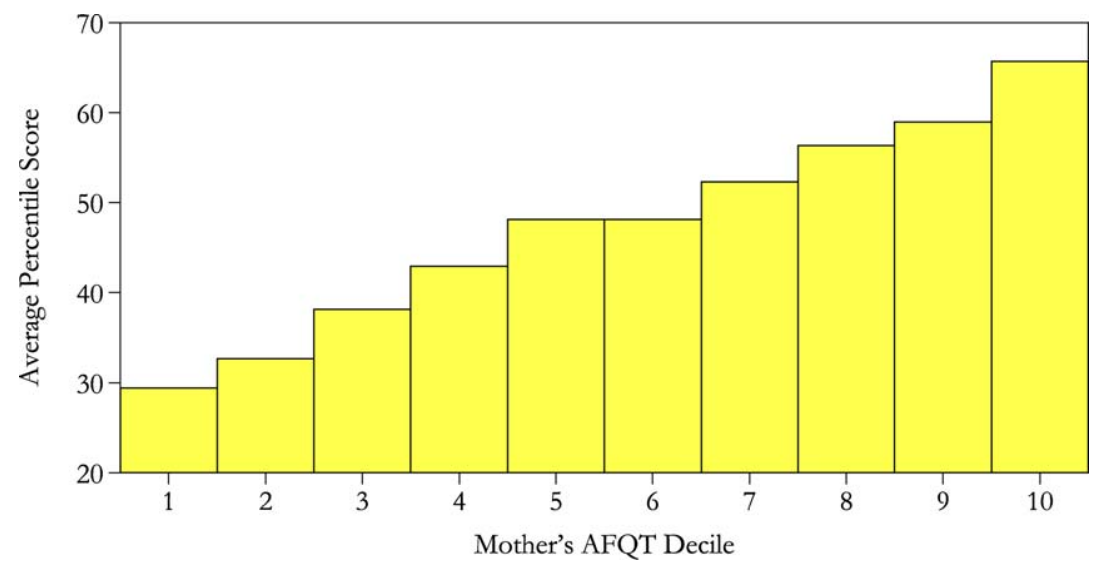

Figure 12C. Average cognitive stimulation score by mother's AFQT decile. Data from CNLSY79.

Note: Overall stimulation is a measure of the quality of the child's home environment. It comprises emotional and cognitive stimulation subscores. It is based on measures of resources, such as books, and on interactions with parents. The score is measured in percentiles.

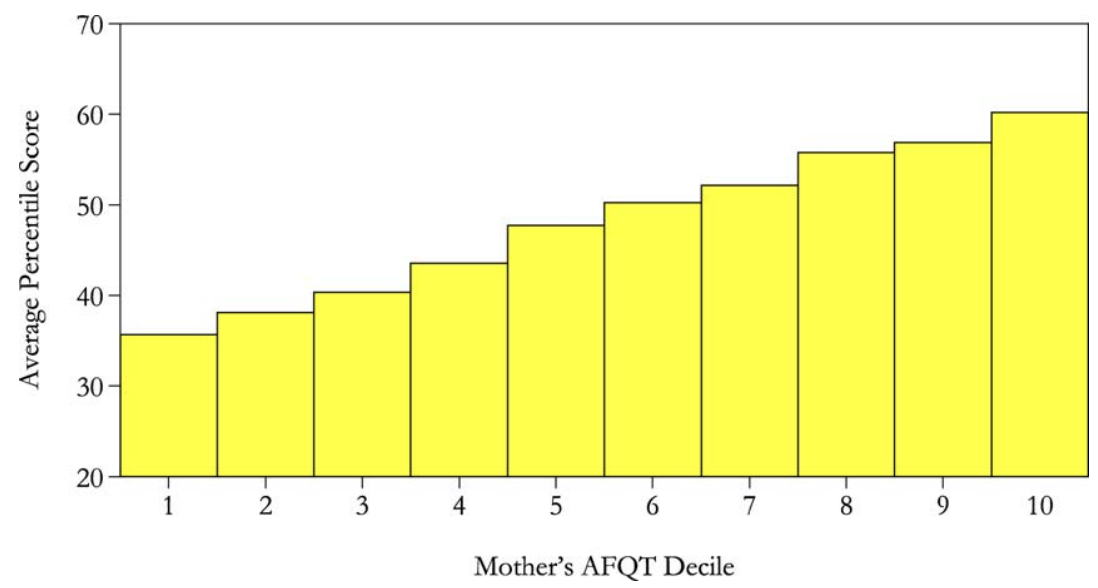

Figure 12D. Average emotional stimulation score by mother's AFQT decile. Data from CNLSY79.

Note: Overall stimulation is a measure of the quality of the child's home environment. It comprises emotional and cognitive stimulation subscores. It is based on measures of resources, such as books, and on interactions with parents. The score is measured in percentiles.

blacks attend worse schools than whites, and therefore blacks are not able to maintain initial test score gains. However, Heckman, Larenas and Urzua (2004) dispute this finding. They show that schooling quality differences which are substantial across ethnic groups have only a slight effect on the levels or rates of growth in 
many of the evaluations of these programs do not follow children into late adolescence or adulthood. Interventions at younger ages seem to produce larger effects. ${ }^{50}$

Three programs have long-term follow-ups, and we focus on them here. They all targeted high-risk children from disadvantaged families. The first is the High/Scope Perry Preschool, a half-day program on a small scale in the Ypsilanti, MI public schools. Children were typically enrolled at age 4 and stayed in the program for two years. It was an experiment with a sample size of 123 and follow-up to age 40. The Abecedarian program, the second one we consider, was a full-day, year-round educational child care program in Chapel Hill, NC. Children entered around the age of 4 months and continued until age 5 . Half of all children were then enrolled in a school-age program until age 8. It was evaluated by randomization and has 111 participants, and students are followed to age 21 .

The final program we consider is the Chicago Child-Parent Centers (CPC), a halfday program during the school year and full-time for six weeks during the summer, conducted on a large scale in the Chicago public schools. It was evaluated by a nonexperimental method (matching) and has a sample of about 1,500 children. All three programs had some sort of parental involvement component.

The programs differ by duration and child age at entry. Abecedarian started with young children in the first months of life. Perry and the CPC program start with older children, 3-5 years old. The programs differ in intensity. For some programs the comparison group received some supplementary resources relative to ordinary children, and for others they did not. Moreover, some comparison group members attended alternative preschool and kindergarten programs.

2.6.1.1. Perry preschool experiment. The Perry preschool experiment was an intensive preschool program that was administered to 65 randomly selected black children who were enrolled in the program over 5 different waves between 1962 and 1967. All the children came from Ypsilanti, MI. A control group of roughly the same size provides researchers with an appropriate benchmark to evaluate the effects of the preschool program.

The experimental group assignment was performed in the following way. Candidate families were identified from a census of the families of the students attending the Perry school at the date of operation of the program, neighborhood group referrals and door to door canvassing. Poor children who scored between 75 and 85 on the standard StanfordBinet IQ test were randomly divided into two undesignated groups. ${ }^{51}$ The children were

test scores. Garces, Thomas and Currie (2002) find comparable results. The Mathematica evaluation of Early Head Start by Love et al. (2002) shows very modest effects as well. However, Head Start is a considerably less intensive program than many of the other programs considered in this section, which may explain why it has limited consequences for the developmental trajectories of disadvantaged children.

50 Morris, Duncan and Clark-Kauffman (2005) find that the biggest impact of a parental wage-subsidy intervention on children's achievement is for preschool children.

51 Poverty status was determined by a formula that considered rooms per person in the child's household, parental schooling and occupational level. The IQ range was labeled as "borderline educable mentally re- 
then transferred across groups to equalize the socioeconomic status, cognitive ability (as measured by the IQ test) and gender composition of the samples. Finally, a coin was tossed to determine which group received the treatment and which did not. Initially the treatment and control groups included 64 children each, but the actual treatment and control groups contained 58 and 65 children, respectively. ${ }^{52}$

Children entered the Perry School in five waves, starting with wave zero (of fouryear-olds) and wave one (of three-year-olds) in 1962, then waves two, three and four (of three-year-olds) entered in each subsequent year through 1965. The average age at entry was 42.3 months. With the exception of wave zero, treatment children spent two years attending the program. In the final year of the program, 11 three-year-olds who were not included in the data attended the program with the 124 -year-olds who were. About half of the children were living with two parents. The average mother was 29 years old and completed 9.4 years of school.

The treatment consisted of a daily $2 \frac{1}{2}$ hour classroom session on weekday mornings and a weekly ninety minute home visit by the teacher on weekday afternoons to involve the mother in the child's educational process. The length of each preschool year was 30 weeks, beginning in mid-October and ending in May. Ten female teachers filled the four teaching positions over the course of the study, resulting in an average childteacher ratio of 5.7 for the duration of the program. ${ }^{53}$ All teachers were certified to teach in elementary, early childhood or special education. ${ }^{54}$ If it were administered today, the Perry preschool program would cost approximately $\$ 9,785$ per participant per year in 2004 dollars.

tarded" by the state of Michigan at the time of the experiment. Only children without an organic mental handicap were included in the study.

52 Some aspect of the assignment was clearly nonrandom and this has led some to call the Perry results into question. First, younger children were assigned to the same group as their older siblings. Two treatment children were transferred to the control group because their mothers were not able to participate in any classes or home visits because they were employed far from home. Four treatment children left the program before completing the second year of preschool when their families relocated, and one control child died. Thus, the final sample consisted of 123 children. The 123 children in the sample came from 100 families. In the control group, 41 families contributed 1 child each, and 12 families contributed 2 children each. In the treatment group, 39 families contributed 1 child apiece, 6 families contributed 2 children apiece, 1 family contributed 3 and another 4 children. Assigning younger siblings to the same group effectively made the family, rather than the individual, the unit of analysis. Still, it is difficult to argue that assigning siblings at random would have been a better strategy. So-called spillovers to the control siblings from home visits would have been one possible source of bias since mothers cannot be expected to treat siblings in accordance with their experimental status. Another potential source of bias is spillover from one sibling to another. In any case, differences in background characteristics between the two experimental groups are virtually nonexistent, with the exception of much higher rates of maternal employment at program entry in the treatment group.

53 This number is low relative to other early education experiments. For instance, the student-teacher ratio for the Chicago Child-Parent Center and Expansion Program ranged from 8 to 12 [see Fuerst and Fuerst (1993)].

54 Schweinhart, Barnes and Weikart (1993) argue that the certification of the teachers is an important component in the success of the Perry preschool. 
2.6.1.2. Abecedarian project. The Abecedarian Project recruited 111 children born between 1972 and 1977 whose 109 families scored high on the High Risk Index. ${ }^{55}$ It enrolled families and intervened in the lives of children beginning a few months after birth. Enrollment was based on the characteristics of the families more than on the characteristics of the children, as in the Perry program. Virtually all of the children were Black, and their parents had low levels of education, income, cognitive ability and high levels of pathological behavior. The children were screened for mental retardation. $76 \%$ of the children lived in a single parent or multigenerational household. The average mother in this group was less than 20 years old, completed 10 years of schooling and had an IQ of 85 . There were 4 cohorts of about 28 students each. By the time they were 6 weeks old, the children were assigned randomly to either a preschool intervention or a control group. The mean age of entry was 4.4 months. At age 5, just as they were about to enter kindergarten, all of the children were reassigned to either a school age intervention through age 8 or to a control group. This yielded 4 groups: children who experienced no intervention at all, those who experienced an intervention when they were young, those who experienced it when they were older, and finally those who enjoyed a high-quality intervention throughout their whole childhood. The children were followed up until age 21 .

The Abecedarian intervention was more intensive than the Perry one. The preschool program was a year-round, full-day intervention. The initial infant-to-teacher ratio was $3: 1$, though it grew to a child-to-teacher ratio of $6: 1$ as the kids progressed through the program. Infants in the control group received an iron-fortified formula for 15 months and diapers as needed to create an incentive for participation. Many of the control children were enrolled in preschool and/or kindergarten.

During the first 3 primary school years, a home-school teacher would meet with the parents and help them in providing supplemental educational activities at home. The teacher provided an individually-tailored curriculum for each child. This home-school teacher also served as a liaison between the ordinary teachers and the family, and she would interact with the parents and the teachers about every two weeks. She would also help the family deal with other issues that might improve their ability to care for the child, such as finding employment, navigating the bureaucracy of social services agencies, and transporting children to appointments. Data were collected regularly up to age 21 .

2.6.1.3. Chicago Child-Parent Center program. The Chicago Child-Parent Center was not evaluated by the method of random assignment but by the method of matching treated children to comparable nontreated children on the basis of age, eligibility

\footnotetext{
55 The factors used to form the index consist of weighted measures of maternal and paternal education levels, family income, absence of the father from the home, poor social or family support for the mother, indication that older siblings have academic problems, the use of welfare, unskilled employment, low parental IQ, and family members who sought counseling or support from various community agencies. Parental income and education were considered most important in calculating the index.
} 
for intervention, and family socioeconomic status. It was started in 1967 in 11 public schools serving impoverished neighborhoods of Chicago. Using federal funds, the center provided half-day preschool program for 3- and 4-year-olds during the 9 months that they were in school. The program provided an array of services, including health and social services, and free meals. Parental participation was encouraged. Parents were helped to complete school and participated in home visits and field trips. In 1978, state funding became available, and the program was extended through third grade and included a full-day kindergarten experience. Eventually, 24 centers provided preschool and after-school activities, up to second or third grade. This is the period during which the sample analyzed by Reynolds, Ou and Topitzes (2004) was enrolled in the program. The preschool program ran 3 hours per day during the week for the 9 months that school was in session, and usually included a 6-week summer program. During the kindergarten years, more services were provided at the affiliated school. Teacher-child ratios were 17:2 for the preschool component and 25:2 for the kindergarten. Participation during the primary years was open to any child in the school. Program participants experienced reduced class sizes of 25 pupils rather than the standard of 35 or more in the Chicago public schools. Teachers' aides, extra instructional materials, and enrichment activities were also available. Some children continued to participate in CPC through age 9 , for a maximum total of 6 years. $93 \%$ of the children were black and $7 \%$ were Hispanic.

2.6.1.4. The effects of early interventions. These and other studies of interventions for children from low-income families find that participants experienced increased achievement test scores, decreased grade retention, decreased time in special education, decreased crime and delinquency and increased high school graduation. The gains vary with quality and age at which the program is started, and there are important differences by the sex of the child.

Programs differ in the measures they use to evaluate the outcomes and in their intensity and quality. As a result, it is hard to compare the programs using a standard basket of benefits. The CPC program, which is less intensive, produced substantial effects on high school graduation rates, reductions in special (remedial) education, grade repetition and juvenile arrest (see Figure 13).

The Perry Preschool Program is the flagship experimental intervention study. Children are followed through age 40 . The initial boost in IQ faded by the time the children were in second grade (see Figure 14A), but the program had substantial effects on educational achievement. Achievement test scores for the treatment group were consistently and statistically significantly higher through age 14. Participants had higher grades and were more likely to graduate from high school. Substantially less time was spent in special education, and higher high school graduation rates were achieved by participants (Figure 14B). Participants were more likely to be employed ${ }^{56}$ and to earn more (Figure 14C) and they were less dependent on welfare. There was substantially less crime

56 The difference in employment rates was only statistically significant at age 19 . 


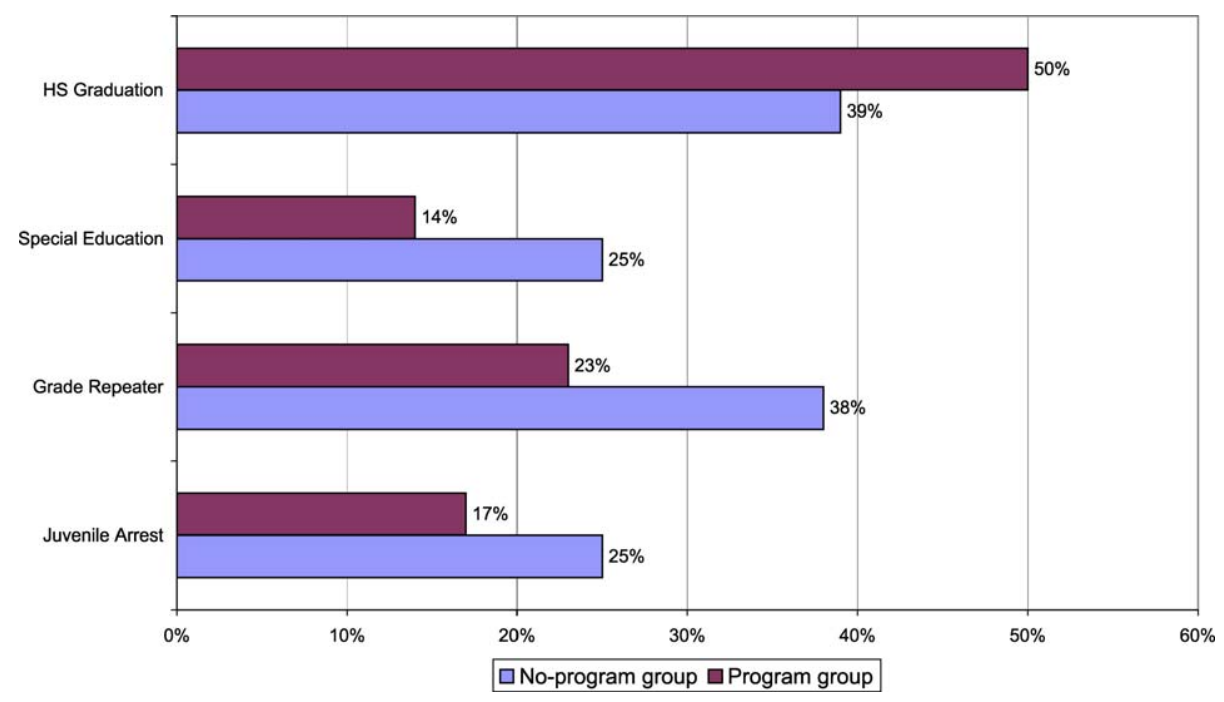

Figure 13. Academic and social benefits at school exit for CPC participants. Source: Barnett (2004).

among participants (Figure 14D) - both in terms of incidence and severity, a recurrent finding of early intervention programs. However, there was no statistically significant difference in grade retention by age 27 between the two groups, although teenage pregnancy was lower, and marriage rates were higher by age 27 for program participants. Results at age 27 are generally more favorable for girls. This reverses when outcomes at age 40 are studied [see Heckman (2005), and Heckman, Savelyev and Yavitz (2006)].

The Abecedarian program boosted IQ, but its effect is concentrated primarily among girls. Figure 15A shows the overall IQ gap between treatments and controls. It is persistent over time. ${ }^{57}$ The Abecedarian program intervenes in the very early years, and it is known that IQ is malleable when children are very young (see, e.g., the discussion in Armor, 2003). This message is reinforced by the fact that the IQ boost was not found among children who only experienced the later intervention. Comparable effects are found for reading scores (Figure 15B) and math achievement scores (Figure 15C). The test score effects persist through age 21 , which is the last age analyzed in the reports available to us.

There were substantial academic benefits as recorded in Figure 15D. Treatment group members participated less in remedial special education at age 15 and repeated fewer grades at all ages. High school graduation and four-year college participation rates were high. Participants were less likely to smoke and had better jobs (see Figure 15E).

57 The decline in IQ over time for both groups may be a consequence of the "Flynn Effect" (see Flynn (1987)). Scores are normed against national averages, but over cohorts IQ is increasing. 


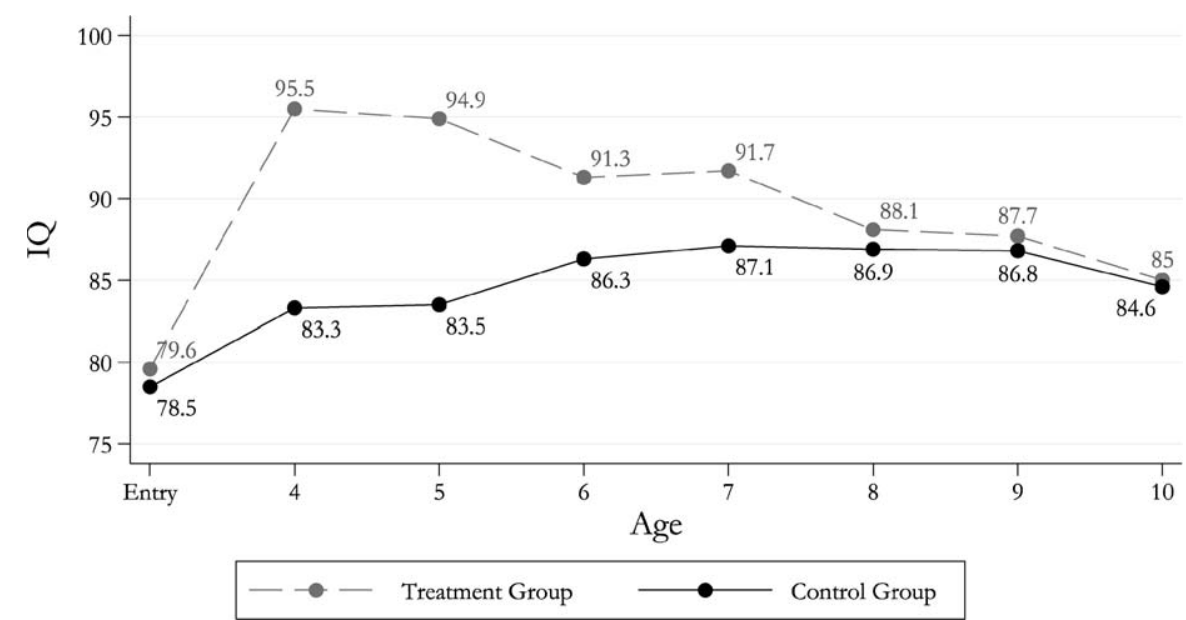

Figure 14A. Perry Preschool Program: IQ, by age and treatment group. Source: Perry Preschool Program. IQ measured on the Stanford-Binet Intelligence Scale (Terman and Merrill, 1960). Test was administered at program entry and each of the ages indicated.

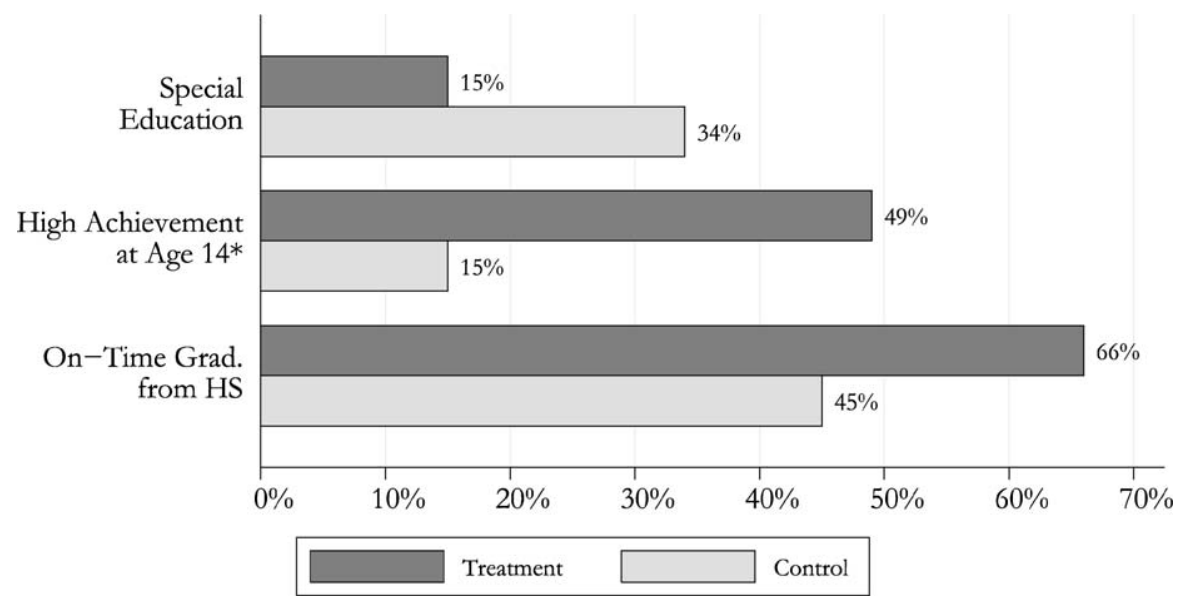

Figure 14B. Perry Preschool Program: Educational effects, by treatment group. Source: Barnett (2004). *High achievement defined as performance at or above the lowest 10th percentile on the California Achievement Test [Tiegs and Clark (1970)].

Table 4 presents estimated costs and benefits of the Perry and Chicago programs with benefits discounted at a $3 \%$ rate. All figures are in 2004 dollars. The benefits vary among programs. ${ }^{58}$ Perry produced some gain to parents in terms of reduced child care costs,

58 There is a cost benefit study of the Abecedarian program [Barnett and Masse (2002)], but it is highly speculative, so that we did not include it here. 


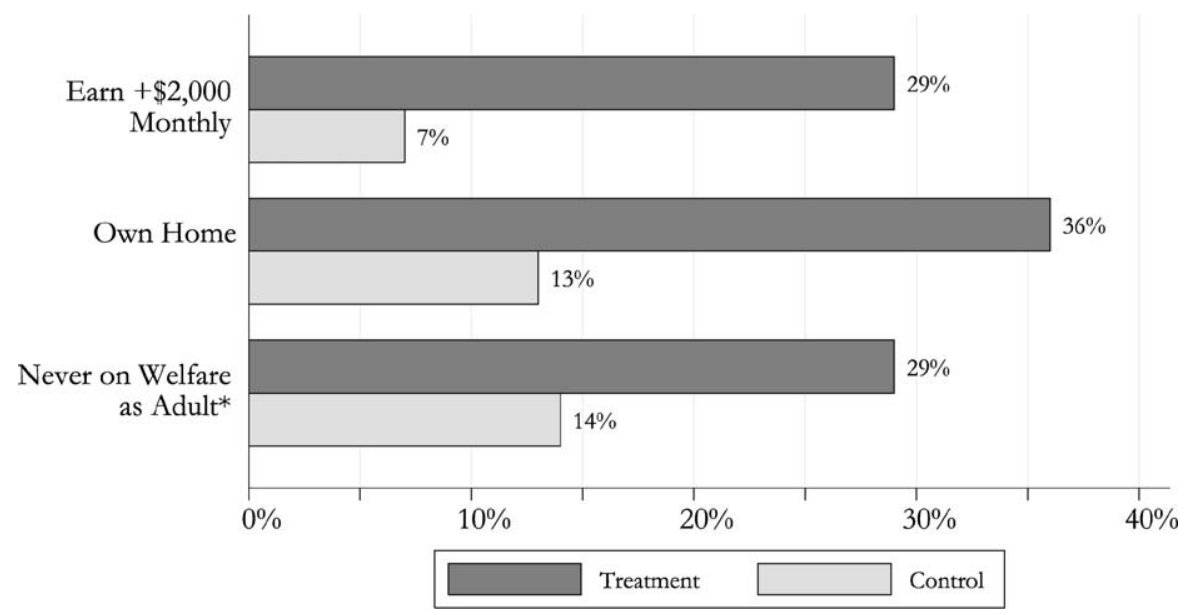

Figure 14C. Perry Preschool Program: Economic effects at age 27, by treatment group. Source: Barnett (2004).

*Updated through age 40 using recent Perry Preschool Program data, derived from self-report and all available state records.

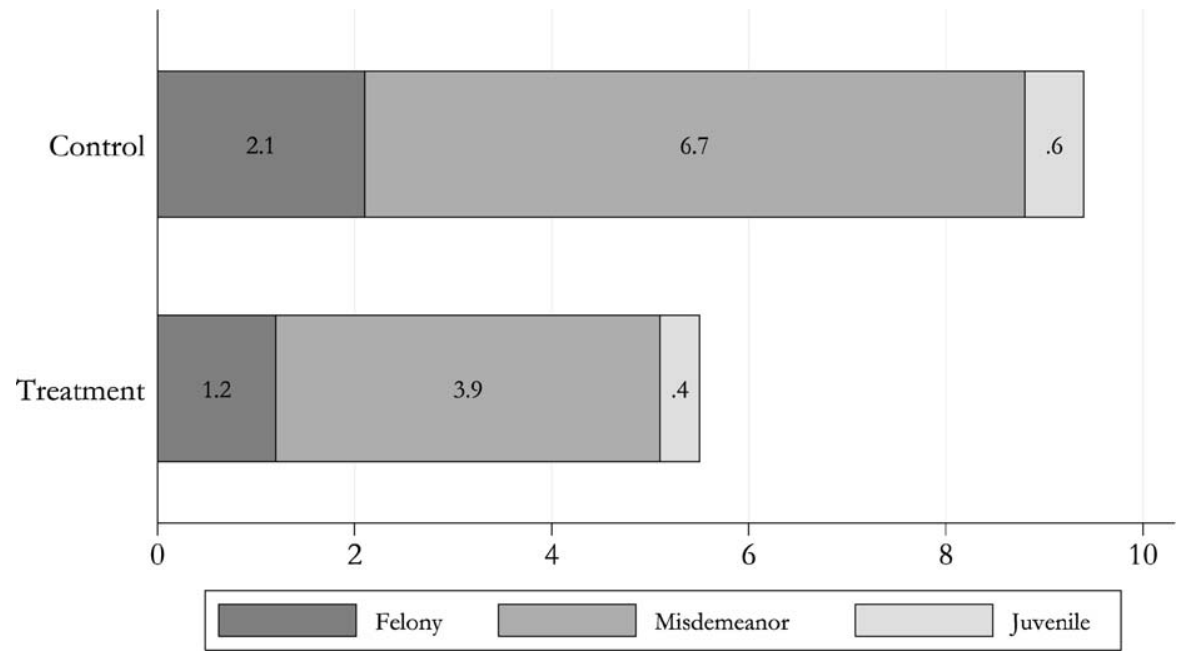

Figure 14D. Perry Preschool Program: Arrests per person before age 40, by treatment group. Source: Barnett (2004). Juvenile arrests are defined as arrests prior to age 19.

and earnings gains for participants were substantial. The K-12 benefit arises from the increment in student quality and a reduction in special education costs. This benefit is substantial across all programs. The college/adult category represents the extra tuition paid by students who go to college. Crime represents the reduction in direct costs (incar- 


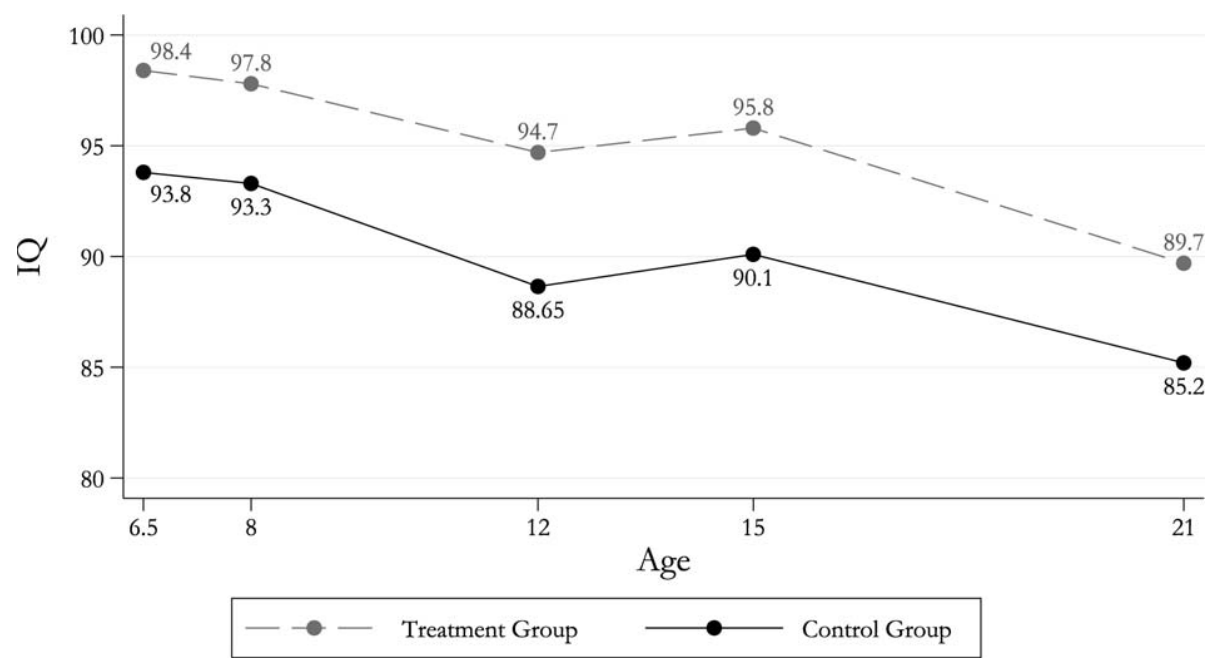

Figure 15A. Abecedarian Program: IQ, by age and treatment group. Source: Barnett (2004).

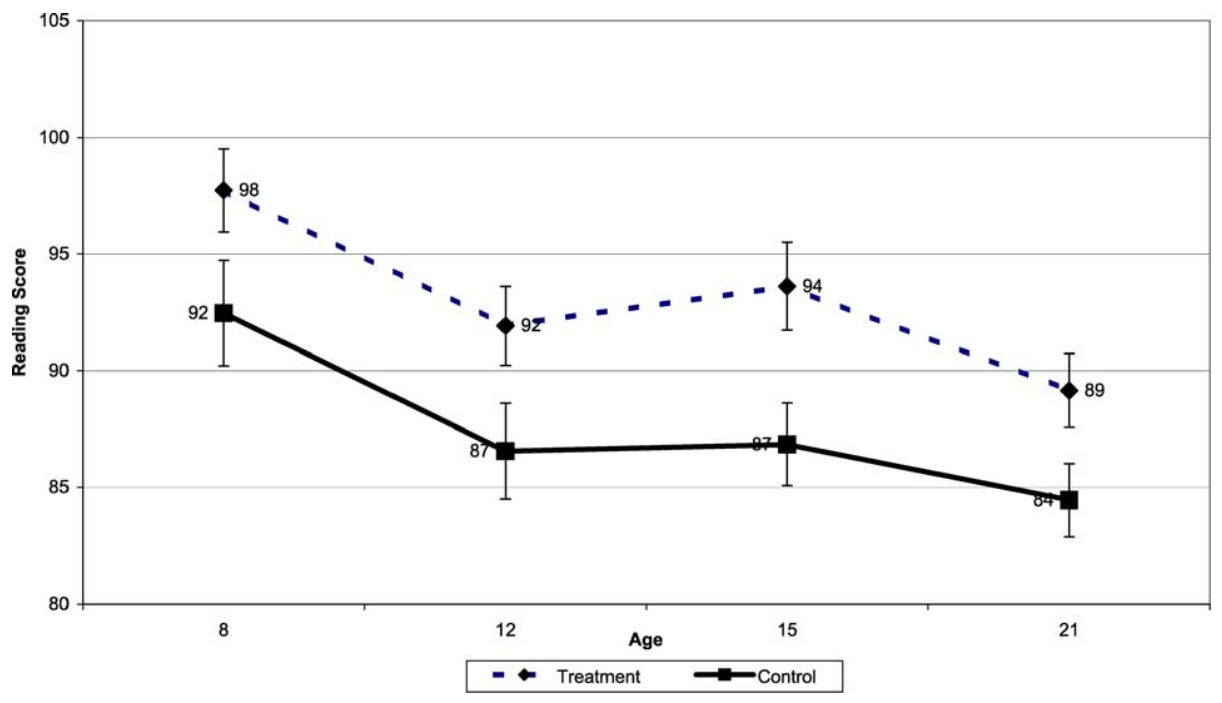

Figure 15B. Abecedarian reading achievement over time. Source: Barnett (2004).

ceration and criminal justice system) as well as damage done to victims. This excludes transfers. Welfare effects are modest. Future Generation (FG) Earnings represents the improvement in the earnings of the descendents of the program participants. 


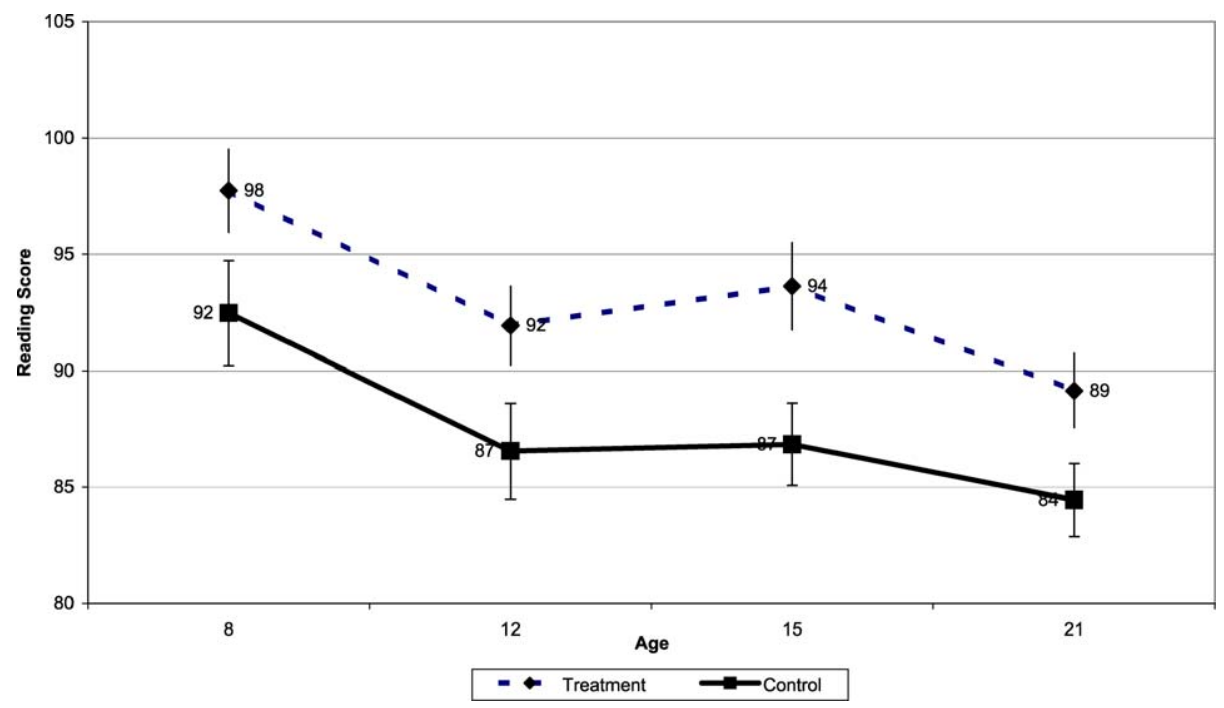

Figure 15C. Abecedarian math achievement over time. Source: Barnett (2004).

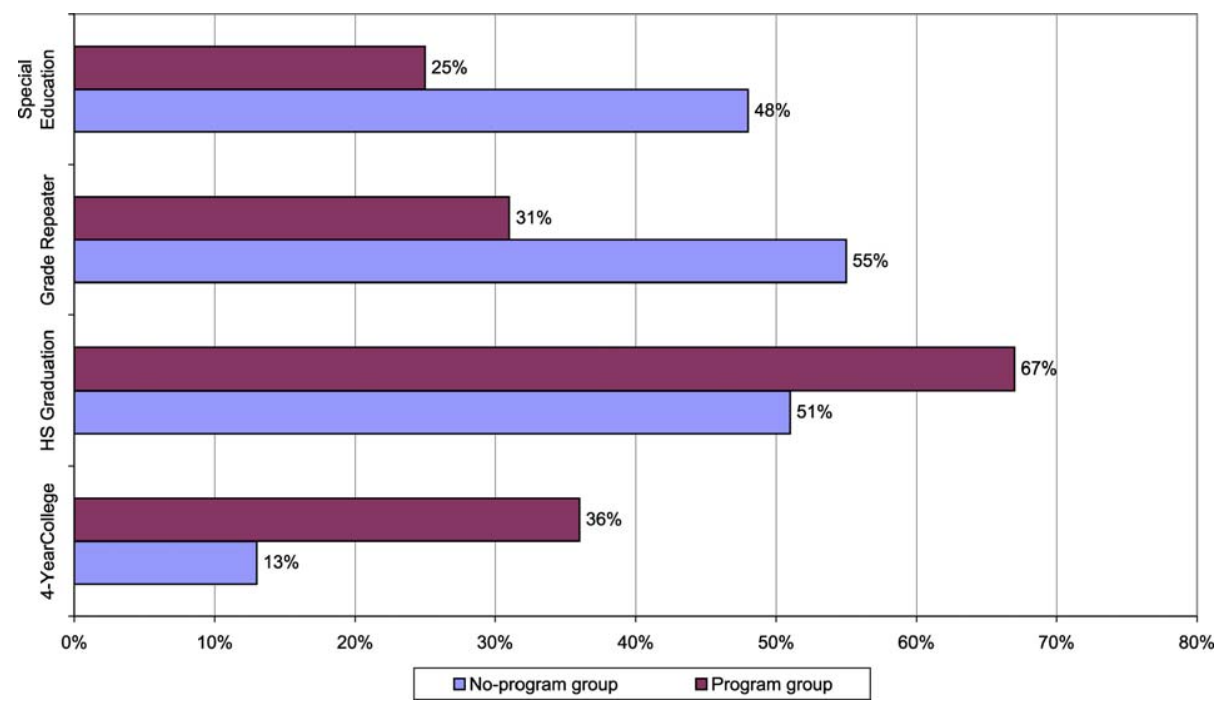

Figure 15D. Abecedarian academic outcomes. Source: Barnett (2004).

Smoking and health benefits were not measured in the Perry and Chicago data. For Abecedarian, there were substantial effects, including major differences in smoking rates. CPC documents a decline in child abuse and the costs of treating abused children. 


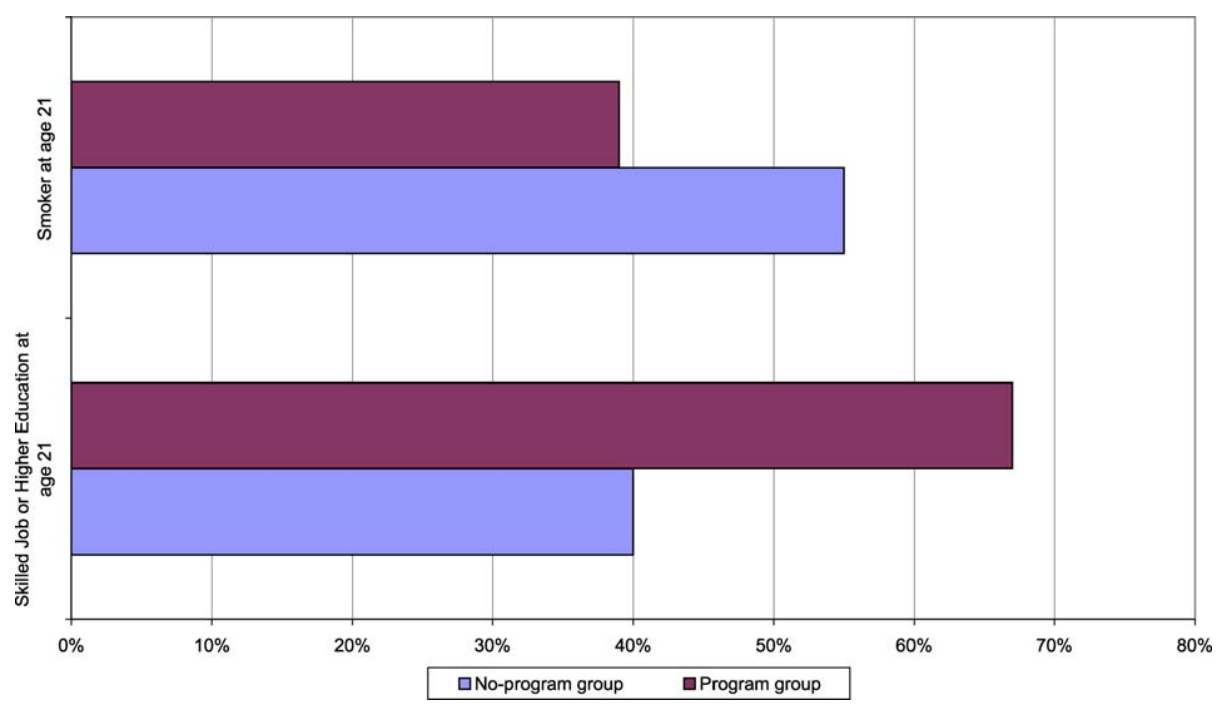

Figure 15E. Other benefits of Abecedarian. Source: Barnett (2004).

Table 4

Economic benefits and costs per treated child

\begin{tabular}{lll}
\hline & Perry & Chicago CPC \\
\hline Child care & 986 & 1,916 \\
Earnings & 40,537 & 32,099 \\
K-12 & 9,184 & 5,634 \\
College/adult & -782 & -644 \\
Crime & 94,065 & 15,329 \\
Welfare & 355 & 546 \\
FG earnings & 6,181 & 4,894 \\
Abuse/neglect & 0 & 344 \\
Total benefits & 150,525 & 60,117 \\
Total costs & 16,514 & 7,738 \\
Net present value & 134,011 & 52,380 \\
Benefits-to-costs ratio & 9.11 & 7.77 \\
\hline
\end{tabular}

All values discounted at 3\% and are in \$2004. Numbers differ slightly from earlier estimates because FG Earnings for Perry and Chicago were estimated using the ratio of Future Generations Earnings Effect (FG) to Earnings Effect (about 15\%) that was found in Abecedarian. Source: Barnett (2004).

The costs of Perry were substantial but per year were about the average cost of expenditure on public school students. CPC per year costs about $\$ 6,796$ for the preschool and $\$ 3,428$ for the school-age component (in 2004 dollars). The benefit cost ratios are 
substantial: 9 to 1 for Perry; 8 to 1 for Chicago CPC. By projecting from the age 27 results, Rolnick and Grunewald (2003) estimate that the annual rate of return for Perry is $4 \%$ for participants and $12 \%$ for society at large. Belfield, Nores, Barnett (2004) use the data on Perry participants through age 40 to estimate that the rate of return for the participants and the general public as a whole is $18.4 \%$. The rate varies by sex of the participants: the rate of return for males alone is $21.9 \%$, while the rate for females is only $12.6 \% .^{59}$

Some of the home visitation programs for low-income young mothers have been shown to have modest effects on maternal and offspring behavior and health. ${ }^{60}$ Olds (2002) summarizes the results from two randomized trials in Elmira, NY and Memphis, TN, which served predominantly rural white and urban black populations, respectively. The treatment in both trials involved a series of pre- and postnatal home visits of poor, unmarried, and young women by specially-trained nurses. ${ }^{61}$ The visits typically lasted 75-90 minutes, and nurses spent more time with women they deemed to have higher needs. The target areas for this intervention were health related behavior during and after pregnancy, childcare skills, and personal development (family planning, education, job search assistance).

The Elmira treatment group made better use of community services and exhibited reduced prenatal-period smoking, with $75 \%$ fewer premature deliveries among smokers. At ages 3-4, children whose mothers smoked 10 or more cigarettes during pregnancy had a mean IQ of 4.5 points lower than women who smoked 0-9 cigarettes. Among the 14- to 16-year-old treatment women, the newborn children were almost 400 grams heavier relative to the children of the control women. The beneficial effects of the program were especially apparent for the most disadvantaged women (i.e., young, poor, and unmarried). ${ }^{62}$ After the birth of the child, the disadvantaged mothers who were visited showed better parenting skills and higher quality of the home environment. They also had $80 \%$ fewer verified cases of child abuse and neglect. Children of visited mothers had $32 \%$ fewer visits to the emergency room, and this effect persisted after the end of the program, though the differences in abuse and neglect faded. ${ }^{63}$ The disadvantaged

59 Excluding the benefits of the program for the participants, the rate for the general public alone is $16.9 \%$. Belfield, Nores, Barnett (2004) do not calculate a rate of return for participants only because they do not bear any significant costs of the program. The rate for the general public on investing in males and females separately is $21.0 \%$ and $7.6 \%$, respectively. The greater return for men comes from the effect of the intervention on crime, a predominantly male activity.

60 Gomby et al. (1999) and Brooks-Gunn, Berlin and Fuligni (2000) show much more modest effects of home visitation programs, though these implementations are considerably less intensive.

61 Only women who were pregnant with their first child were eligible. The mean frequency of nurse visits in the prenatal and postnatal (age 0-2) stages were 9 and 23 for Elmira, and 7 and 27 for Memphis. The treatment group was divided into two subgroups, where the first received only prenatal visits. The control group was also divided. See Olds (2002) for more details on the intervention.

62 This result is found in many studies. Brooks-Gunn et al. (1992), Magnuson et al. (2004), Magnuson, Ruhm and Waldfogel (2004), and Gormley et al. (2004) find higher effects for the disadvantaged population.

63 This may have been due to improved reporting of abuse by the nurses. 
subsample of the treatment group had fewer subsequent pregnancies, longer periods between births, and greater employment rates. These effects were also evident by the time the child was 15 . The children of the disadvantaged women reported fewer instances of running away, less criminal activity, promiscuous sexual behavior and smoking. Both parents and children reported less use of drugs and alcohol. Importantly, there were no differences in other behavioral problems. A cost-benefit analysis of the Elmira trial by Karoly et al. (1998) suggests that the program was very successful for low-income, unmarried women. Extrapolating from the results at age 15, the benefits of the program were 4 times its costs. The program paid for itself before the child's fourth birthday, with the primary savings coming from reduced welfare and criminal justice expenditures, as well as increases in tax revenue. However, the program provided no net savings for the sample as a whole, suggesting that targeting, rather than universal provision, is appropriate.

The effects for the Memphis trial were considerably weaker, even for the disadvantaged subsample. There were no effects on birth outcomes and parenting skills. Many fewer women smoked in this sample, so any reductions were very small. The same may be the case for child abuse and neglect. Children of visited women had fewer health-care visits, especially among the disadvantaged subsample. In the first 2 years of life, more visited mothers attempted breast feeding. At age 4, there were no differences in mental development or reported behavior problems. Visited mothers reported fewer subsequent pregnancies. There were no differences in employment and some evidence of reduced AFDC and Food Stamp use. The children are still too young to perform a reliable costbenefit analysis on their outcomes.

Much more research is needed on Perry, CPC, and a wide variety of other early childhood programs (shown in Tables 5 and 6). These samples and measurements need to be placed in a common analytical framework to better understand the differences in samples, treatments, and effects. For example, are the persistent Abecedarian effects on IQ due to the intensity or the age (4 months) at which the intervention is administered? How important are home visitation efforts? Joint analysis of the multiplicity of generally favorable treatment outcomes using methods appropriate for the small samples that are available, needs to be applied to supplement analyses of one-at-a-time outcome measure studies. A much more careful analysis of the effects of scaling up the model programs to the target population, and its effects on costs, has to be undertaken before these estimates can be considered definitive.

2.6.1.5. Extreme deprivation and remediation. Institutional rearing of children, insofar as it tends to be exceptionally poor, provides scientists with a unique natural experiment that can be used to ascertain the effects of severe environmental deprivation. Evidence on children from such environments allows us to answer questions about the developmental consequences of negative early experience and how amenable exposed children are to interventions such as foster care. It may also enable us to learn if there are critical or sensitive periods for development, which would have important implications for the relationship between the timing of an intervention and the extent 
Table 5

Effects of early intervention programs

\begin{tabular}{|c|c|c|c|c|c|}
\hline Program/study & Costs* & $\begin{array}{l}\text { Program } \\
\text { description }\end{array}$ & Test scores & Schooling & $\begin{array}{l}\text { Pre-delinquency } \\
\text { crime }\end{array}$ \\
\hline $\begin{array}{l}\text { Abecedarian } \\
\text { project** }^{* *} \\
{[\text { Ramey et al. (1988) }}\end{array}$ & N/A & $\begin{array}{l}\text { Full-time year } \\
\text { round classes for } \\
\text { children from } \\
\text { infancy through } \\
\text { preschool }\end{array}$ & $\begin{array}{l}\text { High scores } \\
\text { at ages } 1-4\end{array}$ & $\begin{array}{l}34 \% \text { less grade } \\
\text { retention by } 2 \text { nd } \\
\text { grade; better } \\
\text { reading and math } \\
\text { proficiency }\end{array}$ & \\
\hline $\begin{array}{l}\text { Early training** } \\
\text { [Gray et al. (1982)] }\end{array}$ & N/A & $\begin{array}{l}\text { Part-time classes } \\
\text { for children in } \\
\text { summer; weekly } \\
\text { home visits } \\
\text { during school } \\
\text { year }\end{array}$ & $\begin{array}{l}\text { Higher scores } \\
\text { at ages } 5-10\end{array}$ & $\begin{array}{l}16 \% \text { less grade } \\
\text { retention; } 21 \% \\
\text { higher HS grad. } \\
\text { rates }\end{array}$ & \\
\hline $\begin{array}{l}\text { Harlem study } \\
\text { [Palmer (1983)] }\end{array}$ & N/A & $\begin{array}{l}\text { Individual } \\
\text { teacher-child } \\
\text { sessions } \\
\text { twice-weekly for } \\
\text { young males }\end{array}$ & $\begin{array}{l}\text { Higher scores } \\
\text { at ages } 3-5\end{array}$ & $\begin{array}{l}21 \% \text { less grade } \\
\text { retention }\end{array}$ & \\
\hline $\begin{array}{l}\text { Houston PCDC** } \\
\text { [Johnson (1988)] }\end{array}$ & N/A & $\begin{array}{l}\text { Home visits for } \\
\text { parents for } 2 \text { yrs; } \\
\text { child nursery care } \\
4 \text { days/wk in year } \\
2 \text { (Mexican } \\
\text { Americans) }\end{array}$ & $\begin{array}{l}\text { Higher scores } \\
\text { at age } 3\end{array}$ & & $\begin{array}{l}\text { Rated less } \\
\text { aggressive and } \\
\text { hostile by } \\
\text { mothers } \\
\text { (ages } 8-11 \text { ) }\end{array}$ \\
\hline $\begin{array}{l}\text { Milwaukee } \\
\text { project** }^{* *} \\
\text { [Garber (1988)] }\end{array}$ & N/A & $\begin{array}{l}\text { Full-time } \\
\text { year-round } \\
\text { classes for } \\
\text { children through } \\
\text { 1st grade; job } \\
\text { training for } \\
\text { mothers }\end{array}$ & $\begin{array}{l}\text { Higher scores } \\
\text { at ages } 2-10\end{array}$ & $\begin{array}{l}27 \% \text { less grade } \\
\text { retention }\end{array}$ & \\
\hline $\begin{array}{l}\text { Mother-child } \\
\text { home program } \\
\text { [Levenstein, } \\
\text { O'Hara and } \\
\text { Madden (1983)] }\end{array}$ & N/A & $\begin{array}{l}\text { Home visits with } \\
\text { mothers and } \\
\text { children twice } \\
\text { weekly }\end{array}$ & $\begin{array}{l}\text { Higher scores } \\
\text { at ages } 3-4\end{array}$ & $\begin{array}{l}6 \% \text { less grade } \\
\text { retention }\end{array}$ & \\
\hline $\begin{array}{l}\text { Perry preschool } \\
\text { program** } \\
\text { [Schweinhart, } \\
\text { Barnes and } \\
\text { Weikart (1993)] }\end{array}$ & $\$ 13,400$ & $\begin{array}{l}\text { Weekly home } \\
\text { visits with } \\
\text { parents; intensive, } \\
\text { high quality } \\
\text { preschool } \\
\text { services for 1-2 } \\
\text { years }\end{array}$ & $\begin{array}{l}\text { Higher scores in } \\
\text { all studied years } \\
\text { (ages 5-27) }\end{array}$ & $\begin{array}{l}21 \% \text { less grade } \\
\text { retention or } \\
\text { special services; } \\
21 \% \text { higher HS } \\
\text { grad. rates }\end{array}$ & $\begin{array}{l}2.3 \text { vs. } \\
4.6 \text { lifetime } \\
\text { arrests by age } 27 \\
7 \% \text { vs. } 35 \% \\
\text { arrested } 5 \text { or } \\
\text { more times }\end{array}$ \\
\hline
\end{tabular}


Table 5

(Continued)

\begin{tabular}{|c|c|c|c|c|c|}
\hline Program/study & Costs* & $\begin{array}{l}\text { Program } \\
\text { description }\end{array}$ & Test scores & Schooling & $\begin{array}{l}\text { Pre-delinquency } \\
\text { crime }\end{array}$ \\
\hline $\begin{array}{l}\text { Rome head start } \\
\text { [Monroe and } \\
\text { McDonald } \\
(1981)]\end{array}$ & $\$ 5,400$ & $\begin{array}{l}\text { Part-time classes } \\
\text { for children; } \\
\text { parent } \\
\text { involvement }\end{array}$ & & $\begin{array}{l}12 \% \text { less grade } \\
\text { retention; } 17 \% \\
\text { higher HS grad. } \\
\text { rates }\end{array}$ & \\
\hline $\begin{array}{l}\text { Syracuse } \\
\text { university family } \\
\text { development } \\
\text { [Lally et al. } \\
\text { (1988)] }\end{array}$ & $\$ 38,100$ & $\begin{array}{l}\text { Wekly home } \\
\text { visits for family; } \\
\text { day care year } \\
\text { round }\end{array}$ & $\begin{array}{l}\text { Higher scores } \\
\text { at ages } 3-4\end{array}$ & & $\begin{array}{l}6 \% \text { vs. } 22 \% \text { had } \\
\text { probation files; } \\
\text { offenses were } \\
\text { less severe }\end{array}$ \\
\hline Yale experiment & $\$ 23,300$ & $\begin{array}{l}\text { Family support; } \\
\text { home visits and } \\
\text { day care as } \\
\text { needed for } 30 \\
\text { months }\end{array}$ & $\begin{array}{l}\text { Better language } \\
\text { development } \\
\text { at } 30 \text { months }\end{array}$ & $\begin{array}{l}\text { better-school } \\
\text { attendance and } \\
\text { adjustment; } \\
\text { fewer special } \\
\text { adjustment; } \\
\text { school services } \\
\text { (age } 12 \frac{1}{2} \text { ) }\end{array}$ & $\begin{array}{l}\text { Rated less } \\
\text { aggressive and } \\
\text { pre-delinquent } \\
\text { by teachers and } \\
\text { parents } \\
\left.\text { (age } 12 \frac{1}{2}\right)\end{array}$ \\
\hline
\end{tabular}

All comparisons are for program participants vs. non-participants. Source: Heckman et al. (1997).

* Costs valued in 1990 dollars.

** Studies used a random assignment experimental design to determine program impacts. Data from Donohue and Siegelman (1998), Schweinhart, Barnes and Weikart (1993), and Seitz (1990) for the impacts reported here.

of its success. Some good evidence on this issue comes from the longitudinal studies of initially institutionalized Romanian infants and toddlers who were later placed into foster care abroad. In this section, we will outline the historical context for these studies, some of their results, and the implications that these data have for our model of human development.

The Ceauşescu regime in Romania, which was in power from 1966 to 1989, attempted to enlarge the country's workforce by increasing the birth rate. ${ }^{64}$ Virtually all types of abortion were criminalized, and divorce was made much more difficult. Contraceptives were neither manufactured domestically nor imported. Progressive income taxes on childless adults over 25 were imposed. Monthly cash subsidies were awarded to families with children, and the average allowance per child rose as family size increased. Various labor laws eased working conditions for pregnant and nursing mothers by eliminating overtime and night work entirely, and by reducing physically demanding work. Over three months of paid maternity leave were available, as were additional breaks or reductions in work hours of up to two hours per day. Early retirement was available for

64 Moskoff (1980) enumerates the regime's pronatalist policies. 
Table 6

Outcomes of early intervention programs

\begin{tabular}{|c|c|c|c|c|c|c|}
\hline & Program (years of operation) & Outcome & $\begin{array}{l}\text { Followed up } \\
\text { to age }\end{array}$ & $\begin{array}{l}\text { Age when treatment } \\
\text { effect last statistically } \\
\text { significant }\end{array}$ & $\begin{array}{l}\text { Control } \\
\text { group }\end{array}$ & $\begin{array}{l}\text { Change } \\
\text { in treated } \\
\text { group }\end{array}$ \\
\hline \multicolumn{7}{|l|}{ Cognitive measures } \\
\hline & Early Training Project (1962-1965) & IQ & $16-20$ & 6 & 82.8 & +12.2 \\
\hline & Perry Preschool Project (1962-1967) & IQ & 27 & 7 & 87.1 & +4.0 \\
\hline & Houston PCDC (1970-1980) & IQ & $8-11$ & 2 & 90.8 & +8.0 \\
\hline & Syracuse FDRP (1969-1970) & IQ & 15 & 3 & 90.6 & +19.7 \\
\hline & Carolina Abecedarian (1972-1985) & IQ & 21 & 12 & 88.4 & +5.3 \\
\hline & Project CARE (1978-1984) & IQ & 4.5 & 3 & 92.6 & +11.6 \\
\hline & IHDP (1985-1988) & $\begin{array}{l}\text { IQ (HLBW } \\
\text { sample) }\end{array}$ & 8 & 8 & 92.1 & +4.4 \\
\hline \multicolumn{7}{|l|}{$\begin{array}{l}\text { Educational } \\
\text { outcomes }\end{array}$} \\
\hline & Early Training Project & Special education & $16-20$ & 18 & $29 \%$ & $-26 \%$ \\
\hline & \multirow[t]{2}{*}{ Perry Preschool Project } & Special education & 27 & 19 & $28 \%$ & $-12 \%$ \\
\hline & & $\begin{array}{l}\text { High school } \\
\text { graduation }\end{array}$ & & 27 & $45 \%$ & $+21 \%$ \\
\hline & \multirow[t]{3}{*}{ Chicago CPC (1967-present) } & Special education & 20 & 18 & $25 \%$ & $-10 \%$ \\
\hline & & Grade retention & & 15 & $38 \%$ & $-15 \%$ \\
\hline & & $\begin{array}{l}\text { High school } \\
\text { graduation }\end{array}$ & & 20 & $39 \%$ & $+11 \%$ \\
\hline & Carolina Abecedarian & $\begin{array}{l}\text { College } \\
\text { enrollment }\end{array}$ & 21 & 21 & $14 \%$ & $+22 \%$ \\
\hline
\end{tabular}


Table 6

(Continued)

\begin{tabular}{|c|c|c|c|c|c|c|}
\hline & Program (years of operation) & Outcome & $\begin{array}{l}\text { Followed up } \\
\text { to age }\end{array}$ & $\begin{array}{l}\text { Age when treatment } \\
\text { effect last statistically } \\
\text { significant }\end{array}$ & $\begin{array}{l}\text { Control } \\
\text { group }\end{array}$ & $\begin{array}{l}\text { Change } \\
\text { in treated } \\
\text { group }\end{array}$ \\
\hline \multicolumn{7}{|l|}{ Economic outcomes } \\
\hline & \multirow[t]{4}{*}{ Perry Preschool Project } & Arrest rate & 27 & 27 & $69 \%$ & $-12 \%$ \\
\hline & & Employment rate & & 27 & $32 \%$ & $+18 \%$ \\
\hline & & Monthly earnings & & 27 & $\$ 766$ & $+\$ 453$ \\
\hline & & Welfare use & & 27 & $32 \%$ & $-17 \%$ \\
\hline & $\begin{array}{l}\text { Chicago CPC (preschool vs. no } \\
\text { preschool) }\end{array}$ & Juvenile arrests & 20 & 18 & $25 \%$ & $-8 \%$ \\
\hline & Syracuse FDRP & Probation referral & 15 & 15 & $22 \%$ & $-16 \%$ \\
\hline & Elmira PEIP (1978-1982) & $\begin{array}{l}\text { Arrests (HR } \\
\text { sample) }\end{array}$ & 15 & 15 & 0.53 & -0.029 \\
\hline
\end{tabular}

HLBW = heavier, low birth weight sample; HR = high risk. Cognitive measures include Stanford-Binet and Weshler Intelligence Scales, California Achievement Tests, and other IQ and achievement tests measuring cognitive ability. All results significant at 0.05 level or higher. Source: Karoly (2001). For a discussion of the specific treatments offered under each program see Heckman (2000) and Karoly (2001). 
women as a function of the number of children they raised to age 10. Increasing economic hardship coupled with Ceauşescu's goal of paying off all international debt by imposing rationing, obliged many women to work outside the home. Since childcare for the young (or any other alternative) was scarce, many children were simply abandoned.

Institutionalization of children was not stigmatized, and was even encouraged officially. When the Ceauşescu regime fell in 1989, there were roughly 170,000 children in 700 overcrowded state institutions [see Rosapepe (2001)]. While no rigorous statistics on the conditions in these homes are available, foreign visitors described the situation as appalling [see Rosapepe (2001), Rutter (1998)]. Children remained in their cots all day, with no toys or other types of stimulation. Caregiving and personalized affection were all but nonexistent. Many young children were fed only gruel from bottles that were propped up, and some continued to have difficulty even chewing solid food some years later. Orphanages were frequently located in remote areas of the country; some children were transferred far away from where they were born and were "lost" in the system. By the late 1980s, many institutions had no hot water, no constant heat during winter, no diapers or even detergent. Medical supplies, including antibiotics and syringe needles, were extremely scarce. Children were often tied down or locked in rooms to keep them under control and some were abused. While the prevalence and incidence of these problems are unknown, most children exhibited a range of emotional, behavioral and medical problems when they were adopted abroad.

Several studies have been conducted to evaluate the effects of interventions at various ages on these children. The largest study of this sort was completed in the UK by Michael Rutter, his colleagues and the English and Romanian Adoptees Study Team. The most recent results are summarized in O'Connor et al. (2000). This group studied 165 children who were adopted from Romania into UK families between 1990 and 1992 and compared them at ages 4 and 6 to 52 adopted children from within the UK who were all placed before age 6 months. ${ }^{65}$ Selected results are shown in Table 7. Rutter (1998) shows that at the time of adoption, the orphans showed substantial developmental retardation, malnutrition, and a range of health problems. Relative to ordinary English children, half of the Romanian orphans were below the third percentile on weight, and over a third were below the third percentile on height. The overall mean score on the Denver developmental quotient was 63 , indicating mild retardation. ${ }^{66}$ Interestingly, there were no significant differences in weight or Denver scale by age of adoption. By age 4 , only $2 \%$ of the orphans were below the third percentile on weight, and only $1 \%$ was below that threshold on height. The extent of catch-up to British adoptees on the

65 Only $87 \%$ of the Romanian children were adopted from institutions. The others came from a family setting, but there were no differences in origin by age at the time of adoption. It is true, however, that the noninstitutionalized children exhibited fewer problems.

66 The Denver Developmental Scales were used to conduct this assessment. Parents were asked to recall specific behavior (e.g., standing while holding on to something, lifting the head, making meaningful "da-da" sounds) at the time of adoption. The majority of parents used baby books that recorded these developmental milestones, which made recollection much better. See Rutter (1998) for more details on the analysis. 
Table 7

Anthropomorphic, developmental, and cognitive outcomes of Romanian and within-UK adoptees over time

\begin{tabular}{|c|c|c|c|c|}
\hline \multirow[b]{2}{*}{ Age of adoption (months): } & \multirow{2}{*}{$\frac{\text { Within-UK adoptees }}{6}$} & \multicolumn{3}{|c|}{ Romanian orphans } \\
\hline & & Before 6 & At 6-24 & At $24-42$ \\
\hline \multirow[t]{2}{*}{ Weight at adoption } & - & -2.1 & -2.3 & - \\
\hline & - & $(1.7)$ & $(1.7)$ & - \\
\hline \multirow[t]{2}{*}{ Height at adoption } & - & -1.8 & -2.2 & - \\
\hline & - & $(1.6)$ & $(2.4)$ & - \\
\hline Denver Developmental & - & 76.5 & 48.1 & - \\
\hline Scale at adoption & - & $(48.1)$ & $(25.4)$ & - \\
\hline \multirow[t]{2}{*}{ Weight at age 4} & 0.45 & -0.02 & 0.04 & - \\
\hline & $(0.79)$ & $(0.92)$ & $(0.94)$ & - \\
\hline \multirow[t]{2}{*}{ Height at age 4} & 0.25 & -0.29 & -0.36 & - \\
\hline & $(0.91)$ & $(0.89)$ & $(1.02)$ & - \\
\hline Denver Developmental & 117.7 & 115.7 & 96.7 & - \\
\hline Scale at age 4 & $(24.3)$ & $(23.4)$ & $(21.3)$ & - \\
\hline \multirow[t]{2}{*}{ McCarthy GCI at age 4} & 109.4 & 105.9 & 91.7 & - \\
\hline & $(14.8)$ & $(17.9)$ & $(18.0)$ & - \\
\hline \multirow[t]{2}{*}{ Weight at age 6} & 0.30 & 0.02 & -0.25 & -0.85 \\
\hline & $(0.90)$ & $(0.97)$ & $(0.96)$ & $(0.98)$ \\
\hline Percentage with & 2 & 0 & 5 & 18 \\
\hline Denver Developmental & (1) & $(0)$ & (2) & (7) \\
\hline Scale at age 6 below 70 & & & & \\
\hline \multirow[t]{2}{*}{ McCarthy GCI at age 6} & 117 & 114 & & 90 \\
\hline & $(17.8)$ & $(18.3)$ & $(19.2)$ & $(23.8)$ \\
\hline
\end{tabular}

Standard deviations are reported below in parentheses. All anthropometric measurements are standardized using the UK age-specific distributions. The Denver Developmental Scale is are based on specific behaviors (e.g., standing while holding on to something, lifting the head, making meaningful "da-da" sounds). Due to ceiling effects, the Denver scale is not meaningful at age 6, so O'Connor et al. (2000) use the percentage with impairment (defined as a score below 70) as the test criterion. The GCI is the total score on the McCarthy Scales of Children's Abilities. It summarizes verbal, quantitative, perceptual, and memory performance. See Rutter et al. (1998) and O'Connor et al. (2000) for more details on the analysis.

Denver developmental quotient was greater for the orphans who entered foster care before they were 6 months of age. ${ }^{67}$ At age 6 , the same result was obtained. ${ }^{68}$ The same

67 The mean Denver scale for within-UK adoptees was $117.7(S D=24.3), 115.7(S D=23.4)$ for Romanians adopted before 6 months, and $96.7(S D=21.3)$ for those adopted when they were between 6 and 24 months of age. See Rutter (1998).

68 O'Connor et al. (2000) add a third group of Romanian children who were adopted between the ages of 24 to 42 months. This group exhibits the worst performance on the Denver scale. Due to ceiling effects, the Denver scale is not meaningful at age 6, so O'Connor et al. (2000) use the presence of impairment (defined as a score below 70$)$ as a test criterion. For within-UK adoptees, only $2 \%(S D=1)$ qualify as impaired. The corresponding percentages for the Romanians adopted before 6, 6-24 and 24-42 months are $0(S D=0)$, $5(S D=2)$, and $18(S D=7)$. See O'Connor et al. (2000). 
pattern appears to hold for cognitive development at ages 4 and 6, as measured using the McCarthy General Cognitive Index. ${ }^{69}$

Romanian orphans who were adopted into UK families from an environment of severe early deprivation exhibited remarkable improvement. This recovery was characterized by a negative linear dose-response relationship with the duration (or perhaps severity) of the exposure to poor pre and postnatal environments. The children who caught up to ordinary UK adoptees were the ones who were adopted before 6 months of age. This shows the importance of early vs. late intervention that we have documented throughout this chapter. This evidence is also consistent with the notion that early environments are a sensitive, rather than a critical period of development for many child outcomes. Had the interventions occurred later in the life of the children, it is likely that they would have been less effective.

\subsubsection{Intervention in the adolescent years}

How effective are interventions in the adolescent years? Is it possible to remedy the consequences of neglect in the early years? These questions are relevant because cognitive abilities are fairly well determined and stable by age 10 in the sense that IQ at later ages is highly correlated with IQ at ages 8-10. Just as early intervention programs have a high payoff primarily from the social skills and motivation they impart to the child and the improved home environment they produce, so do interventions that operate during the adolescent years.

Tables 8 and 9 summarize evidence on the effects of adolescent interventions on education, earnings, and crime rates. There are few estimates of rates of return for these programs. School-based and training-based programs are compared in the tables. We briefly discuss what is known about school-based interventions during the adolescent years. A few recent studies of mentoring programs like Big Brothers/Big Sisters (BB/BS) and Philadelphia Futures Sponsor-A-Scholar (SAS) have shown that these programs have broad positive social and academic impacts on participating school-aged children and adolescents. The BB/BS program pairs unrelated adult volunteers with youth from single-parent households for the purpose of providing youth with an adult friend. This activity promotes private youth development and surrogate parenthood. No specific attempts were made to ameliorate particular deficiencies or to reach specific educational goals. A broad, supportive role is envisioned for the mentor.

In a random-assignment study, Tierney, Grossman and Resch (1995) found that eighteen months after being matched with a mentor, Little Brothers and Sisters (ages 10 to 16 at the time of the match) were less likely to have initiated drug or alcohol use, to hit someone, to skip class or a day of school, or to lie to their parents; they had higher average grades and were more likely to feel competent in their school work and report a better relationship with their parents.

69 The GCI is the total score on the McCarthy Scales of Children's Abilities. It summarizes verbal, quantitative, perceptual, and memory performance. 
Table 8

Estimated benefits of mentoring programs (Treatment group reductions compared to control group)

\begin{tabular}{|c|c|c|c|}
\hline Program & Outcome measure & Change & $\begin{array}{l}\text { Program costs } \\
\text { per participant }\end{array}$ \\
\hline \multirow[t]{11}{*}{ Big Brother/Big Sister } & & & $\$ 500-1500^{*}$ \\
\hline & Initiating drug use & $-45.8 \%$ & \\
\hline & Initiation alcohol use & $-27.4 \%$ & \\
\hline & \# of times hit someone & $-31.7 \%$ & \\
\hline & \# of times stole something & $-19.2 \%$ & \\
\hline & Grade point average & $3.0 \%$ & \\
\hline & Skipped class & $-36.7 \%$ & \\
\hline & Skipped day of school & $-52.2 \%$ & \\
\hline & Trust in parent & $2.7 \%$ & \\
\hline & Lying to parent & $-36.6 \%$ & \\
\hline & Peer emotional support & $2.3 \%$ & \\
\hline \multirow[t]{5}{*}{ Sponsor-A-Scholar } & & & $\$ 1485$ \\
\hline & 10th grade GPA (100 point scale) & 2.9 & \\
\hline & llth grade GPA (100 point scale) & 2.5 & \\
\hline & $\%$ attending college ( 1 year after $\mathrm{HS}$ ) & $32.8 \%$ & \\
\hline & $\%$ attending college ( 2 years after $\mathrm{HS}$ ) & $28.1 \%$ & \\
\hline \multicolumn{4}{|c|}{ Quantum opportunity program } \\
\hline & Graduated HS or GED & $+26 \%$ & \\
\hline & Enrolled in 4-year college & $+15 \%$ & \\
\hline & Enrolled in 2-year college & $+24 \%$ & \\
\hline & Currently employed full time & $+13 \%$ & \\
\hline & Self receiving welfare & $-22 \%$ & \\
\hline & $\%$ ever arrested & $-4 \%$ & \\
\hline
\end{tabular}

Sources: Benefits from Heckman (1999) and Taggart (1995), costs from Johnson (1996) and Herrera et al. (2000).

*Costs, in 1996 dollars, for school-based programs are as low as $\$ 500$ and more expensive community based mentoring programs cost as high as $\$ 1500$; HS $=$ high school.

The primary goal of Sponsor-A-Scholar (SAS) was to help students from Philadelphia public high schools make it to college. The program provides long-term mentoring (throughout high school and for one year beyond), substantial academic support, help with college application and financial-aid procedures, and financial support for collegerelated expenses. Individually matched mentors served as surrogate parents, provided a successful role model, monitored student progress, and provided encouragement and support. SAS provided students with $\$ 6,000$ in financial assistance throughout college for those choosing to enroll in an accredited two- or four-year postsecondary institution. The program also provided a coordinator for groups of about thirty students to ensure a successful relationship is built between mentors and students. Using a matched sample of non-SAS students in Philadelphia high schools, Johnson (1996) estimates statisti- 
Table 9

Effects of selected adolescent social programs on schooling, earnings, and crime

\begin{tabular}{|c|c|c|c|c|c|}
\hline Program/Study & Costs* & $\begin{array}{l}\text { Program } \\
\text { Description }\end{array}$ & Schooling & Earnings* & Crime* \\
\hline $\begin{array}{l}\text { Job Corps } \\
\text { [Long et al. (1981)] }\end{array}$ & $\$ 11,000$ & $\begin{array}{l}7 \text { mo. of educ. } \\
\text { and vocational } \\
\text { training for } \\
16-21 \text { yr. olds } \\
\text { (mostly male) }\end{array}$ & no effect & $\begin{array}{l}\text { disc. pres. } \\
\text { value of } \\
\text { increased } \\
\text { earnings of } \\
\$ 10,000\end{array}$ & $\begin{array}{l}\text { Estimated } \\
\text { Reduction in } \\
\text { crime valued at } \\
\text { approx. }\end{array}$ \\
\hline $\begin{array}{l}\text { STEP [Walker and } \\
\text { Viella-Velez } \\
(1992)]\end{array}$ & N/A & $\begin{array}{l}2 \text { summers of } \\
\text { employment, } \\
\text { academic/ } \\
\text { remediation } \\
\text { and life skills } \\
\text { for } 14 \text { and } 15 \\
\text { year olds }\end{array}$ & $\begin{array}{l}\text { short-run gains } \\
\text { in test scores; } \\
\text { no effect on } \\
\text { school } \\
\text { completion } \\
\text { rates }\end{array}$ & & \\
\hline $\begin{array}{l}\text { Quantum } \\
\text { opportunities } \\
\text { program** } \\
\text { [Taggart (1995)] }\end{array}$ & $\$ 10,600$ & $\begin{array}{l}\text { counseling; } \\
\text { educ., comm., } \\
\text { and devp. } \\
\text { services; } \\
\text { financial } \\
\text { incentives for } \\
\text { part. (4 yrs. } \\
\text { beginning in } \\
\text { 9th grade) }\end{array}$ & $\begin{array}{l}34 \% \text { higher HS } \\
\text { grad./GED } \\
\text { rates ( } 2 \text { yrs. } \\
\text { post- program) }\end{array}$ & & $\begin{array}{l}4 \% \text { vs. } 16 \% \\
\text { convicted; } 0.28 \\
\text { vs. } 0.56 \text { avg. } \\
\text { number of } \\
\text { arrests ( } 2 \text { yrs. } \\
\text { post-program) }\end{array}$ \\
\hline
\end{tabular}

Notes: All comparisons are for program participants vs. nonparticipants.

Source: Heckman et al. (1997).

*All dollar figures are in 1990 values.

** Studies used a random assignment experimental design to determine program impacts.

cally significant increases in grade point averages for tenth and eleventh grades, as well as a 22 percent (16 percent) increase in college attendance one year (two years) after graduation from high school. Because the primary goal of SAS is to increase college enrollment, Johnson did not collect other social and psychological measures.

Much like SAS, the Quantum Opportunity Program (QOP) offered disadvantaged minority students counseling and financial incentives (one dollar up front and one dollar put in a college fund) for every hour spent in activities aimed at improving social and market skills. Students who were randomly chosen to participate in the program were provided with a mentor at the beginning of ninth grade. All participants were kept in the program for four years regardless of whether they stayed in school. Over four years, the average participant logged 1,286 hours of educational activities like studying with tutors or visiting museums. Two years after program completion, about a third more participating students graduated from high school (or obtained a GED) than similar nonparticipants. Since many participants were enrolled in postsecondary schooling 
at the time of the follow-up study, it is difficult to determine the program's effect on earnings. Arrest rates for program participants, however, were one-half those for nonparticipants. These benefits did not come without substantial expenditures, however, as the average four-year cost per participant was $\$ 10,600$. Still, a cost-benefit analysis estimated positive net social returns to QOP. [See Taggart (1995) for a more detailed description of the program and an evaluation of its impacts]. Tables 8 and 9 present evidence from a randomized-trial evaluation of the QOP program. Again, the evidence shows that QOP and programs like it can dramatically improve social skills and the adaptation of adolescents to society. However, these programs do not produce miracles. The recent evaluation of QOP by Maxfield, Schirm and Rodriguez-Planas (2003) found that the program did not improve grades or achievement test scores and the effect on risky behaviors was ambiguous. It was also more effective for teens from the middle of the eligible grade distribution than for enrollees at the top or bottom of the distribution. There was considerable variability in effect by program site.

Two other studies provide additional evidence that creative programs designed to keep adolescents in school can be effective. These are discussed more extensively in Heckman (2000) and Heckman and Lochner (2000), and we briefly summarize these discussions here. Ohio's Learning, Earning, and Parenting (LEAP) program and the Teenage Parent Demonstration (TPD) provided financial incentives for teenage parents on welfare to stay in school or take GED classes (or, alternatively, imposed financial penalties for nonenrollment). LEAP showed increases in high school graduation or GED rates among randomly assigned participants who were still enrolled in school when they entered the program. TPD showed mixed results on educational attainment depending on the program site. Young women who had already dropped out of school at the time of enrollment in the program (and, to a lesser extent, those who were still attending school when they entered the program) may have substituted GED training for high school graduation as an easier way to meet program requirements, raising concerns about an unintended, potentially negative effect. Both of these programs show positive post-program effects on earnings and employment for students who were still in school when they entered the program. The estimated effects were often negative, however, for participants who had already dropped out of school before entering the program. Both studies thus show more positive impacts for individuals still enrolled in school than for dropouts. It is still unknown whether the effects of the programs are more positive for those still in school because, on average, they are of higher ability than those who have already dropped out, or because there is some advantage to intervening before adolescents leave school.

The available schooling literature demonstrates that providing disadvantaged students with financial incentives to stay in school and participate in learning activities can increase schooling and improve employment outcomes. It should be noted that although programs providing such incentives have proven to influence employment and earnings positively (and, in the case of QOP, to reduce crime), they do not perform miracles. The impacts they achieve are modest, but positive. 
The Summer Training and Employment Program (STEP) provided remedial academic education and summer jobs to disadvantaged youth ages 14 and 15. Each summer, participants enrolled in 110 hours of classes and 90 hours of part-time work. Although program participants achieved modest short-term gains in reading and math skills, those gains did not last. Two to three years after program completion, program participation was found to have no effects on high school graduation rates, grades, or employment (see Table 9). The program has been criticized for not attempting to follow up on its summer program with a school year curriculum. Maryland's Tomorrow program did just that: it combined an intensive summer program with a school year follow-up, offering participants summer jobs and academic instruction, career guidance, and counseling through adult mentors, peer support, or tutoring. Although the program did not reduce final attrition rates, it did seem to delay attrition (dropout rates were lower for program participants during the ninth grade but not by the end of the twelfth grade). The program also increased the pass rate for twelfth grade students taking the Maryland Functional Tests, a series of tests of basic skills [see Heckman and Lochner (2000)].

There is also some non-experimental evidence that Catholic secondary schooling is associated with increased college participation among urban students, especially minorities [see Grogger and Neal (2000)]. This increase does not appear to be accompanied by large gains in math scores, at least for the groups whose attainment is most affected. This is consistent with our hypothesis that adolescent interventions alter noncognitive skills but have weaker effects on cognitive skills. Altonji, Elder and Taber (2005) find a similar pattern that attendance at Catholic schools raises high school graduation rates and, more tentatively, promotes college attendance but has no effect on test scores.

The evidence on programs aimed at increasing the skills and earnings of disadvantaged youth suggests that sustained interventions targeted at adolescents still enrolled in school can positively affect learning and subsequent employment and earnings. The studies discussed in this section also suggest that interventions for dropouts are much less successful. One plausible interpretation, consistent with other evidence reported in this chapter, is that those who choose to drop out have less motivation and lower ability, making programs less effective for them regardless of when the intervention takes place. It is important to note, however, that the interventions conducted by such programs only alleviate and do not fully reverse early damage caused by low quality family environments.

\subsubsection{The effectiveness of late adolescent and young adult remediation programs}

The evidence from public job training and second chance programs like the GED suggests that remediation targeted towards children from disadvantaged environments is costly and at current expenditure levels is ineffective [see Carneiro and Heckman (2003)]. Heckman, LaLonde and Smith (1999) survey evaluations of public job training programs in the United States. Returns are low (and sometimes negative) and even when they are positive they do not lift most persons treated out of poverty. Similar evidence 
is reported for remediation efforts in public schools. As discussed above, the return to GED certification is very low. While the return to private sector on-the-job training is high, access to such training is difficult for the less able and the disadvantaged (recall Table 2). Adolescent remediation programs are effective for a targeted few who use them as second chance opportunities. They are not effective for the rest.

Some look to public schooling as a way to remedy early ability deficits and to alleviate disadvantage in endowments. Hansen, Heckman and Mullen (2004) and Heckman, Larenas and Urzua (2004) address this issue. They use a variety of methods to control for the endogeneity of schooling. All methods show that schooling, while it raises measured ability, does not eliminate gaps between children from different racial and economic strata, and if anything widens them. This evidence parallels the evidence on military experience and productivity discussed in Section 2.5.6. Experience raises performance but does not close gaps.

Figures 16A and 16B, taken from Heckman, Larenas and Urzua (2004), show how schooling raises achievement test scores at different levels of ability. These authors use the methodology of Hansen, Heckman and Mullen (2004) to isolate causal effects of schooling on AFQT test scores, holding pure cognitive ability constant. The level of latent ability is determined by a version of factor analysis. Graphs are given by decile of ability from the lowest to the highest. Their analysis is based on longitudinal data to

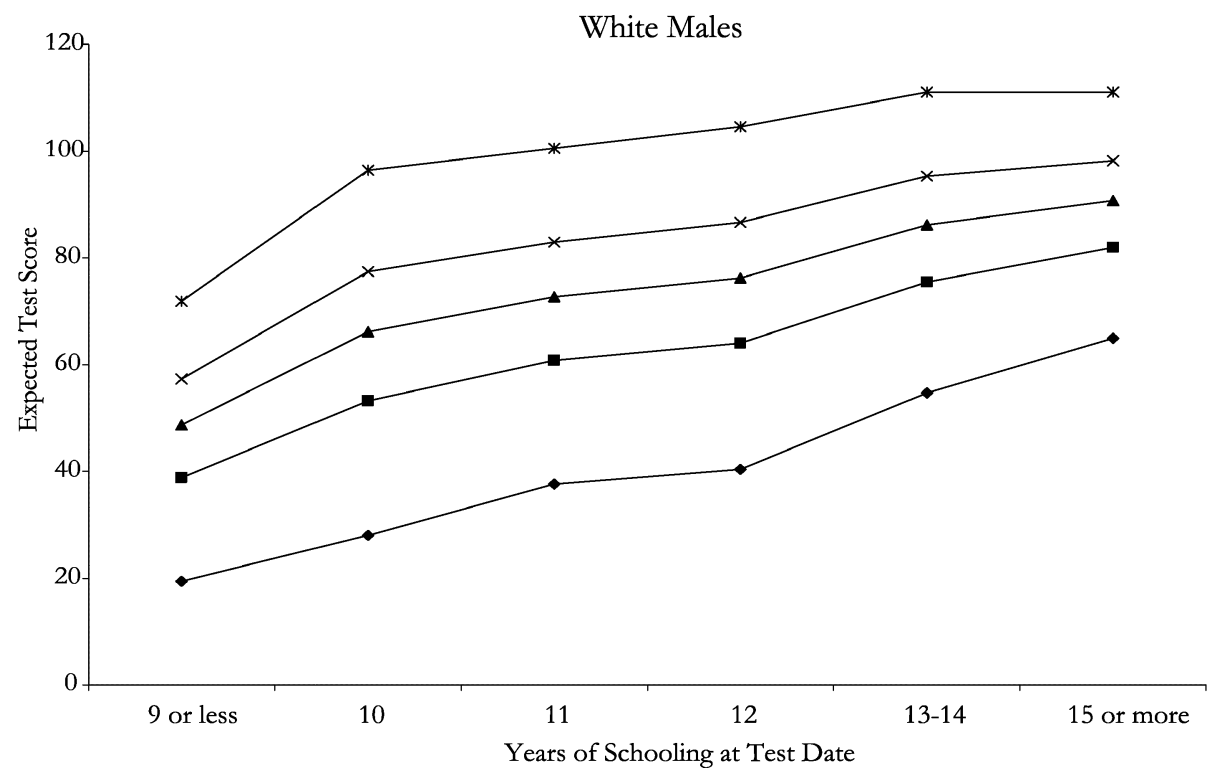

Figure 16A. Expected value of AFQT score conditional on latent ability (plots are by decile of latent ability). Notes: The structural model includes the following covariates: urban status, broken home and southern residence at age 14, number of siblings and family income in 1979, mother's and father's education, and age of the child at December 1980. 

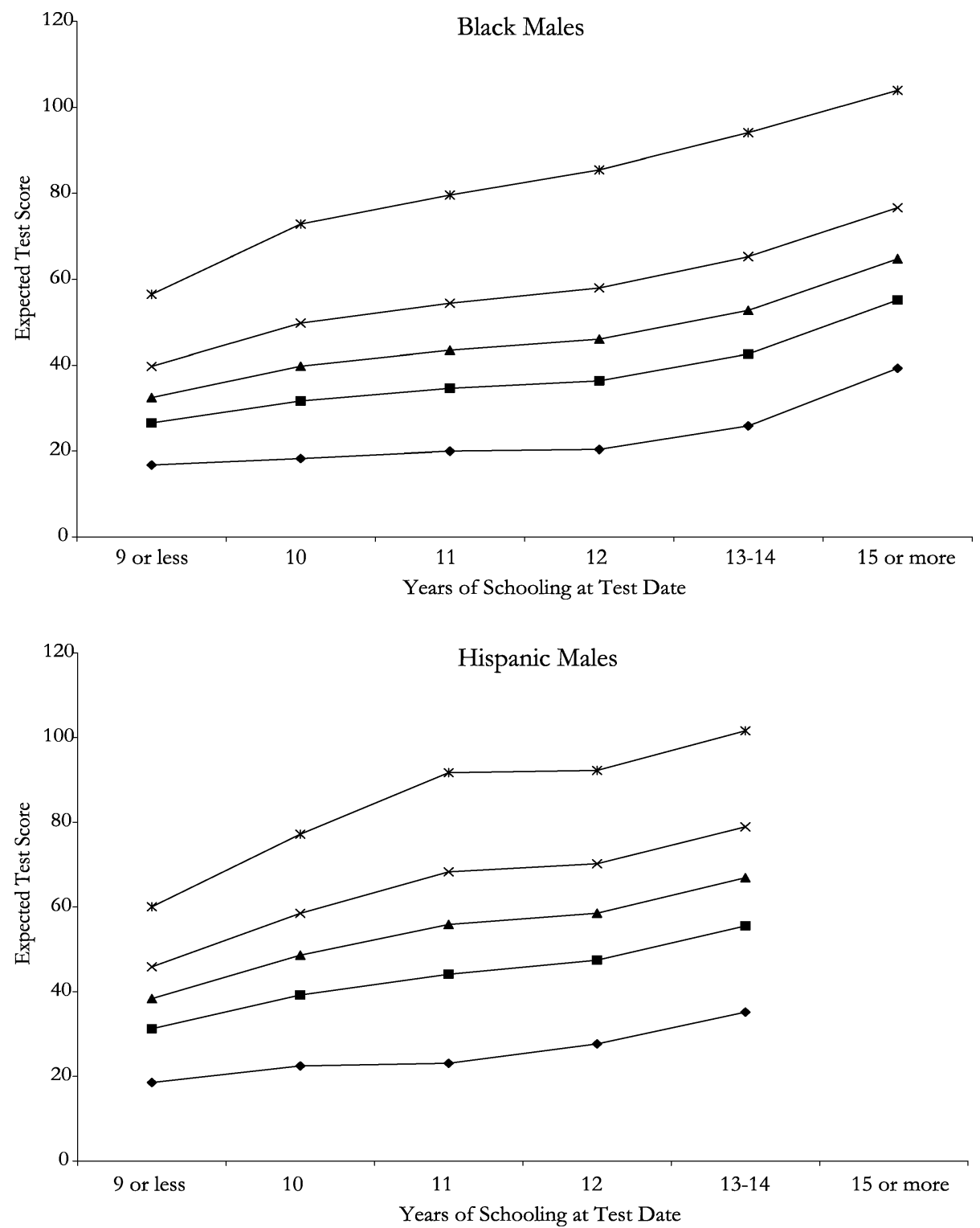

$\multimap-2.5$ th Percentile $\rightarrow-25$ th Percentile $\rightarrow$ 50th Percentile $\rightarrow$-75th Percentile $\rightarrow$-97.5th Percentile

Figure 16A. (Continued.) 

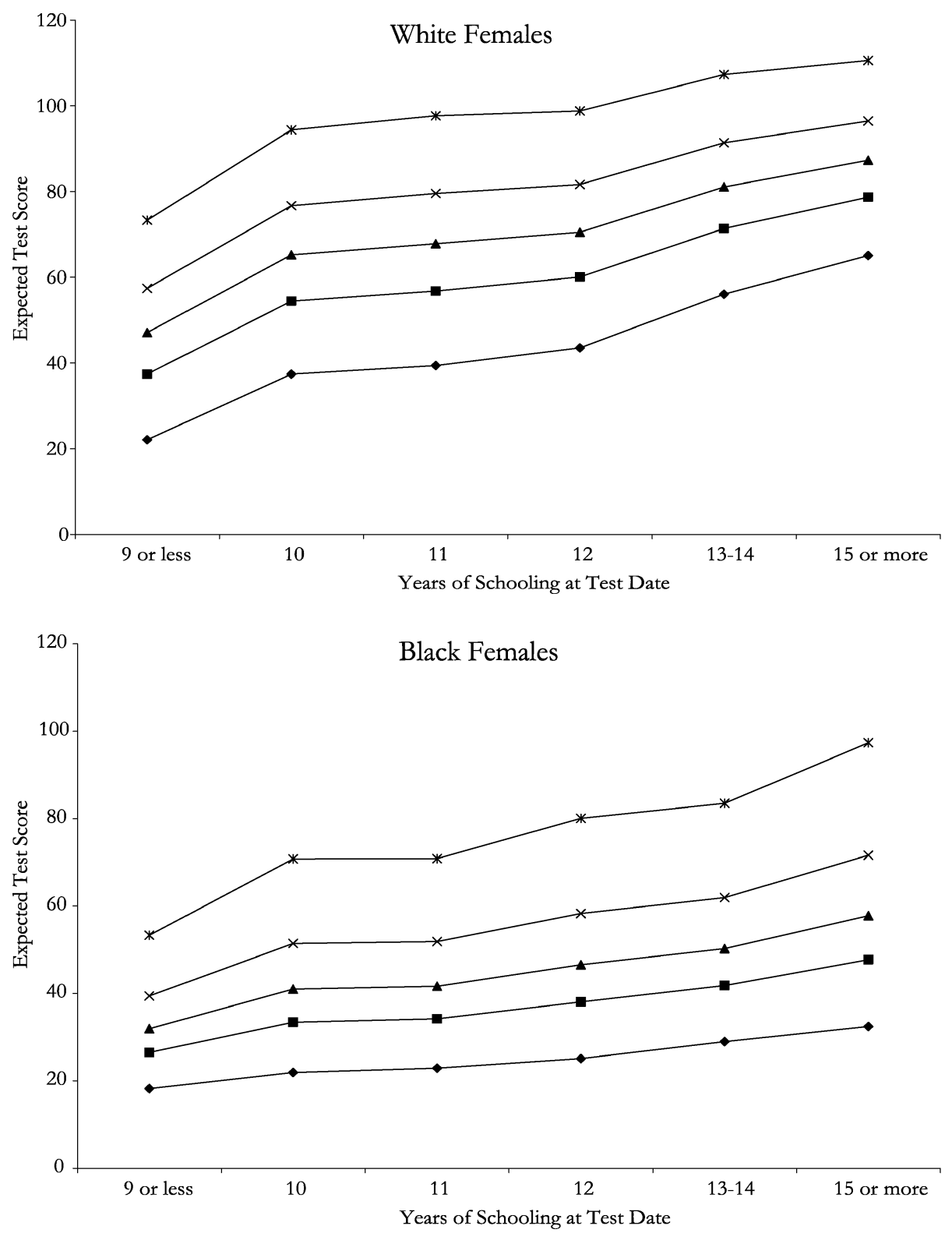

Figure 16B. Expected value of AFQT score conditional on factor.

Note: The structural model includes the following covariates: urban status, broken home and south residence at age 14, number of sibling, family income in 1979, mother's and father's education, and age of the child at December 1980 . 


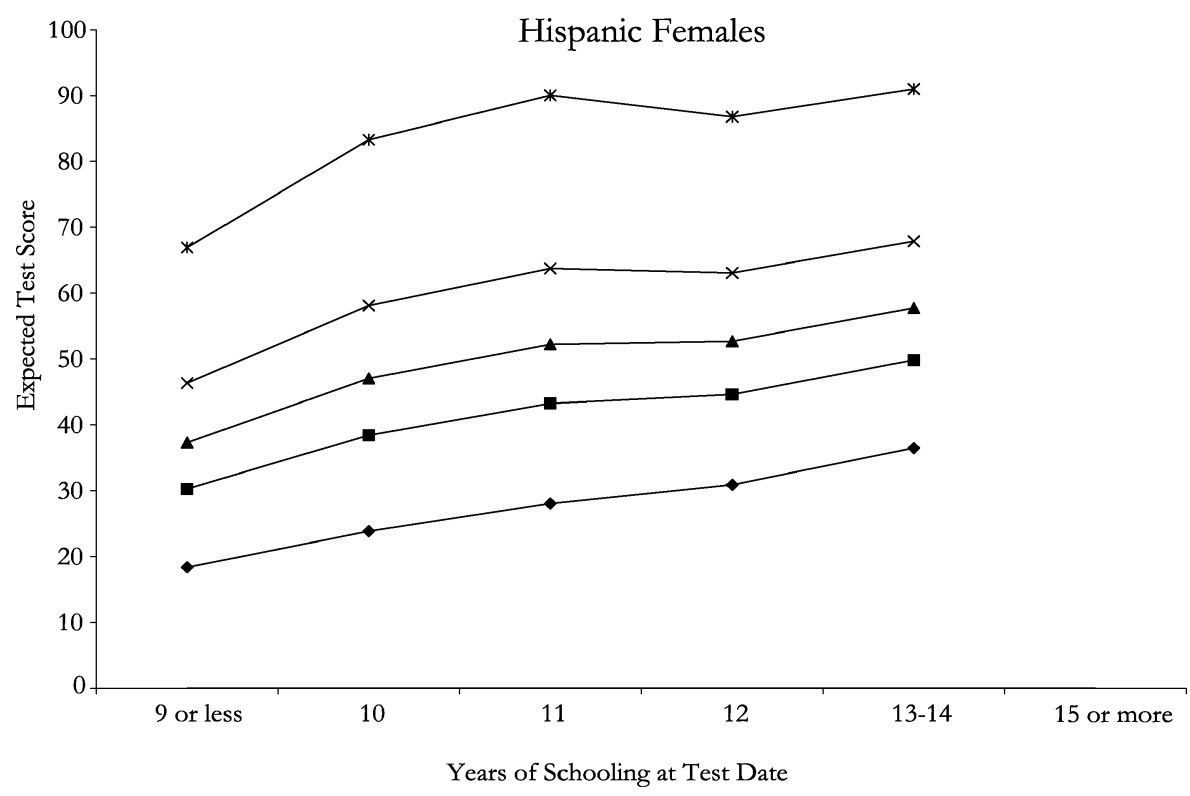

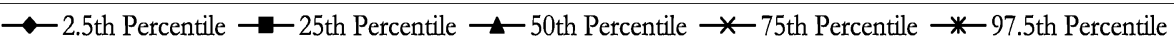

Figure 16B. (Continued.)

measure the effects of different levels of schooling attained at the date the test is taken on achievement for people who all eventually get the same schooling. For all major demographic groups, initial (ninth grade) test score gaps are maintained regardless of schooling level. Schooling raises test scores, but it does not equalize them. These results persist even after controlling for measures of schooling quality. One cannot count on schooling to eliminate early test score deficits. On the other hand, one cannot blame schools for widening initial test score gaps.

The evidence reviewed in Section 2 points to the empirical importance of selfproductivity and complementarity. Skill begets skill. Later remediation of early skill deficits can be costly. This evidence supports the qualitative conclusions of Figures 1A and $1 \mathrm{~B}$ that returns to investment are higher for the young and the disadvantaged. We next present a more formal model of the technology of skill formation that is a starting point for the theoretical unification of a scattered literature on treatment effects that presents "effects" for different programs in different environments directed towards different clientele. 


\section{Using the technology of skill formation to explain the evidence}

\subsection{A model of skill formation}

We use simple economic models to organize the evidence presented in Section 2 as summarized in Figures 1A and 1B. We define the concepts of recursive productivity or "self-productivity" and complementarity and show how the skill multiplier (as defined in this section) and the notion of complementarity help to organize the empirical evidence surveyed in Section 2. These concepts are essential for understanding why early interventions are more effective than later interventions and why there is no trade-off between equity and efficiency in the early years of childhood but why there is such a trade-off in the later years.

In the models presented in this section, parents make decisions about their children. We ignore how the parents get to be who they are and the decisions of the children about their own children. We develop a more generationally consistent model in Section 3.2, after developing the basic framework of the technology of skill formation.

Suppose that there are two periods in a child's life, "1" and " 2 ", before the child becomes an adult. Adulthood is a distinct third period. The child works for a fixed number of periods after the two periods of childhood. Models based on the analysis of Becker and Tomes (1979) assume only one period of childhood. We assume that there are two kinds of skills: $S^{C}$ and $S^{N}$. For example, $S^{C}$ can be thought of as cognitive skill and $S^{N}$ as noncognitive skill. Our treatment of ability is in contrast to the view of the traditional literature on human capital formation that views IQ as innate ability. In our analysis, IQ is just another skill. What differentiates IQ from other cognitive and noncognitive skills is that IQ is subject to accumulation during critical periods. That is, parental and social interventions can increase the IQ of the child, but they can do so successfully only for a limited time. Recall our evidence that an enriched early intervention like the Abecedarian program raised IQ but Head Start and Perry Preschool - directed towards later ages - did not. Compare Figure 15A for the Abecedarian program with Figure 14A for the later-intervention Perry program. ${ }^{70}$

Let $I_{t}^{k}$ denote parental investments in child skill $k$ at period $t, k=C, N$ and $t=$ 1,2 . Let $h$ be the level of human capital as the child starts adulthood. It depends on both components of $\left(S_{2}^{C}, S_{2}^{N}\right)$. The parents fully control the investment of the child. A richer model incorporates, among other features, investment decisions of the child as influenced by the parent through preference formation processes [see Cunha and Heckman (2004, 2006)].

We first describe how skills evolve over time. Assume that each agent is born with initial conditions $S_{0}=\left(S_{0}^{C}, S_{0}^{N}\right)$. At each stage $t$ let $S_{t}=\left(S_{t}^{C}, S_{t}^{N}\right)$ denote the vector

\footnotetext{
70 One has to be careful in making this comparison because the Abecedarian program was much more intensive. One cannot separate out the effect that Abecedarian started at 4 months age (as opposed to Perry's 3-4 years) from the greater resource intensity of the Abecedarian program.
} 
of skill or ability stocks. The technology of production of skill $k$ at period $t$ is:

$$
S_{t}^{k}=f_{t}^{k}\left(S_{t-1}, I_{t}^{k}\right)
$$

for $k=C, N$ and $t=1,2$. We assume that $f_{t}^{k}$ is twice continuously differentiable, increasing and concave in $I_{t}^{k} .^{71}$ In this model, stocks of both skills and abilities produce next period skills and the productivity of investments. Cognitive skills can promote the formation of noncognitive skills and vice versa.

We define adult human capital $h$ as a combination of different period 2 skills:

$$
h=g\left(S_{2}^{C}, S_{2}^{N}\right) .
$$

The function $g$ is assumed to be continuously differentiable and increasing in $\left(S_{2}^{C}, S_{2}^{N}\right)$. This model assumes that there is no comparative advantage in the labor market or in life itself. $^{72}$

Period 1 is a critical period for $S_{2}^{C}$ if

$$
\frac{\partial S_{2}^{C}}{\partial I_{2}^{C}}=\frac{\partial f_{2}^{C}\left(S_{1}, I_{2}^{C}\right)}{\partial I_{2}^{C}} \equiv 0 \text { for all } S_{1}, I_{2}^{C},
$$

but

$$
\frac{\partial S_{1}^{C}}{\partial I_{1}^{C}}=\frac{\partial f_{1}^{C}\left(S_{0}, I_{1}^{C}\right)}{\partial I_{1}^{C}}>0 \text { for some } S_{0}, I_{1}^{C} .
$$

This says that investments in $C$ are productive in period 1 but not in period 2 . In the analysis of Section 2, the early periods (before age 8) are critical periods for IQ but not for achievement tests or for noncognitive skills.

Period 1 is a sensitive period for $S_{2}^{C}$ if

$$
\left.\frac{\partial S_{2}^{C}}{\partial I_{2}^{C}}\right|_{S_{1}=s, I_{2}^{C}=i}<\left.\frac{\partial S_{1}^{C}}{\partial I_{1}^{C}}\right|_{S_{0}=s, I_{1}^{C}=i} .
$$

Thus, 1 is a sensitive period if, at the same level of inputs, investment is more productive in stage 1 than in stage 2. The evidence in Section 2 suggests that early investments in both cognitive and noncognitive abilities and skills are more productive than later investments.

As defined in the introduction, and clarified in the Appendix A, direct complementarity of skill $l$ acquired in period 1 on the output of investment $k$ in producing skill $k$ in

\footnotetext{
71 Twice continuous differentiability is a convenience.

72 Thus we rule out one potentially important avenue of compensation that agents can specialize in tasks that do not require the skills in which they are deficient. In Appendix A and in Section 1, we briefly consider a more general task function that captures the notion that different tasks require different combinations of skills and abilities.
} 
period 2 is defined by

$$
\frac{\partial^{2} S_{2}^{k}}{\partial I_{2}^{k} \partial S_{1}^{l}}>0, \quad k=C, N .
$$

Early stocks of abilities and skills promote later skill acquisition by making it more productive. Students with greater early cognitive and noncognitive abilities are more efficient in later learning of both cognitive and noncognitive skills. Thus the enriched early environments of the Abecedarian, Perry and CPC programs promote greater efficiency in learning in high schools and reduce problem behaviors. See the evidence in Figures $13-15$ on reduction in remedial education and problem behavior for the treatment group in these programs.

This technoloy also is sufficiently rich to describe learning in rodents and rhesus monkeys as documented by Meaney (2001) and Cameron (2004). It also captures the critical and sensitive periods in animals documented by Knudsen et al. (2006). Emotionally nurturing early environments create preconditions for later cognitive learning. More emotionally secure young animals explore their environments more actively and learn more quickly. This is an instance of complementarity.

To fix ideas, consider the following specialization of our model. Ignore the effect of initial conditions and assume that first period skills are just due to first period investment:

$$
S_{1}^{C}=f_{1}^{C}\left(S_{0}, I_{1}^{C}\right)=I_{1}^{C}
$$

and

$$
S_{1}^{N}=f_{1}^{C}\left(S_{0}, I_{1}^{C}\right)=I_{1}^{N},
$$

where $I_{1}^{C}$ and $I_{1}^{N}$ are scalars. For the second period technologies, we assume a CES structure:

$$
\begin{aligned}
& S_{2}^{C}=f_{2}^{C}\left(S_{1}, I_{2}^{C}\right) \\
& \quad=\left\{\gamma_{1}\left(S_{1}^{C}\right)^{\alpha}+\gamma_{2}\left(S_{1}^{N}\right)^{\alpha}+\left(1-\gamma_{1}-\gamma_{2}\right)\left(I_{2}^{C}\right)^{\alpha}\right\}^{1 / \alpha}, \\
& \text { where } 1 \geqslant \gamma_{1} \geqslant 0,1 \geqslant \gamma_{2} \geqslant 0,1 \geqslant 1-\gamma_{1}-\gamma_{2} \geqslant 0,
\end{aligned}
$$

and

$$
\begin{aligned}
& S_{2}^{N}=f_{2}^{N}\left(S_{1}, I_{2}^{N}\right) \\
& \quad=\left\{\eta_{1}\left(S_{1}^{C}\right)^{\sigma}+\eta_{2}\left(S_{1}^{N}\right)^{\sigma}+\left(1-\eta_{1}-\eta_{2}\right)\left(I_{2}^{N}\right)^{\sigma}\right\}^{1 / \sigma}, \\
& \text { where } 1 \geqslant \eta_{1} \geqslant 0,1 \geqslant \eta_{2} \geqslant 0,1 \geqslant 1-\eta_{1}-\eta_{2} \geqslant 0,
\end{aligned}
$$

where $\frac{1}{1-\alpha}$ is the elasticity of substitution in the inputs producing $S_{2}^{C}$ and $\frac{1}{1-\sigma}$ is the elasticity of substitution of inputs in producing $S_{2}^{N}$ where $\alpha \in(-\infty, 1]$ and $\sigma \in(-\infty, 1]$. Notice that $I_{2}^{N}$ and $I_{2}^{C}$ are direct complements with $\left(S_{1}^{C}, S_{1}^{N}\right)$ irrespective of the substitution parameters $\alpha$ and $\sigma$, except in limiting cases. 
The CES technology is well known and has convenient properties. It imposes direct complementarity even though inputs may be more or less substitutable depending on $\alpha$ or $\sigma .^{73}$ We distinguish between direct complementarity and CESsubstitution/complementarity in this section. Focusing on the technology for producing $S_{2}^{C}$, when $\alpha=1$, the inputs are perfect substitutes in the intuitive use of that term (the elasticity of substitution is infinite). The inputs $S_{1}^{C}, S_{1}^{N}$ and $I_{2}^{C}$ can be ordered by their relative productivity in producing $S_{2}^{C}$. The higher $\gamma_{1}$ and $\gamma_{2}$, the higher the productivity of $S_{1}^{C}$ and $S_{1}^{N}$ respectively. When $\alpha=-\infty$, the elasticity of substitution is zero. All inputs are required in the same proportion to produce a given level of output so there are no possibilities for technical substitution, and

$$
S_{2}^{C}=\min \left\{S_{1}^{C}, S_{1}^{N}, I_{2}^{C}\right\} .
$$

In this technology, early investments are a bottleneck for later investment. Compensation for adverse early environments through late investments is impossible. These polar cases generalize the cases developed in Section 1.

The evidence from numerous studies previously cited shows that IQ is no longer malleable after ages $8-10$. Taken at face value, this implies that if $S^{C}$ is IQ, for all values of $I_{2}^{C}, S_{2}^{C}=S_{1}^{C}$. Period 1 is a critical period for IQ but not necessarily for other skills and abilities. More generally, period 1 is a critical period if

$$
\frac{\partial S_{t}^{C}}{\partial I_{t}^{C}}=0 \quad \text { for } t>1 .
$$

For parameterization (5), this is obtained by imposing $\gamma_{1}+\gamma_{2}=1$.

The evidence on adolescent interventions surveyed in Section 2 shows substantial positive results for such interventions on noncognitive skills $\left(S_{2}^{N}\right)$ and at most modest gains for cognitive skills. Technologies (5) and (6) can rationalize this pattern. Since the populations targeted by adolescent intervention studies tend to come from families with poor backgrounds, we would expect $I_{1}^{C}$ and $I_{1}^{N}$ to be below average. Thus, $S_{1}^{C}$ and $S_{1}^{N}$ will be below average. Interventions make $I_{2}^{C}$ and $I_{2}^{N}$ relatively large for the treatment group in comparison to the control group in the adolescent intervention experiments. At stage $2, S_{2}^{C}$ (cognitive ability) is essentially the same in the control and treatment groups, while $S_{2}^{N}$ (noncognitive ability) is higher for the treated group. Large values of $\left(\gamma_{1}+\gamma_{2}\right)$ (associated with a small coefficient on $\left.I_{2}^{C}\right)$ or small values of $\left(\eta_{1}+\eta_{2}\right)$ (so the coefficient on $I_{2}^{N}$ is large) and high values of $\alpha$ and $\sigma$ can produce this pattern. Another case that rationalizes the evidence is when $\alpha \rightarrow-\infty$ and $\sigma=1$. Under these conditions:

$$
S_{2}^{C}=\min \left\{S_{1}^{C}, S_{1}^{N}, I_{2}^{C}\right\}
$$

73 See footnote 13 in Section 1. 
while

$$
S_{2}^{N}=\eta_{1} S_{1}^{C}+\eta_{2} S_{1}^{N}+\left(1-\eta_{1}-\eta_{2}\right) I_{2}^{N} .
$$

The attainable period 2 stock of cognitive skill $\left(S_{2}^{C}\right)$ is limited by the minimum value of $S_{1}^{C}, S_{1}^{N}, I_{2}^{C}$. In this case, any level of investment in period 2 such that $I_{2}^{C}>$ $\min \left\{S_{1}^{C}, S_{1}^{N}\right\}$ is ineffective in incrementing the stock of cognitive skills. Period 1 is a bottleneck period. Unless sufficient skill investments are made in $S_{C}$ in period 1, it is not possible to raise skill $S_{C}$ in period 2. This phenomenon does not appear in the production of the noncognitive skill, provided that $\left(1-\eta_{1}-\eta_{2}\right)>0$. More generally, the higher $\sigma$ and the larger $\left(1-\eta_{1}-\eta_{2}\right)$, the more productive is investment $I_{2}^{N}$ in producing $S_{2}^{N}$.

To complete the CES example, assume that adult human capital $h$ is a CES function of the two skills accumulated at stage two:

$$
h=\left\{\tau\left(S_{2}^{C}\right)^{\phi}+(1-\tau)\left(S_{2}^{N}\right)^{\phi}\right\}^{\rho / \phi},
$$

where $\rho \in(0,1), \tau \in[0,1]$, and $\phi \in(-\infty, 1]$. In this parameterization, $\frac{1}{1-\phi}$ is the elasticity of substitution across different skills in the production of adult human capital. Equation (9) reminds us that the market, or life in general, requires use of multiple skills. Being smart isn't the sole determinant of success. In general, different tasks require both skills in different proportions. One way to remedy early skill deficits is to make compensatory investments. Another way is to motivate people from disadvantaged environments to pursue tasks that do not require the skill that deprived early environments do not produce. A richer theory would account for this choice of tasks and its implications for remediation. ${ }^{74}$ For the sake of simplifying our argument, we work with equation (9) that captures the notion that skills can trade off against each other in producing effective people. Highly motivated, but not very bright, people may be just as effective as bright but unmotivated people. That is one of the lessons from the GED program. [See Heckman and LaFontaine (2007), Heckman and Rubinstein (2001), Heckman, Stixrud and Urzua (2006)].

The analysis is simplified by assuming that investments are general in nature: $I_{1}^{C}=$ $I_{1}^{N}=I_{1}, I_{2}^{C}=I_{2}^{N}=I_{2} \cdot{ }^{75}$ Cunha and Heckman $(2004,2006)$ develop the more general case of skill-specific investments which requires more notational complexity.

With common investment goods, we can solve out for $S_{1}^{C}$ and $S_{1}^{N}$ in terms of $I_{1}$ to simplify (5) and (6) to reach

$$
S_{2}^{C}=\left\{\left(\gamma_{1}+\gamma_{2}\right)\left(I_{1}\right)^{\alpha}+\left(1-\gamma_{1}-\gamma_{2}\right)\left(I_{2}\right)^{\alpha}\right\}^{1 / \alpha}
$$

\footnotetext{
74 We sketch such a model in Appendix A.

75 Thus when a parent buys a book in the first period of childhood, this book may be an investment in all kinds of skills. It is an investment in cognitive skills, as it helps the child get exposure to language and new words. It can also be an investment in noncognitive skills, if the book may contain a message on the importance of being persistent and patient.
} 
and

$$
S_{2}^{N}=\left\{\left(\eta_{1}+\eta_{2}\right)\left(I_{1}\right)^{\sigma}+\left(1-\eta_{1}-\eta_{2}\right)\left(I_{2}\right)^{\sigma}\right\}^{1 / \sigma} .
$$

If we then substitute these expressions into the production function for adult human capital (9), we obtain

$$
h=\left\{\tau\left[\tilde{\gamma}\left(I_{1}\right)^{\alpha}+(1-\tilde{\gamma})\left(I_{2}\right)^{\alpha}\right]^{\phi / \alpha}+(1-\tau)\left[\tilde{\eta}\left(I_{1}\right)^{\sigma}+(1-\tilde{\eta})\left(I_{2}\right)^{\sigma}\right]^{\phi / \sigma}\right\}^{\rho / \phi},
$$

where $\tilde{\gamma}=\gamma_{1}+\gamma_{2}, \tilde{\eta}=\eta_{1}+\eta_{2}$. Equation (12) expresses adult human capital as a function of the entire sequence of childhood investments in human capital. Current investments in human capital are combined with the existing stocks of skills in order to produce the stock of next period skills.

A conveniently simple formulation of the problem arises if we assume that $\alpha=\sigma=\phi$ so that CES substitution among inputs in producing outputs and CES substitution among skill in producing human capital are the same. This produces the convenient and familiar-looking CES expression for adult human capital stocks:

$$
h=\left\{\gamma I_{1}^{\phi}+(1-\gamma) I_{2}^{\phi}\right\}^{\rho / \phi},
$$

where $\gamma=\tau \tilde{\gamma}+(1-\tau) \tilde{\eta}$ and $\phi=\alpha=\sigma$. The parameter $\gamma$ is a skill multiplier. It arises because $I_{1}$ affects the accumulation of $S_{1}^{C}$ and $S_{1}^{N}$. These stocks of skills in turn affect the productivity of $I_{2}$ in forming $S_{2}^{C}$ and $S_{2}^{N}$. Thus $\gamma$ captures the net effect of $I_{1}$ on $h$ through both self-productivity and direct complementarity. ${ }^{76} \frac{1}{1-\phi}$ is a measure of how easy it is to substitute between $I_{1}$ and $I_{2}$ where the substitution arises from both the task performance (human capital) function in equation (9) and the technology of skill formation. Within the CES technology, $\phi$ is a measure of the ease of substitution of inputs. In this analytically convenient case, the parameter $\phi$ plays a dual role. First, it informs us how easily one can substitute across different skills in order to produce one unit of adult human capital $h$. Second, it also represents the degree of complementarity

76 To repeat an observation made in Section 1 , direct complementarity between $I_{1}$ and $I_{2}$ arises if

$$
\frac{\partial^{2} h}{\partial I_{1} \partial I_{2}}>0
$$

As long as $\rho>\phi, I_{1}$ and $I_{2}$ are direct complements, because

$$
\operatorname{sign}\left(\frac{\partial^{2} h}{\partial I_{1} \partial I_{2}}\right)=\operatorname{sign}(\rho-\phi) \text {. }
$$

This definition of complementarity is to be distinguished from the notion based on the elasticity of substitution between $I_{1}$ and $I_{2}$, which is $\frac{1}{1-\phi}$. When $\phi<0, I_{1}$ and $I_{2}$ are sometimes called complements. When $\phi>0$, $I_{1}$ and $I_{2}$ are sometimes called substitutes. When $\rho=1, I_{1}$ and $I_{2}$ are always direct complements, but if $1>\phi>0$, they are CES substitutes. 
(or substitutability) between early and late investments in producing skills. In this second role, the parameter $\phi$ dictates how easy it is to compensate for low levels of stage 1 skills in producing late skills.

In principle, compensation can come through two channels: (i) through skill investment or (ii) through choice of market activities, substituting deficits in one skill by the relative abundance in the other through choice of tasks. We do not develop the second channel of compensation in this chapter, deferring it to later work.

When $\phi$ is small, low levels of early investment $I_{1}$ are not easily remediated by later investment $I_{2}$ in producing human capital. The other face of CES complementarity is that when $\phi$ is small, high early investments should be followed with high late investments. In the extreme case when $\phi \rightarrow-\infty,(13)$ converges to $h=\left(\min \left\{I_{1}, I_{2}\right\}\right)^{\rho}$. We analyzed this case in Section 1. The Leontief case contrasts sharply with the case of perfect CES substitutes, which arises when $\phi=1: h=\left[\gamma I_{1}+(1-\gamma) I_{2}\right]^{\rho}$. When we impose the further restriction that $\gamma=1 / 2$, we generate the model that is implicitly assumed in the existing literature on human capital investments that collapses childhood into a single period. In this special case, only the total amount of human capital investments, regardless of how it is distributed across childhood periods, determines adult human capital. In the case of perfect CES substitutes, it is possible in a physical productivity sense to compensate for early investment deficits by later investments, although it may not be economically efficient to do so.

When $\rho=1$, we can rewrite (13) as

$$
h=I_{1}\left\{\gamma+(1-\gamma) \omega^{\phi}\right\}^{1 / \phi}
$$

where $\omega=I_{2} / I_{1}$. Fixing $I_{1}$ (early investment), an increase in $\omega$ is the same as an increase in $I_{2}$. The marginal productivity of late investment is

$$
\frac{\partial h}{\partial \omega}=(1-\gamma) I_{1}\left\{\gamma+(1-\gamma) \omega^{\phi}\right\}^{\frac{1-\phi}{\phi}} \omega^{\phi-1} .
$$

For $\omega>1$ and $\gamma<1$, marginal productivity is increasing in $\phi$ and $(1-\gamma)$. Thus, provided that late investments are greater than earlier investments, the more substitutable $I_{2}$ is with $I_{1}$ (the higher $\phi$ ) and the lower the skill multiplier $\gamma$, the more productive are late investments. Figure 17A graphs the isoquants for $\frac{\partial h}{\partial \omega}$ when $\omega=2$. It shows that a high $\phi$ trades off with a high $\gamma$. As $(\phi, 1-\gamma)$ increases along a ray, $\frac{\partial h}{\partial \omega}$ increases. For a fixed skill multiplier $\gamma$, the higher $\phi$, the higher the marginal productivity of second period investment.

If, however, $\omega<1$, as in Figure 17B, then $\frac{\partial h}{\partial \omega}$ could be decreasing as $(\phi, 1-\gamma)$ increases along a ray and the trade-off between $\phi$ and $(1-\gamma)$ along a $\left(\frac{\partial h}{\partial \omega}, \omega\right)$ isoquant is reversed. If $I_{1}$ is large relative to $I_{2}$ (i.e., $\omega<1$ ), for a fixed $\gamma$ the marginal product of $I_{2}$ is decreasing in $\phi$. More CES complementarity implies greater productivity (see Figure 17B). ${ }^{77}$ The empirically relevant case for the analysis of investment in disadvantaged children is $\omega>1$, as shown in Figure 17A, so greater CES-substitutability and

77 One can show that at sufficiently low values of $\phi$, the marginal productivity is no longer increasing in $\phi$. 


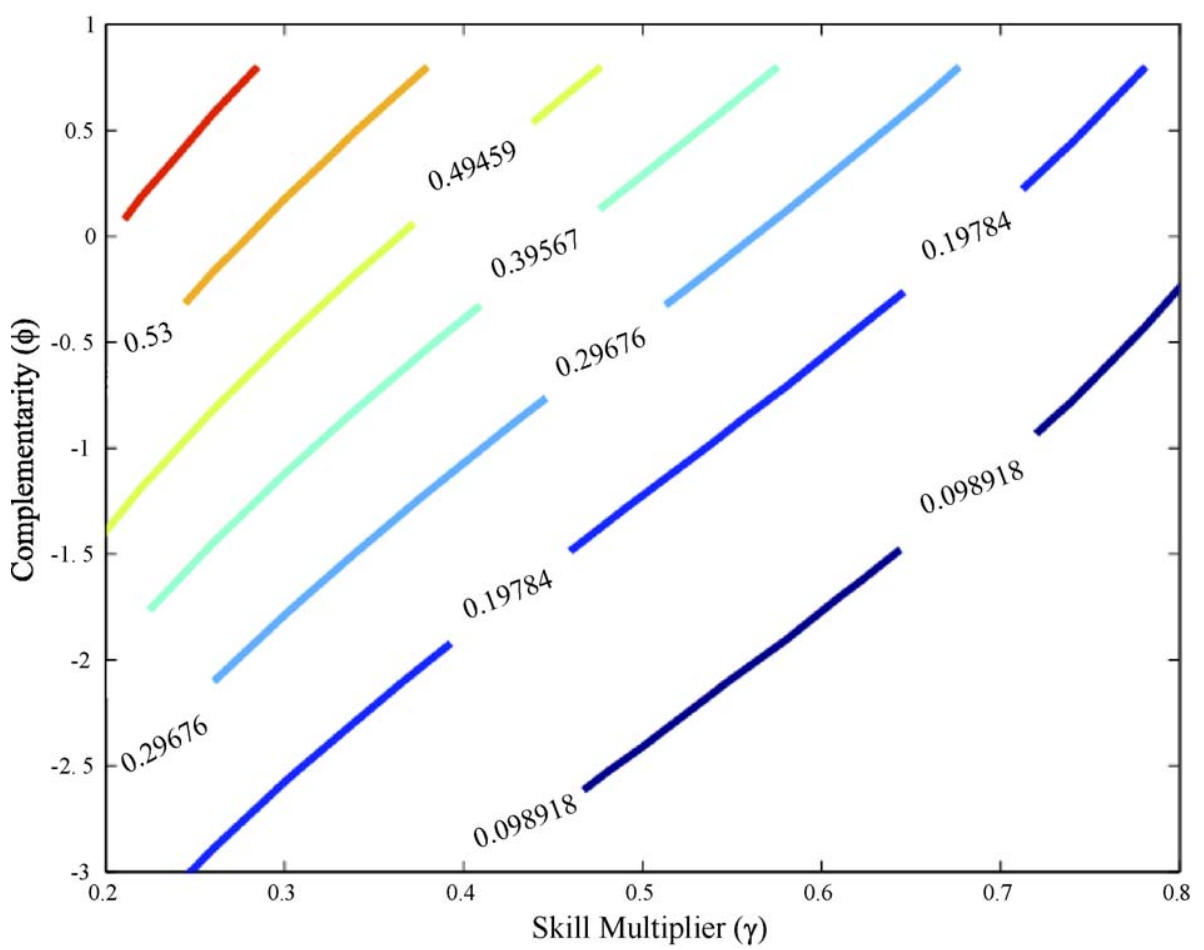

Figure 17A. The indifference curves of the marginal productivity of the ratio of late to early investments as a function of $\phi$ and $\gamma$ when $I_{2} / I_{1}=2$.

Define $\omega=I_{2} / I_{1}$, the ratio of late to early investments in human capital. From the homogeneity of degree one we can rewrite the technology as:

$$
h=I_{1}\left[\gamma+(1-\gamma) \omega^{\phi}\right]^{1 / \phi} .
$$

The marginal product of the ratio of late to early investment, $\omega$, holding early investment constant, is

$$
\frac{\partial h}{\partial \omega}=(1-\gamma) I_{1}\left[\gamma+(1-\gamma) \omega^{\phi}\right]^{\frac{1-\phi}{\phi}} \omega^{\phi-1} .
$$

This figure displays the indifference curves of $\frac{\partial h}{\partial \omega}$ when $\omega=2$. Each indifference curve shows the corresponding level of $\frac{\partial h}{\partial \omega}$. Note that for a given value of $\gamma$ the value of the function tends to increase as we increase $\phi$. The function also increases as we decrease $\gamma$.

a smaller skill multiplier produce a higher marginal productivity of remedial second period investment.

It is important to distinguish the case when it is technologically efficient to compensate for adverse early environments from the case when it is economically efficient to do so. If $\gamma$ is near 1 , it may be very costly to remediate shortfalls in early investments even though it is technically possible to do so. We return to this point below. 


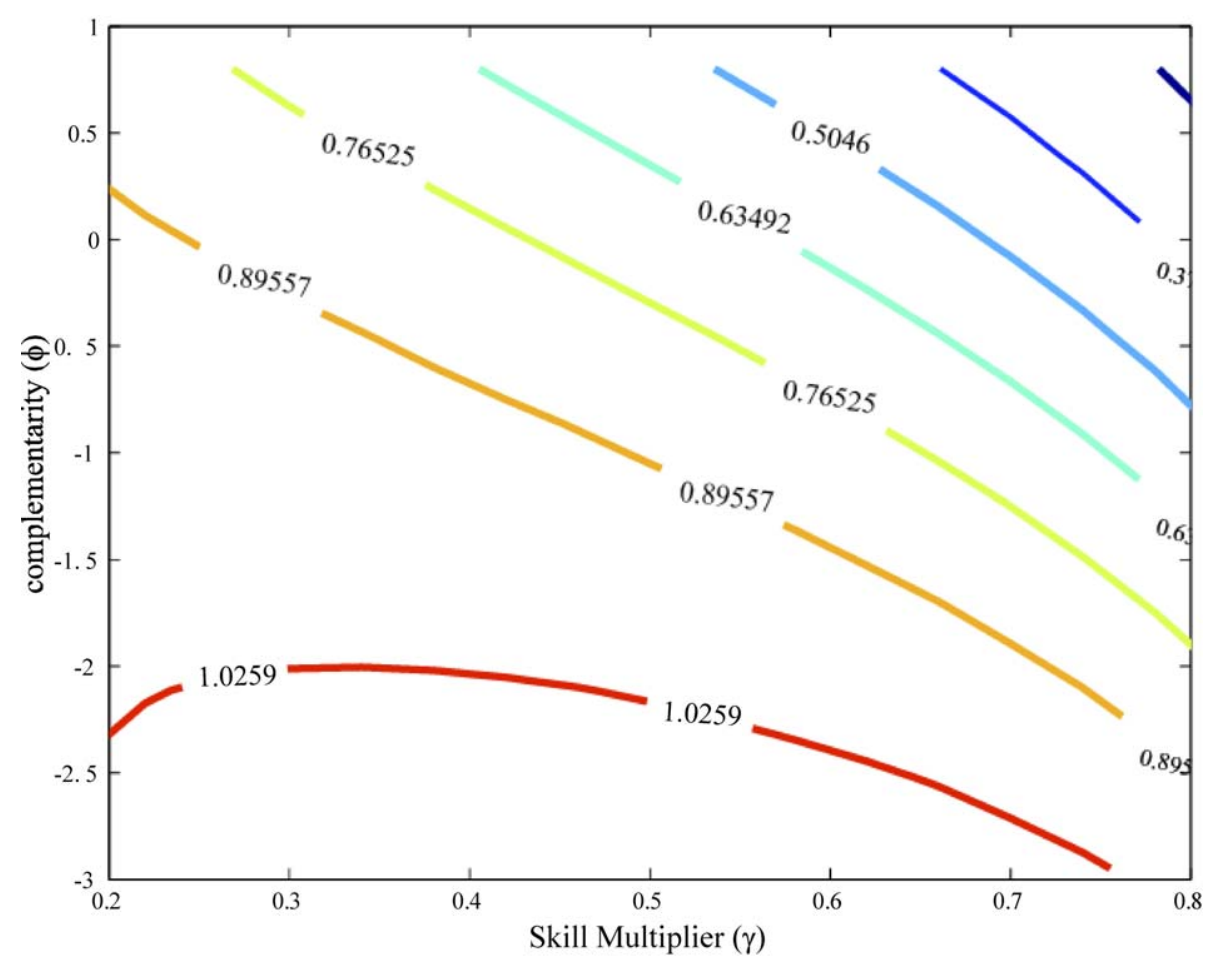

Figure 17B. The indifference curves of the marginal productivity of the ratio of late to early investments as a function of $\phi$ and $\gamma$ when $I_{2} / I_{1}=1 / 2$.

Consider the CES specification for the technology of human capital formation:

$$
h=\left[\gamma I_{1}^{\phi}+(1-\gamma) I_{2}^{\phi}\right]^{1 / \phi} .
$$

Define $\omega=I_{2} / I_{1}$, the ratio of late to early investments in human capital. From the homogeneity of degree one we can rewrite the technology as:

$$
h=I_{1}\left[\gamma+(1-\gamma) \omega^{\phi}\right]^{1 / \phi} .
$$

The marginal product of the ratio of late to early investment, $\omega$, holding early investment constant, is

$$
\frac{\partial h}{\partial \omega}=(1-\gamma) I_{1}\left[\gamma+(1-\gamma) \omega^{\phi}\right]^{\frac{1-\phi}{\phi}} \omega^{\phi-1} .
$$

This figure displays the indifference curves of $\frac{\partial h}{\partial \omega}$ when $\omega=0.5$. Each indifference curve shows the corresponding level of $\frac{\partial h}{\partial \omega}$. Note that for a given value of $\gamma$ the value of the function tends to decrease as we increase $\phi$. However, the function may not be monotonic with respect to $\gamma$.

In analyzing the optimal timing of investment, it is convenient to work with the technology embodied in (13). We now show how the ratio of early to late investments varies as a function of $\phi, \gamma$, and $\rho$. Consider the following model in which parents maximize 
the present value of net wealth of their children. ${ }^{78}$ In order to do that, parents decide how much to invest in period " 1 ," $I_{1}$, how much to invest in period " 2 ," $I_{2}$, and how much to transfer in risk-free assets, $b$, given total parental resources $M$. Period " 1 " could include in utero investments. Parents cannot extract resources from children, so $b \geqslant 0$. From period " 3 " to period $T$, the age of retirement from the workforce, persons are assumed to work full time. Let $r$ denote the time-invariant interest rate, set exogenously and assumed to be constant for all periods, and let $q$ denote the present value of future earnings per efficiency unit of adult human capital $\left\{w_{t}\right\}_{t=3}^{T}$ :

$$
q=\sum_{t=3}^{T}\left(\frac{1}{1+r}\right)^{t-3} w_{t} .9
$$

Lifetime earnings of children when they start working at period " 3 " are given by $q g\left(I_{1}, I_{2}\right)$, where $g$ is the function determining the adult stock of human capital. Discounted to period 1 , the present value of lifetime earnings is $\frac{q}{(1+r)^{2}} g\left(I_{1}, I_{2}\right)$. The problem of the parents is to maximize the present value of the child's net wealth:

$$
\max _{I_{1}, I_{2}, b}\left\{\frac{1}{(1+r)^{2}}\left[q g\left(I_{1}, I_{2}\right)+b\right]\right\},
$$

subject to the standard budget constraint

$$
I_{1}+\frac{1}{1+r} I_{2}+\frac{1}{(1+r)^{2}} b=M,
$$

and the constraint that parents cannot leave negative bequests to their children

$$
b \geqslant 0 \text {, }
$$

where $g\left(I_{1}, I_{2}\right)$ is as defined in equation (13) and is concave in $I_{1}$ and $I_{2}$.

When $\phi=1$, early and late investments are perfect CES substitutes. The optimal investment strategy for this technology in this simple environment is straightforward. The price of early investment is $\$ 1$. The price of the late investment is $\$ \frac{1}{(1+r)}$. Thus the parents can purchase $(1+r)$ units of $I_{2}$ for every unit of $I_{1}$. The amount of human capital produced from one unit of $I_{1}$ is $\gamma$, while $\$(1+r)$ of $I_{2}$ produces $(1+r)(1-\gamma)$ units of human capital. Therefore, the parent invests early if $\gamma>(1-\gamma)(1+r)$ and late otherwise. Two forces act in opposite directions. High productivity of initial investment (the skill multiplier) drives the agent toward making early investments. Intertemporal prices (the interest rate) drive the agent to invest late. It is optimal to invest early if $\gamma>\frac{1+r}{2+r}$.

78 This setup is overly simplistic but allows us to focus on the important points. See Caucutt and Lochner (2004), Cunha (2004) and Cunha and Heckman (2004, 2006) for more general models.

79 We abstract from endogenously determined on-the-job training, learning-by-doing, and assume that agents supply labor inelastically. 
As $\phi \rightarrow-\infty$, the CES production function converges to the Leontief case and the optimal investment strategy is to set $I_{1}=I_{2}$. CES complementarity dominates and the profile of investments is such that $\frac{I_{1}}{I_{2}}$ converges to one. In this extreme case, CES complementarity has a dual face. Investments in the young are essential. At the same time, later investments are needed to harvest early investments. On efficiency grounds, early disadvantages should be perpetuated, and compensatory investments at later ages are economically inefficient.

For $-\infty<\phi<1$, the first-order conditions are necessary and sufficient given concavity of the technology in terms of $I_{1}$ and $I_{2}$. Let $\mu, \lambda$ denote the Lagrange multipliers associated with restrictions (14) and (15), respectively. The first-order conditions for $I_{1}, I_{2}$, and $b$ are

$$
\begin{aligned}
& \frac{q}{(1+r)^{2}} \rho \gamma\left\{\gamma I_{1}^{\phi}+(1-\gamma) I_{2}^{\phi}\right\}^{\frac{\rho-\phi}{\phi}} I_{1}^{\phi-1}=\mu, \\
& \frac{q}{(1+r)} \rho(1-\gamma)\left\{\gamma I_{1}^{\phi}+(1-\gamma) I_{2}^{\phi}\right\}^{\frac{\rho-\phi}{\phi}} I_{2}^{\phi-1}=\mu, \\
& \mu-1=\lambda(1+r)^{2} .
\end{aligned}
$$

Notice that if restriction (15) is not binding, then $\lambda=0, \mu=1$ and optimal early and late investments are only functions of $(q, r)$. In this case, all unconstrained families that make bequests will invest the same in their children. The only difference is in the transfers of assets to their children. If $M_{A}>M_{B}$ then $b_{A}>b_{B}$.

For an interior solution, if we take the ratio of (16) to (17) and rearrange terms we obtain

$$
\frac{I_{1}}{I_{2}}=\left[\frac{\gamma}{(1-\gamma)(1+r)}\right]^{\frac{1}{1-\phi}} .
$$

Figure 18 plots the ratio of early to late investments as a function of the skill multiplier $\gamma$, under different values of the complementarity parameter $\phi$. When $\phi \rightarrow-\infty$, we obtain the Leontief technology and there is high CES-complementarity between early and late investments. In this case, the ratio is not sensitive to variations in $\gamma$. CEScomplementarity dominates, and the optimal investment profile distributes investments equally across different periods. When $\phi=0$, the function $g$ is given by the CobbDouglas function:

$$
h=\left(I_{1}\right)^{\rho \gamma}\left(I_{2}\right)^{\rho(1-\gamma)} .
$$

In this case, from equation (19), $I_{1} / I_{2}$ is close to zero for low values of $\gamma$, but explodes to infinity as $\gamma$ approaches one.

Another way to express these conclusions is to work in terms of growth rates of investment, which yields the expression

$$
\ln \left(\frac{I_{1}}{I_{2}}\right)=\frac{1}{1-\phi}\left[\ln \left(\frac{\gamma}{1-\gamma}\right)-\ln (1-r)\right]
$$




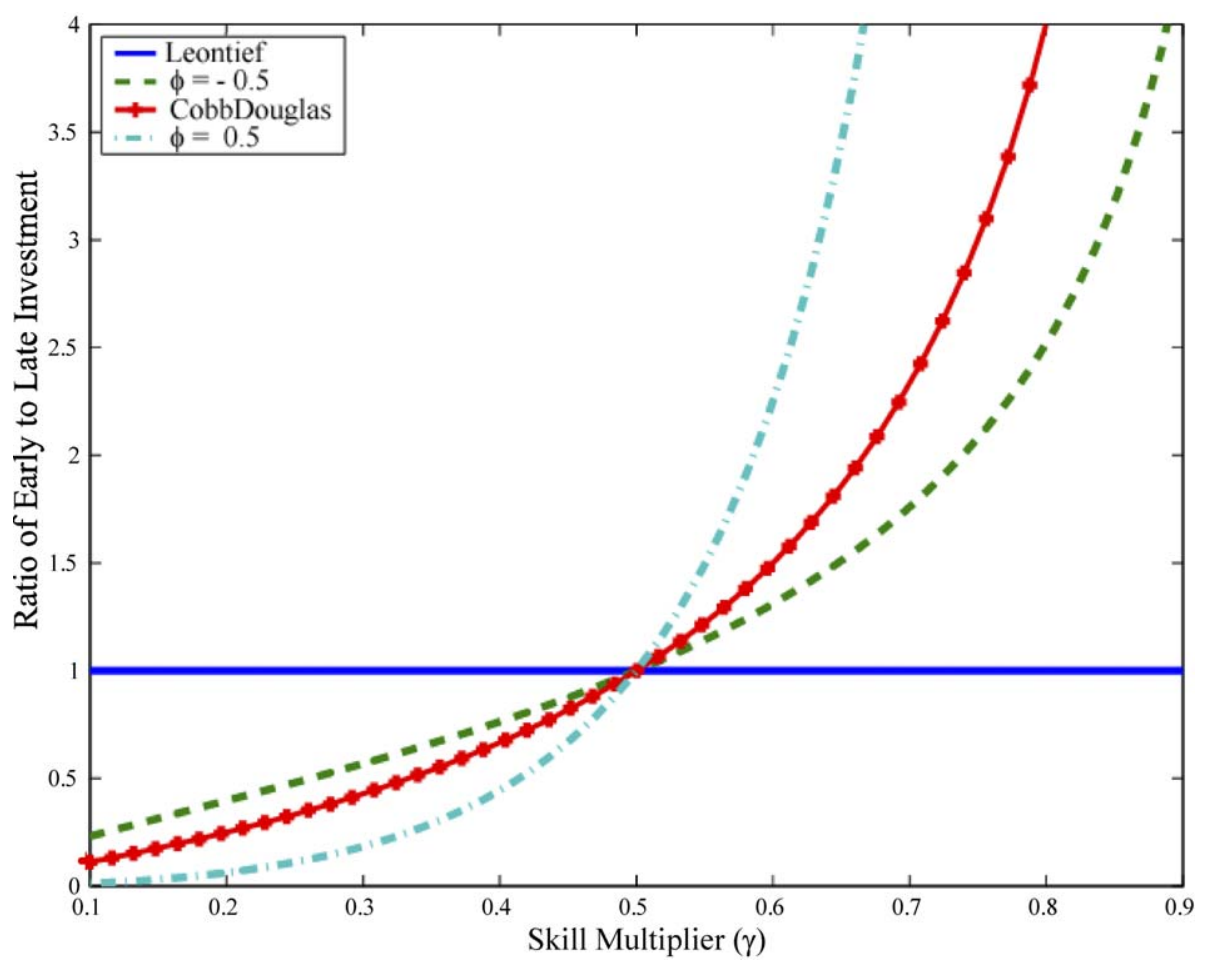

Figure 18. The ratio of early to late investment in human capital as a function of the skill multiplier for different values of complementarity.

This figure shows the optimal ratio of early to late investments, $I_{1} / I_{2}$, as a function of the skill multiplier parameter $\gamma$, for different values of the complementarity parameter $\phi$, assuming that the interest rate $r$ is zero. The optimal ratio $I_{1} / I_{2}$ is the solution of the parental problem of maximizing the present value of the child's wealth through investments in human capital, $h$, and transfers of risk-free bonds, $b$. In order to do that, parents have to decide how to allocate a total of $M$ dollars into early and late investments in human capital, $I_{1}$ and $I_{2}$, respectively, and risk-free bonds. Let $q$ denote the present value as of period " 3 " of the future prices of one efficiency unit of human capital: $q=\sum_{t=3}^{T} \frac{w_{t}}{(1+r)^{t-3}}$. The parents solve

$$
\max \left(\frac{1}{1+r}\right)^{2}[g h+b]
$$

subject to the budget constraint

$$
I_{1}+\frac{I_{2}}{(1+r)}+\frac{b}{(1+r)^{2}}=M
$$

and the technology of skill formation:

$$
h=\left[\gamma I_{1}^{\phi}+(1-\gamma) I_{2}^{\phi}\right]^{\rho / \phi}
$$

for $0<\rho<1,0 \leqslant \gamma \leqslant 1$, and $\phi \leqslant 1$. From the first-order conditions it follows that $\frac{I_{1}}{I_{2}}=\left[\frac{\gamma}{(1-\gamma)(1+r)}\right]^{\frac{1}{1-\phi}}$. This ratio is plotted in this figure when $\phi \rightarrow-\infty$ (Leontief), $\phi=-0.5, \phi=0$ (Cobb-Douglas) and $\phi=0.5$ and for values of the skill multiplier $\gamma$ between 0.1 and 0.9 . 
This expression does not depend on $\rho$. In the special case $\gamma=\frac{1+r}{2+r}$, investment will be the same in both periods regardless of the value assumed by $\phi$. More generally, the ratio of early to late investments varies with the complementarity between early and late investments, $\phi$, with the skill multiplier for human capital, $\gamma$, and with the interest rate. Ceteris paribus, the higher the skill multiplier, $\gamma$, the higher the ratio of early to late investments. Intuitively, if early investments have a substantial impact in determining future stocks of human capital, optimality implies that early investments should also be high. The higher the interest rate, the lower the ratio of early to late investments. This result reflects the opportunity costs of investing today relative to investing tomorrow. The higher the interest rate today, the cheaper it is to postpone investments. Ceteris paribus, if $\left(\frac{\gamma}{1-\gamma}\right)>(1+r)$ and $\left(\frac{I_{1}}{I_{2}}\right)>1$, the higher $\phi$, the higher $\left(\frac{I_{1}}{I_{2}}\right)$. If $\left(\frac{\gamma}{1-\gamma}\right)<$ $(1+r)$, the higher $\phi$, the lower $\left(\frac{I_{1}}{I_{2}}\right)$.

The lessons we take from this simple analysis are summarized in Table 10. When CES complementarity is high, the skill multiplier $\gamma$ plays a limited role in shaping the ratio of early to late investments. High early investments should be followed by high late investments. As the degree of CES complementarity decreases, the role of the skill multiplier increases, and the higher the multiplier, the more investments should be concentrated in the early ages.

This simple model also has implications for the timing of interventions. If $M_{A}>M_{B}$ and family $A$ is unconstrained while family $B$ is constrained, then for family $B, \lambda_{B}>0$, $\mu_{B}=\left[1+\lambda_{B}(1+r)^{2}\right]$. Consequently, in equilibrium, the marginal return to one dollar invested in the poor child from family $B$ is above the marginal return to the same dollar invested in the rich child from family $A$, so family $B$ underinvests compared to the less constrained family $A$.

Table 10

The ratio of optimal early and late investments $I_{1} / I_{2}$ under different assumptions about the skill formation technology

\begin{tabular}{lll}
\hline & Low self-productivity: & $\begin{array}{l}\text { High self-productivity: } \\
\gamma>\frac{1+r}{2+r}\end{array}$ \\
\hline High degree of complementarity: $\phi<0$ & $\frac{I_{1}}{I_{2}} \rightarrow 1$ as $\phi \rightarrow-\infty$ & $\frac{I_{1}}{I_{2}} \rightarrow 1$ as $\phi \rightarrow-\infty$ \\
Low degree of complementarity: $0 \leqslant \phi \leqslant 1$ & $\frac{I_{1}}{I_{2}} \rightarrow 0$ as $\phi \rightarrow 1$ & $\frac{I_{1}}{I_{2}} \rightarrow \infty$ as $\phi \rightarrow 1$ \\
\hline
\end{tabular}

This table summarizes the behavior of the ratio of optimal early to late investments according to four cases: $I_{1}$ and $I_{2}$ have high complementarity, but self-productivity is low; $I_{1}$ and $I_{2}$ have both high complementarity and self-productivity; $I_{1}$ and $I_{2}$ have low complementarity and self-productivity; and $I_{1}$ and $I_{2}$ have low complementarity, but high self-productivity. When $I_{1}$ and $I_{2}$ exhibit high complementary, complementarity dominates and is a force towards equal distribution of investments between early and late periods. Consequently, self-productivity plays a limited role in determining the ratio $I_{1} / I_{2}$ (row 1 ). On the other hand, when $I_{1}$ and $I_{2}$ exhibit a low degree of complementarity, self-productivity tends to concentrate investments in the late period if self-productivity is low, but in the early period if it is high (row 2). 
There is no trade-off between equity and efficiency in early childhood investments. Government policies to promote early accumulation of human capital should be targeted to the children of poor families. However, the optimal second period intervention for a child from a disadvantaged environment depends critically on the nature of human capital aggregation and function (13), the technology of skill production. If $I_{1}$ and $I_{2}$ are perfect CES complements, then a low level of $I_{1}$ cannot be compensated at any level of investment by a high $I_{2}$.

On the other hand, suppose that $\phi=1$, so the reduced form technology can be written with inputs as perfect CES substitutes:

$$
h=\left[\gamma I_{1}+(1-\gamma) I_{2}\right]^{\rho}, \quad 0 \leqslant \gamma \leqslant 1 .
$$

Then a second-period intervention can, in principle, eliminate initial skill deficits (low values of $I_{1}$ ). At a sufficiently high level of second-period investment, it is technically possible to offset low first period investments. However, it may not be cost effective to do so. For example, if $\rho=1$ and $q(1-\gamma)<1+r$, then the gains from future earnings do not justify the costs of investment. It would be more efficient to give the child a bond that earns interest rather than to invest in human capital in order to put the child at a certain level of income. Carneiro and Heckman (2003) show that classroom size reductions at current levels of funding in the U.S. are an example of such a policy.

We previously discussed the concepts of critical and sensitive periods in terms of the technical possibilities of remediation. These were defined in terms of the technology of skill formation. Here, we consider the net effects operating through investment and market substitution. The higher $\phi$, the greater are the possibilities for alleviating early disadvantage. When $\phi=1$, as in this example, it is always technically possible to remediate early disadvantage. But it may not be economically efficient to do so. From an economic point of view, critical and sensitive periods should be defined in terms of the costs and returns of remediation, and not solely in terms of technical possibilities.

Cunha and Heckman (2004, 2006) estimate a log linear (Cobb-Douglas) version of technology (3) and establish the importance of sensitive periods for parental investments in cognitive and noncognitive skills. The sensitive periods for cognitive skills occur earlier in the life cycle of the child than do the sensitive periods for noncognitive skills. Cunha, Heckman and Schennach (2006) develop and apply a methodology for estimating the key substitution parameters. We next embed the technology developed in this section into a market setting where choices and credit constraints can be clearly articulated.

\subsection{The technology of skill formation in overlapping generations economies}

In this section we embed the technology (13) developed in the preceding section into simple dynamic economies. These simple economies serve as baselines for the discussion of two conceptually distinct market failures: credit constraints in a deterministic economy, and an economy with incomplete markets with uncertainty in the labor mar- 
Table 11

The generational structure

\begin{tabular}{llllll}
\hline $\begin{array}{l}\text { Generation } \\
\text { born at period }\end{array}$ & Periods & & & \\
\cline { 2 - 5 } & $t=0$ & $t=1$ & $t=2$ & $t=3$ & $t=4$ \\
\hline-3 & Old adult & & & & \\
-2 & Young adult & Old adult & & & \\
-1 & Adolescent & Young adult & Old adult & & \\
0 & Child & Adolescent & Young adult & Old adult & \\
1 & & Child & Adolescent & Young adult & Old adult \\
2 & & & Child & Adolescent & Young adult \\
3 & & & Child & $\begin{array}{l}\text { Adolescent } \\
\text { Child }\end{array}$ \\
4 & & & & & \\
\hline
\end{tabular}

ket, as analyzed in Cunha (2004), Cunha and Heckman (2004, 2006) and subsequent work by Caucutt and Lochner (2004).

\subsubsection{Generational structure and the human capital production function}

The environment we consider is an overlapping generations economy with an infinite number of periods, each one denoted $t \in\{0,1,2, \ldots\}$. Each agent lives for four periods. In the first period of his life, the agent is a young child. In the second period of his life the agent is an adolescent. In the third period of his life, the agent is a young adult and has a child of his own. In the fourth period of his life the agent is an old adult. At the end of the old adult period, the agent dies and is replaced by the generation of his grandchild. Note that in every period there are agents of every possible demographic type (child, adolescent, young adult and old adult). Life goes on in the future in similar fashion. Table 11 describes the demographics of the economy.

\subsubsection{Formalizing the problem of the agent}

First, we describe the way agents go through life. Children and adolescents do not work. They only receive investments in human capital which may include components of their consumption. When they become young adults they conceive one child. In this setup, neither children nor adolescents have volition and make no economic decisions at this stage of their life cycles. As long as parents' and children's objectives are aligned, this assumption is not crucial, but a more general model would allow for child volition and parental actions to promote preference alignment through incentives [Akabayashi (1996), Weinberg (2001)].

The young parent starts the third period of his life with a stock of human capital (or efficiency units) $h$, an inheritance in the form of physical assets $b$, and gives birth to one child. We assume that labor supply is perfectly inelastic, so that the labor income of the parents is given by $w h$, where $w$ is the wage rate of one efficiency unit. Because the 
focus is on steady states, we assume that $w_{t}=w$ for all $t=0,1,2, \ldots$ Given $h$ and $b$, the young parent chooses consumption when he is young and old, $\left(c_{y}, c_{o}\right)$; early and late investments, $\left(I_{1}, I_{2}\right)$, in the human capital of his child; and how much to bequeath in physical capital to his child, $b^{\prime}$. " $s$ " is the savings of the young parent. Let $\beta$ be the discount factor and $r$ the interest rate. The agent's problem is to maximize the value of lifetime utility defined as

$$
V(h, b)=\max \left\{u\left(c_{y}\right)+\beta u\left(c_{o}\right)+\beta^{2} V\left(h^{\prime}, b^{\prime}\right)\right\},
$$

subject to

$$
\begin{aligned}
& c_{y}+I_{1}+\frac{s}{1+r}=w h+b, \\
& c_{o}+I_{2}+\frac{b^{\prime}}{1+r}=w h+s,
\end{aligned}
$$

and technology (13).

Cunha and Heckman (2004) close the model by introducing a firm that operates under a constant returns to scale technology and uses both human and physical capital to produce a good that can be used for consumption, human capital investment, or physical capital investment. In this chapter, we focus our attention on the behavior of investments in the child's human capital in an economy in which the equilibrium allocation is first best.

In this simple economy, the equation describing the ratio of the marginal productivity of investments is the same as equation (19) obtained in the simple static model:

$$
\frac{I_{1}}{I_{2}}=\left(\frac{\gamma}{(1-\gamma)(1+r)}\right)^{\frac{1}{1-\phi}} .
$$

Thus, the main conclusions of the simple, static model developed in Section 3.1 are valid in a more fully specified economic environment.

\subsection{The technology of skill formation in a model with credit constraints}

We now study how the technology of skill formation affects investment in human capital when we introduce market imperfections into the economy just described. Caucutt and Lochner (2004) use a general technology to analyze how the interaction between the technology of skill formation and credit constraints during different periods affects the life cycle profile of the sequence of investments in human capital. They assume that parents make monetary transfers to children every period. These transfers cannot be negative, because parents cannot extract resources from children. Here, for the sake of simplicity, we focus on the implications for the profile of investments when there exists a limit $d \geqslant 0$ on how much parents can borrow when children are young:

$$
\begin{aligned}
& s \geqslant-d, \\
& b^{\prime} \geqslant 0 .
\end{aligned}
$$


Allocations over time will depend on whether or not borrowing constraints bind. Taking the first-order condition for savings $s$ it follows that

$$
u^{\prime}\left(c_{y}\right)=\beta(1+r) u^{\prime}\left(c_{o}\right)+\beta^{-1} \lambda,
$$

where $\lambda \geqslant 0$ represents the Lagrange multiplier on the debt constraint. If $\beta(1+r)=$ 1 and the technology is described by (13), it is straightforward to show that relative investments are generated by the following equation:

$$
\log \left(\frac{I_{1}}{I_{2}}\right)=\frac{1}{1-\phi} \log \left(\frac{\gamma}{1-\gamma}\right)-\frac{1}{1-\phi} \log (1+r)+\frac{1}{1-\phi} \log \frac{u^{\prime}\left(c_{o}\right)}{u^{\prime}\left(c_{y}\right)} .
$$

Note that in comparison to first order condition (20), we acquire a new term, given by the ratio of the marginal utility of consumption, which reflects the severity of credit constraints. Investment in early childhood will be reduced with age among constrained families compared with unconstrained families.

The effects of early constraints on later investment decisions will depend on the CES-complementarity or substitutability of investment across ages. When investments are very CES-substitutable, families will tend to respond to early constraints by reallocating investments to later periods. In this case, investments during constrained periods should decline, while investments at later ages should increase to partially offset any reductions in human capital. On the other hand, when investments are very CEScomplementary over time, any reduction in early investments makes later investments less productive. If investments are strongly complementary, investment may decline at all ages in response to constraints that only bind for a few.

\subsection{The technology of skill formation in a model with market incompleteness}

We now consider a stochastic version of this model with incomplete markets, following the analyses of Cunha (2004) and Cunha and Heckman $(2004,2006) .{ }^{80}$ We focus here on the assumption that parental earnings are subject to temporary idiosyncratic shocks $\varepsilon$ (when parents are young) and $\eta$ (when parents are old). The $\varepsilon$ and $\eta$ are statistically independent. The support of $\varepsilon$ is given by the interval $\left[\varepsilon_{\min }, \varepsilon_{\max }\right]$, with $\varepsilon_{\min }>0$. The distribution of $\varepsilon$ is given by $F_{\varepsilon}$. Similarly, we have that the support of $\eta$ is given by the interval $\left[\eta_{\min }, \eta_{\max }\right]$, with $\eta_{\min }>0$. The distribution of $\eta$ is given by $F_{\eta}$. The market failure in their analysis is that there are no markets that allow agents to insure against realizations of $\varepsilon$ or $\eta$. Furthermore, parents cannot leave debts to their children. Their setup extends the framework developed in the income fluctuation literature analyzed by Schechtman (1976), Bewley (1986), Clarida (1987), Laitner (1979, 1992), Huggett (1993), and Aiyagari (1994) to account for child investment decisions.

80 Recent work by Caucutt and Lochner (2004) also considers a stochastic version of this model. 
In a simplified version of Cunha (2004) and Cunha and Heckman (2004, 2006), the problem of the parent is to maximize the utility of the parents using the recursive representation for first period preferences:

$$
V_{1}(h, b, \varepsilon)=\max _{c_{y}, I_{1}, s}\left\{u\left(c_{y}\right)+\beta E\left[V_{2}\left(h, s, I_{1}, \eta\right) \mid \varepsilon\right]\right\},
$$

where $c_{y}$ is the consumption of the parents while their children are young, subject to

$$
c_{y}+I_{1}+\frac{s}{1+r}=w h \varepsilon+b
$$

where $s$ is saving and

$$
s \geqslant-w h \eta_{\min } \text {. }
$$

The second period parental utility problem in recursive form is

$$
V_{2}\left(h, s, I_{1}, \eta\right)=\max _{c_{0}, I_{2}, b^{\prime}}\left\{u\left(c_{o}\right)+\beta E\left[V_{2}\left(h^{\prime}, b^{\prime}, \varepsilon^{\prime}\right) \mid \eta\right]\right\}
$$

where $c_{o}$ is the consumption of the parents in the second period of their child's life cycle, subject to the constraints

$$
\begin{aligned}
& c_{o}+I_{2}+\frac{b^{\prime}}{1+r}=w h \eta+s, \\
& b^{\prime} \geqslant 0,
\end{aligned}
$$

and technology (13).

Restriction (25) is what Aiyagari (1994) calls the natural borrowing limit. It arises as a combination of the restrictions that parents cannot leave negative debts to their children and that consumption cannot be negative. Note that the natural borrowing limit varies with parental human capital $h$. The higher the parental human capital, the more parents can borrow to finance consumption and early investments. The first-order condition for bequest $b^{\prime}$ may bind or not. Assuming it does not bind, the first order condition is given by

$$
-\lambda_{2} \frac{1}{1+r}+\beta \frac{\partial E\left[V_{2}\left(h^{\prime}, b^{\prime}, \varepsilon^{\prime}\right) \mid \eta\right]}{\partial b^{\prime}}=0 \quad \text { if } b^{\prime}>0 .
$$

The fact that parents cannot extract resources from their descendents has consequences for the profile of investments in the human capital of the child. The inability of the parents to leave debts for their children in order to finance human capital investments makes both early and late investments a function of parental lifetime resources. Parents who are very poor tend to invest much less, both early and late, than parents who are better off. Consequently, gaps in skill formation arise even in the early ages of child development, a fact consistent with the evidence presented in Section 2 and in an entire literature (see, e.g. the essays in Duncan and Brooks-Gunn, 1997a).

Figure 19 is reproduced from Cunha and Heckman (2004), who study educational policies in a Laitner (1992) economy. It is based on their provisional estimates for the 
The Costs of Remediation of Late vs. Early and Late Interventions

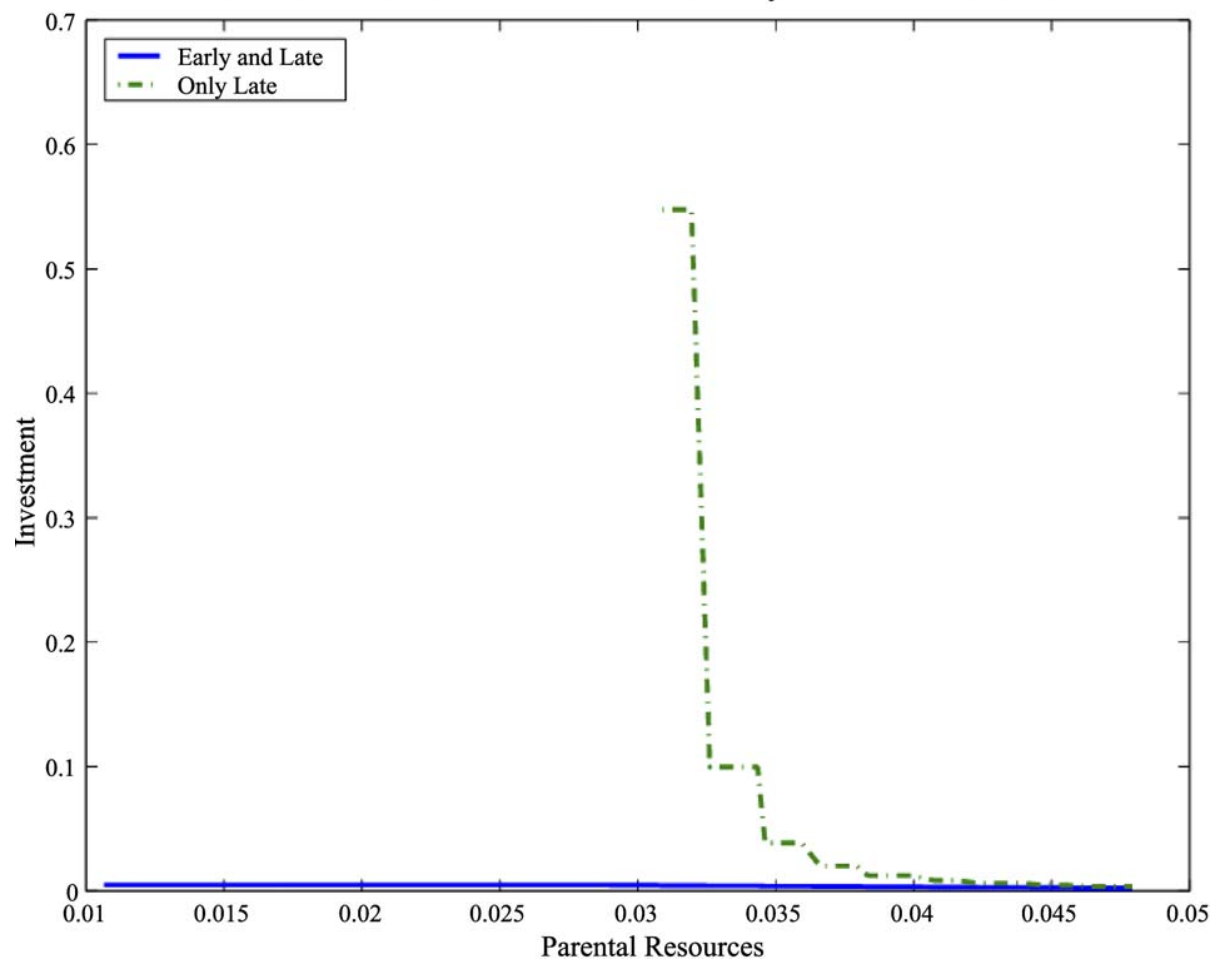

Figure 19. The costs of remediation of late vs. early and late interventions.

This figure is from Cunha and Heckman (2004), and is based on estimates reported above: $\rho=0.7012, \gamma=0.8649$, and $\phi=-0.4108$. It shows the costs of remediation when the government makes up for parental deficits in investments due to binding lifetime credit constraints. Formally, the young parents solve $V_{1}(h, b, \varepsilon)=\max \left\{u\left(c_{y}\right)+\beta E\left[V_{2}\left(h, s, I_{1}, \eta\right) \mid \varepsilon\right]\right\}$, subject to the young budget constraint $c_{y}+I_{1}+\frac{s}{1+r}=w h \varepsilon+b$, and the natural borrowing limit $s \geqslant w h \eta_{\min }$. When old, the parents solve $V_{2}\left(h, s, I_{1}, \eta\right)=\max \left\{u\left(c_{0}\right)+\beta E\left[V_{2}\left(h^{\prime}, b^{\prime}, \varepsilon^{\prime}\right) \mid \eta\right]\right\}$, subject to the budget constraint when old, $c_{0}+I_{2}+\frac{b^{\prime}}{1+r}=w h \eta+s$; the constraint that prevents parents from extracting resources from their children, $b^{\prime} \geqslant 0$; and the technology of skill formation. This figure plots the remediation costs for parents that receive no bequest in risk-free bonds, so that $b=0$. The goal is to calculate the short-run costs of implementing a policy that attains the counterfactual human capital stock of the child if parents had access to full insurance against realizations of idiosyncratic shocks. There are two ways the government can pursue this policy. In the first case, the government provides educational goods and services in both early and late investment periods. In the second case, the government intervenes only during the late investment period. The message from this figure is clear: when the government intervenes only in the late period, remediation costs are much higher than when the government acts in both periods for all levels of parental income. Furthermore, for parents with very low income, there is no amount of government-provided educational goods and services that can attain the objective of the policy. In this figure, it is assumed that the government policy is unexpected when parents allocate resources to investments. See Cunha (2004) for long-run effects of government remediation policies. 
technology of skill formation. ${ }^{81}$ It shows the costs of remediation when the government makes up for parental deficits in investments due to binding lifetime credit constraints, so that $b=0$ (that is, the parents receive no bequests from the grandparents). ${ }^{82}$ The graph plots the short-run costs, by a measure of parental resources, of a policy that attains the counterfactual human capital stock of the child that would arise if households had access to complete markets in an Arrow-Debreu sense. ${ }^{83}$ There are two ways the government can pursue this policy. In the first case, the government provides educational goods and services in both early and late investment periods. In the second case, the government intervenes only during the late investment period (e.g., a tuition policy).

The lesson from their analysis is that when the government intervenes only in the late period but not the early period and attempts to achieve a first best solution at all levels of parental income, remediation costs are much higher than when the government intervenes in both periods. Furthermore, for parents with very low income, so that early investments are very low, there is no amount of government-provided educational goods and services that can attain the objectives of the policy due to the high level of CEScomplementarity and self-productivity. ${ }^{84}$

In long-run equilibrium, the possibility of substitution among investments at different stages of the life cycle raises challenges for designing an optimal economic policy. If in the first period agents know that late investments are subsidized, such subsidies may either encourage or discourage early investments. It will discourage early investment if $I_{1}$ and $I_{2}$ are close substitutes. It will encourage early investment if $I_{1}$ and $I_{2}$ are strong complements. Empirically, the latter appears to be the relevant case. Cunha (2004) shows that for the parameter values of Cunha and Heckman (2004), a tuition subsidy causes parents to increase the amount of early investments in human capital of the child. The case for tuition subsidies lies more in their effect on early childhood investment than in their effect on alleviating credit constraints operating on the family during the child's adolescent years.

\section{Summary and conclusions}

This paper reviews the evidence on the life cycle of human skill formation and interprets it using basic economic models. The new economics of the life cycle recognizes that childhood is a multistage process where early investments feed into later investments. Skill begets skill; learning begets learning. The early influential work of Becker and

\footnotetext{
81 In recent work Cunha, Heckman and Schennach (2006) develop more refined estimates of the technology of skill formation.

82 The estimates of the parameters of (13) reported in Cunha and Heckman (2004) are $\rho=0.7012, \gamma=$ 0.8649 , and $\phi=-0.4108$.

83 By complete markets in this case we mean that parents can buy insurance against the realizations of temporary shocks in earnings $\varepsilon$ and $\eta$.

84 Note, however, that this is not the pure Leontief case.
} 
Tomes $(1979,1986)$ collapsed childhood into a single period and implicitly assumed that all investments at all ages of the child are perfect substitutes. This misses important features of the skill development process.

The evidence reported here is broadly consistent with the self-productivity of human capital investment and the complementarity of investments at different ages. Both factors combine to produce the phenomenon that skill begets skill. Complementarity implies that early investments need to be followed by later investments if the early investments are to pay off.

We formalize the concept of critical and sensitive periods and introduce the concept of the skill multiplier which captures the combined effects of complementarity and selfproductivity on the child development process. Complementarity and the skill multiplier produce no trade-off between equity and efficiency at early ages of human development but a substantial trade-off at later ages. Once skills are crystallized, complementarity implies that the returns are highest for investment in the most able. At the youngest ages, it is possible to form ability and create the complementarity that characterizes late adolescent and early adult human capital investment processes. Thus early interventions targeted toward the disadvantaged can be highly effective. Later investments are not.

The main findings of the literature can be summarized succinctly. First, abilities matter. A large number of empirical studies document that cognitive ability affects both the likelihood of acquiring advanced training and higher education, and the economic returns to those activities. Both cognitive and noncognitive abilities matter in determining participation in crime, teenage pregnancy, drug use and participation in other deviant activities. The evidence that abilities matter tells us nothing whatsoever about whether they are genetically determined.

Second, ability is multidimensional. IQ has to be distinguished from what is measured by achievement tests, although it partly determines success on achievement tests. Noncognitive skills (perseverance, motivation, self-control and the like) have direct effects on wages (given schooling), schooling, teenage pregnancy, smoking, crime and achievement tests. Both cognitive and noncognitive skills affect socioeconomic success. Both are strongly influenced by family environments. The old dichotomy between an invariant, genetically determined ability and acquired skills is a false one that still continues to influence the literature in economics. Abilities and skills are both acquired. They are influenced both by genes and the environment.

Third, ability gaps in both cognitive and noncognitive skills across individuals and across socioeconomic groups open up at early ages. They are strongly correlated with family background factors, like parental education and maternal ability, which, when controlled for in a statistical sense, largely eliminate these gaps. Inputs of schooling quality and resources have relatively small effects on early ability deficits. Parenting practices have strong effects on emotional development and motivation. This correlational evidence is supported by the experimental evidence from the Perry Preschool Program and the Abecedarian program.

Fourth, the importance of family credit constraints in the child's adolescent years in explaining college attendance (and other) differentials across socioeconomic groups is 
greatly exaggerated in the recent literature. While there is an identifiable group of families constrained in this fashion, it is not numerically large. Interventions targeted toward this group can be effective but will not substantially eliminate gaps in college attendance. The real binding constraint is the inability of children to buy favorable family environments at early ages.

Fifth, it is possible to partially compensate for adverse family environments. Evidence from randomized trials conducted on intervention programs targeted at disadvantaged children who are followed into adulthood, suggests that it is possible to eliminate some of the gaps due to early disadvantage. Enriched and sustained interventions at the youngest ages raise IQ. The Abecedarian program provided an enriched intervention for disadvantaged children starting at age 4 months. The children who received the intervention score consistently higher than the children who do not, even long after the treatment is discontinued. Later interventions like the Perry Preschool program show no lasting effect on IQ. However, effects on motivation and, hence, achievement test scores are found. Children are less likely to commit crime and have out of wedlock births and are more likely to participate in regular schooling. Early interventions have a substantial effect on adult performance and have a high economic return.

Sixth, different types of abilities appear to be manipulable at different ages. Thus, while factors affecting IQ deficits need to be addressed at very early ages for interventions to be effective, there is evidence that later interventions in the adolescent years can affect noncognitive skills as well as the knowledge measured by achievement tests. Achievement is determined by both cognitive and noncognitive factors. This evidence is rooted in the neuroscience that establishes the malleability of the prefrontal cortex into the early 20s. This is the region of the brain that governs emotion and self-regulation.

Seventh, the later the remediation, the less effective it is. Classroom remediation programs designed to combat early cognitive deficits have a poor track record. Public job training programs and adult literacy and educational programs, like the GED, that attempt to remediate years of educational and emotional neglect among disadvantaged individuals have a low economic return, and for young males, the return is negative. This evidence is consistent with strong complementarity of investment over the life cycle of the child.

Eighth, the economic returns to initial investments at early ages are high. The economic return to investment at older ages is lower. The technology of skill formation which we analyze in this essay suggests a strong skill multiplier effect of investment. Investment at an early age produces a high return through self-productivity and direct complementarity. Early investment in cognitive and noncognitive skills lowers the cost of later investment by making learning at later ages more efficient. The skill multiplier highlights the value of early investment. It also demonstrates that there is no trade-off between equity (targeting programs at disadvantaged families) and efficiency (getting the highest economic returns), provided that the investments are made at early ages. There is such a trade-off at later ages.

Ninth, CES-complementarity of early with late investments implies that early investments must be followed up by later investments in order to be effective. Nothing in the 
new economics of human skill formation suggests that we should starve later educational and skill enhancement efforts. The main finding from the recent literature is that we should prioritize, and shift our priorities, in a marginal fashion by redirecting a given total sum of expenditure on skill investment to earlier ages relative to how it is currently allocated toward disadvantaged populations that do not provide enriched environments for their children.

\section{Acknowledgements}

This research was supported by NICHD R01-34598-03 and by a grant from the Pew Charitable Trusts through the Committee for Economic Development. Cunha acknowledges support by the Claudio Haddad Dissertation Fund at the University of Chicago. Lochner acknowledges support from Social Sciences and Humanities Research Council of Canada grant 410-2004-1026. An early version of this paper was presented at a conference at the Minneapolis Federal Reserve, October 2003; at the meetings of the Society of Economic Dynamics in Florence, July 2004; at a seminar at Washington University, St. Louis in April 2004; at the Conference on Wages, Education and Risk at the Centre for Applied Microeconometrics of the Copenhagen University, sponsored by Martin Browning in August 2004; in a special Institute for Research on Poverty Lecture on Poverty in America, November 2004; at a presentation at the Chicago Labor Seminar, April 1, 2005, at the Federal Reserve Bank of Chicago; and at the Roy Geary Institute Inaugural Lecture, Dublin, April 22, 2005. We thank Pedro Carneiro, John Kennan, John Laitner and Robert Pollak for comments on the first draft. We thank Greg Duncan for helpful comments on the second draft. We thank Jeff Campbell, Jeff Grogger and Chris Taber for comments on this draft. Finola Kennedy of University College Dublin directed us to the apt quote from Marshall that begins this chapter.

\section{Appendix A}

\section{A.1. The general technology of skill formation}

Let $S_{t}$ be a $L \times 1$ vector of skills or abilities at stage $t$. Included are pure cognitive abilities (e.g., IQ) as well as noncognitive abilities (time preference, self control, patience, judgment). The notation is sufficiently flexible to include acquired skills like general education or a specific skill. Agents start out life with vector $S_{0}$ of skills (abilities). The $S_{0}$ are produced by genes and in utero environments which are known to affect child outcomes (see the essays in Keating and Hertzman, 1999).

Let $I_{t}$ be a $K \times 1$ vector of investments at stage $t$. These include all inputs invested in the child including parental and social inputs. The technology of skill formation can be written as

$$
S_{t}=f_{t}\left(S_{t-1}, I_{t}\right),
$$


where $f_{t}$ is a stage- $t$ function mapping skill (ability) levels and investment at stage $t$ into skill (ability) levels at the end of the period. For simplicity we assume that $f_{t}$ is twice continuously differentiable in its arguments. Its domain of definition is the same for all inputs. The inputs may be different at different stages of the life cycle, so the inputs in $I_{t}$ may be different from the inputs at period $\tau$ different from $t$.

Universal self-productivity at stage $t$ is defined as

$$
\frac{\partial S_{t}}{\partial S_{t-1}}=\frac{\partial f_{t}}{\partial S_{t-1}}>0
$$

In the general case this is a $L \times L$ matrix. More generally, some components of this matrix may be zero at all stages while other components may always be positive. In principle, some skills could have negative effects in some periods. At some stages, some components may be zero while at other stages they may be positive.

Universal direct complementarity at stage $t$ is defined by the $L \times K$ matrix:

$$
\frac{\partial^{2} S_{t}}{\partial S_{t-1} \partial I_{t}^{\prime}}>0
$$

Higher levels of $S_{t}$ raise the productivity of $I_{t}$. Alternatively, higher levels of $I_{t}$ raise the productivity of $S_{t}$. Again, in the general case, some components at some or all stages may have zero effects, and some may have negative effects. They can switch signs across stages.

This notation is sufficiently general to allow for the possibility that some components of skill are produced only at certain critical periods. Period $t$ is critical for skill (ability) $j$ if

$$
\frac{\partial S_{t, j}}{\partial I_{t}} \neq 0, \quad \text { for some levels of } S_{t-1}=s_{t-1}, I_{t}=i_{t},
$$

but

$$
\frac{\partial S_{t+k, j}}{\partial I_{t+k}}=0, \quad k>0, \text { for all levels of } S_{t-1}=s_{t}, I_{t}=i_{t} .
$$

Sensitive periods might be defined as those periods where, at the same level of input $S_{t-1}, I_{t}$, the $\frac{\partial S_{t}}{\partial I_{t}}$ are high. More formally, letting $S_{t-1}=s, I_{t}=i, t$ is a sensitive period for skill (or ability) $j$ if

$$
\left.\frac{\partial S_{t+k, j}}{\partial I_{t+k}}\right|_{S_{t+k-1}=s, I_{t+k}=i}<\left.\frac{\partial S_{t, j}}{\partial I_{t}}\right|_{S_{t-1}=s, I_{t}=i}, \quad \text { for all } k \neq 0 \text {. }
$$

Clearly there may be multiple sensitive periods, and there may be sensitivity with respect to one input that is not true of other inputs.

An alternative definition of critical and sensitive periods works with a version of the technology that solves out $S_{t, j}$ as a function of lagged investments and initial conditions $S_{0}=s_{0}$ :

$$
S_{t, j}=M_{t, j}\left(I_{t}, I_{t-1}, \ldots, I_{1}, S_{0}\right), \quad S_{0}=s_{0}, j=1, \ldots, J .
$$


Stage $t^{*}$ is a critical period for $S_{t, j}$ if investments are productive at $t^{*}$ but not at any other stage $k \neq t^{*}$. Formally,

$$
\frac{\partial S_{t, j}}{\partial I_{k}}=\frac{\partial M_{t, j}\left(I_{t}, I_{t-1}, \ldots, I_{1}, S_{0}\right)}{\partial I_{k}} \equiv 0, \quad k \neq t^{*}, j=1, \ldots, J,
$$

for all $S_{0}, I_{1}, \ldots, I_{t}$, but

$$
\frac{\partial S_{t, j}}{\partial I_{t^{*}}}=\frac{\partial M_{t, j}\left(I_{t}, I_{t-1}, \ldots, I_{1}, S_{0}\right)}{\partial I_{t^{*}}}>0, \quad j=1, \ldots, J,
$$

for some $S_{0}, I_{1}, \ldots, I_{t}$.

Stage $t^{*}$ is a sensitive period for $S_{t, j}$ if at the same level of inputs, investment is more productive at stage $t^{*}$ than at stage $t$. Formally, $t^{*}$ is a sensitive period for $S_{t, j}$ if for $k \neq t^{*}$,

$$
\left.\frac{\partial S_{t, j}}{\partial I_{k}}\right|_{S_{0}=s_{0}, I_{k}=i_{k}, k=1, \ldots, t, k \neq t^{*}} \leqslant\left.\frac{\partial S_{t, j}}{\partial I_{t^{*}}}\right|_{S_{0}=s_{0}, I_{k}=i_{k}, k=1, \ldots, t} .
$$

The inequality is strict for at least one period $k=1, \ldots, t, k \neq t^{*}$.

This definition of critical periods agrees with the previous one. Our second definition of sensitive periods may not agree with the previous one, which is defined only in terms of the effect of investment on the next period's output. The second definition fixes the period at which output is measured and examines the marginal productivity of inputs in producing the output. It allows for feedback effects of the investment in $j$ on output beyond $j$ through self-productivity in a way that the first definition does not.

At each stage $t$, agents can perform certain tasks. The level of performance in task $l$ at stage $t$ is $T_{l, t}=T_{l, t}\left(S_{t}\right)$. For some tasks, and some stages, components of $S_{t}$ may be substitutes or complements. Thus we distinguish complementarity or substitution in skills (abilities) in stage $t$ in task performance from complementarity or substitution in skill production. Agents deficient in some skills may specialize in some tasks. This is an alternative form of remediation compared to remediation through skill investment.

\section{A.2. Relationship with the Ben-Porath (1967) model}

The conventional formulation of the technology of skill formation is due to Ben-Porath. Let $h_{t}$ be a scalar human capital. This corresponds to a model with one skill (general human capital) and one task. In his setup, $T_{t}\left(S_{t}\right)=h_{t}\left(S_{t}\right)$. Ben-Porath makes the additional (implicit) assumption that $h_{t}\left(S_{t}\right)=h\left(S_{t}\right)$. His model postulates that human capital at time $t+1$ depends on human capital at $t$, invariant ability (denoted $\theta$ ), and investment at $t, I_{t}$. $I_{t}$ may be a vector. The same type of investments are made at each stage. Skill is measured in the same units over time. His specification of the investment technology is

$$
h_{t+1}=f\left(I_{t}, h_{t}, \theta\right) \text {, }
$$


where $f$ is concave in $I_{t}$. The technology is specialized further to allow for depreciation of scalar human capital at rate $\sigma$. Thus we obtain

$$
h_{t+1}=g\left(I_{t}, h_{t}, \theta\right)+(1-\sigma) h_{t} .
$$

When $\sigma=0$, there is no depreciation. " $h_{t}$ " is carried over (not fully depreciated) as long as $\sigma<1$.

Self-productivity in his model arises when $\frac{\partial h_{t+1}}{\partial h_{t}}=\frac{\partial g\left(\theta, h_{t}, I_{t}\right)}{\partial h_{t}}+(1-\sigma)>0$. This comes from two sources: a carry over effect, $(1-\sigma)>0$, arising from the human capital that is not depreciated, and the effect of $h_{t}$ on gross investment $\left(\frac{\partial g\left(\theta, h_{t}, I_{t}\right)}{\partial h_{t}}>0\right)$. If $g\left(I_{t}, h_{t}, \theta\right)=\phi_{1}\left(h_{t}, \theta\right)+\phi_{2}\left(I_{t}, \theta\right)$, there is no essential distinction between $(1-\sigma) h_{t}$ and $g\left(I_{t}, h_{t}, \theta\right)$ as sources of self-productivity if we allow $\sigma$ to depend on $\theta(\sigma(\theta))$.

Complementarity of all inputs is

$$
\frac{\partial^{2} g\left(I_{t}, h_{t}, \theta\right)}{\partial h_{t} \partial I_{t}^{\prime}}>0 .
$$

In a more general case, some components of this vector may be negative or zero. In the case of universal complementarity, the stock of $h_{t}$ raises the marginal productivity of $I_{t}$. Direct complementarity and self-productivity, singly and together, show why skill begets skill. Our model generalizes the Ben-Porath model by (a) allowing for different skill formation technologies at different stages; (b) allowing qualitatively different investments at different stages; (c) allowing for both skill and ability formation and (d) considering the case of vector skills and abilities.

\section{References}

Aiyagari, S.R. (1994). "Uninsured idiosyncratic risk and aggregate saving". Quarterly Journal of Economics 109 (3), 659-684.

Aiyagari, S.R., Greenwood, J., Seshadri, A. (2002). "Efficient investment in children". Journal of Economic Theory 102 (2), 290-321.

Akabayashi, H. (1996). On the Role of Incentives in the Formation of Human Capital in the Family. Ph.D. Thesis, University of Chicago.

Altonji, J.G., Dunn, T.A. (1996). "The effects of family characteristics on the return to education". Review of Economics and Statistics 78 (4), 692-704.

Altonji, J.G., Elder, T.E., Taber, C.R. (2005). "Selection on observed and unobserved variables: Assessing the effectiveness of catholic schools". Journal of Political Economy 113 (1), 151-184.

Armor, D.J. (2003). Maximizing Intelligence. Transaction Publishers, New Brunswick, NJ.

Armor, D.J., Roll Jr., C.R. (1994). "Military manpower quality: Past, present, future". In: Green Jr., B.F., Mavor, A.S. (Eds.), Modeling Cost and Performance for Military Enlistment: Report of a Workshop. National Academy Press, Washington, DC, pp. 13-34.

Barnett, W.S. (2004). "Benefit-cost analysis of preschool education". PowerPoint presentation. November. Available at: http://nieer.org/resources/files/BarnettBenefits.ppt.

Barnett, W.S., Masse, L.N. (2002). "A benefit-cost analysis of the Abecedarian early childhood intervention". Technical report. National Institute for Early Education Research (NIEER), New Brunswick, NJ.

Becker, G.S. (1964). Human Capital: A Theoretical and Empirical Analysis, with Special Reference to Education. National Bureau of Economic Research, New York. Distributed by Columbia University Press. 
Becker, G.S., Tomes, N. (1979). "An equilibrium theory of the distribution of income and intergenerational mobility”. Journal of Political Economy 87 (6), 1153-1189.

Becker, G.S., Tomes, N. (1986). "Human capital and the rise and fall of families". Journal of Labor Economics 4 (3, Part 2), S1-S39.

Belfield, C.R., Nores, M., Barnett, W.S. (2004). "The high/scope Perry pre-school program: Cost-benefit analysis using data from the age-40 follow-up". Technical report. National Institute for Early Education Research (NIEER), New Brunswick, NJ.

Ben-Porath, Y. (1967). "The production of human capital and the life cycle of earnings". Journal of Political Economy 75 (4, Part 1), 352-365.

Benabou, R. (2000). "Unequal societies: Income distribution and the social contract". American Economic Review 90 (1), 96-129.

Benabou, R. (2002). "Tax and education policy in a heterogeneous agent economy: What levels of redistribution maximize growth and efficiency?" Econometrica 70 (2), 481-517.

Bewley, T.F. (1986). "Stationary monetary equilibrium with a continuum of independently fluctuating consumers". In: Hildenbrand, W., Mas-Collel, A. (Eds.), Contributions to Mathematical Economics in Honor of Gerard Debreu. North-Holland, Amsterdam.

Blossfeld, H.-P., Shavit, Y. (1993). Persistent Inequality: Changing Educational Attainment in Thirteen Countries. Westview Press, Boulder, CO.

Bowles, S., Gintis, H. (1976). Schooling in Capitalist America: Educational Reform the Contradictions of Economic Life. Basic Books, New York.

Brooks-Gunn, J., Berlin, L.J., Fuligni, A.S. (2000). "Early childhood intervention programs: What about the family?”. In: Meisels, S., Shonkoff, J. (Eds.), The Handbook of Early Childhood Interventions. Cambridge University Press, New York, pp. 549-588.

Brooks-Gunn, J., Gross, R., Kraemer, H., Spiker, D., Shapiro, S. (1992). "Enhancing the cognitive outcomes of low birth weight, premature infants: For whom is the intervention most effective?" Pediatrics 89 (6, Part 2), 1209-1215.

Bruer, J.T. (1999). The Myth of the First Three Years: A New Understanding of Early Brain Development and Lifelong Learning. Free Press, New York.

Bureau of Labor Statistics (2001). NLS Handbook 2001: The National Longitudinal Surveys. U.S. Department of Labor, Washington, DC.

Cameron, J. (2004). "Evidence for an early sensitive period for the development of brain systems underlying social affiliative behavior". Unpublished manuscript. Oregon National Primate Research Center.

Cameron, S.V., Heckman, J.J. (1998). "Life cycle schooling and dynamic selection bias: Models and evidence for five cohorts of American males". Journal of Political Economy 106 (2), 262-333.

Cameron, S.V., Heckman, J.J. (1999). “Can tuition policy combat rising wage inequality?” In: Kosters, M. (Ed.), Financing College Tuition: Government Policies and Educational Priorities. AEI Press, Washington, DC, Chapter 5, p. 125.

Cameron, S.V., Heckman, J.J. (2001). "The dynamics of educational attainment for black, Hispanic, and white males". Journal of Political Economy 109 (3), 455-499.

Cameron, S.V., Taber, C. (2004). "Estimation of educational borrowing constraints using returns to schooling”. Journal of Political Economy 112 (1), 132-182.

Card, D. (1999). "The causal effect of education on earnings". In: Ashenfelter, O., Card, D. (Eds.), Handbook of Labor Economics, vol. 5. North-Holland, New York, pp. 1801-1863.

Card, D. (2001). "Estimating the return to schooling: Progress on some persistent econometric problems". Econometrica 69 (5), 1127-1160.

Cardak, B.A., Givon, D. (2004). "Why the poor don't go to university: Attainment constraints and twostaged education.” Presented at the Fifth APET International Conference on Public Economics, Peking University, Beijing, China, 25-29 August, 2004.

Carneiro, P. (2002). "Heterogeneity in the returns to schooling: Implications for policy evaluation." Ph.D. thesis, University of Chicago.

Carneiro, P., Hansen, K., Heckman, J.J. (2001). "Removing the veil of ignorance in assessing the distributional impacts of social policies". Swedish Economic Policy Review 8 (2), 273-301. 
Carneiro, P., Hansen, K., Heckman, J.J. (2003). "Estimating distributions of treatment effects with an application to the returns to schooling and measurement of the effects of uncertainty on college choice". International Economic Review 44 (2), 361-422. 2001 Lawrence R. Klein Lecture.

Carneiro, P., Heckman, J.J. (2002). "The evidence on credit constraints in post-secondary schooling”. Economic Journal 112 (482), 705-734.

Carneiro, P., Heckman, J.J. (2003). "Human capital policy". In: Heckman, J.J., Krueger, A.B., Friedman, B.M. (Eds.), Inequality in America: What Role for Human Capital Policies? MIT Press, Cambridge, MA.

Carneiro, P., Heckman, J.J., Masterov, D.V. (2005). "Labor market discrimination and racial differences in pre-market factors". Journal of Law and Economics 48 (1), 1-39.

Caucutt, E., Kumar, K. (2003). "Higher education subsidies and heterogeneity: A dynamic analysis". Journal of Economic Dynamics and Control 27 (8), 1459-1502.

Caucutt, E., Lochner, L.J. (2004). "Early and late human capital investments, credit constraints, and the family". Unpublished manuscript. University of Western Ontario, Department of Economics.

Cawley, J., Heckman, J.J., Lochner, L.J., Vytlacil, E.J. (2000). "Understanding the role of cognitive ability in accounting for the recent rise in the return to education". In: Arrow, K., Bowles, S. (Eds.), Meritocracy and Economic Inequality. Princeton University Press, Princeton, NJ.

Clarida, R.H. (1987). "Consumption, liquidity constraints and asset accumulation in the presence of random income fluctuations". International Economic Review 28 (2), 339-351.

Cunha, F. (2004). Skill formation in a laitner economy. Ph.D. Thesis. University of Chicago.

Cunha, F., Heckman, J.J. (2004). "The technology of skill formation”. Unpublished manuscript, University of Chicago, presented at AEA Meetings, January 2003, San Diego, CA, and Federal Reserve Bank of Minneapolis, October 2004 and Society for Economic Dynamics Meetings in Florence, Italy, 2004. Revised May 2005 for presentation at the Society for Economic Dynamics and Control.

Cunha, F., Heckman, J.J. (2006). "Formulating identifying and estimating the technology of cognitive and noncognitive skill formation". Unpublished manuscript. University of Chicago, Department of Economics.

Cunha, F., Heckman, J.J., Navarro, S. (2005). "Separating uncertainty from heterogeneity in life cycle earnings, the 2004 Hicks lecture". Oxford Economic Papers 57 (2), 191-261.

Cunha, F., Heckman, J.J., Schennach, S.M. (2006). "Estimating the technology of cognitive and noncognitive skill formation". Unpublished manuscript, University of Chicago, Department of Economics. Presented at the Yale Conference on Macro and Labor Economics, May 5-7, 2006.

Currie, J. (2001). "Early childhood education programs". Journal of Economic Perspectives 15 (2), $213-238$.

Currie, J., Blau, D. (2006). "Who's minding the kids? Preschool day care, and after school care, and after school case". In: Welch, F., Hanushek, E. (Eds.), Handbook of the Economics of Education. Elsevier, Amsterdam. In Volume 2 of this Handbook.

Currie, J., Thomas, D. (2000). "School quality and the longer-term effects of head start". Journal of Human Resources 35 (4), 755-774.

Donohue, J.J., Siegelman, P. (1998). "Allocating resources among prisons and social programs in the battle against crime". Journal of Legal Studies 27 (1), 1-43. January.

Duncan, G., Claessens, A., Engel, M. (2004). "The contributions of hard skills and socio-emotional behavior to school readiness". Unpublished manuscript. Northwestern University.

Duncan, G.J., Brooks-Gunn, J. (1997a). Consequences of Growing Up Poor. Russell Sage Foundation, New York.

Duncan, G.J., Brooks-Gunn, J. (1997b). "Income effects across the life span: Integration and interpretation". In: Duncan, G., Brooks-Gunn, J. (Eds.), Consequences of Growing Up Poor. Russell Sage Foundation, New York, pp. 596-610.

Dynarski, S.M. (2000). "Hope for whom? Financial aid for the middle class and its impact on college attendance". National Tax Journal 53 (3, Part 2), 629-661.

Dynarski, S.M. (2003). "Does aid matter? Measuring the effect of student aid on college attendance and completion". American Economic Review 93 (1), 279-288.

Edwards, R.C. (1976). "Individual traits and organizational incentives: What makes a "good" worker?" Journal of Human Resources 11 (1), 51-68. 
Ellwood, D.T., Kane, T.J. (2000). "Who is getting a college education? Family background and the growing gaps in enrollment". In: Danziger, S., Waldfogel, J. (Eds.), Securing the Future: Investing in Children from Birth to College. Russell Sage Foundation, New York, pp. 283-324.

Fisher, I. (1982). "Mathematical investigations in the theory of value and prices". Transactions of the Connecticut Academy of Arts and Sciences 9, 1-124.

Flynn, J.R. (1987). "Massive IQ gains in 14 nations: What IQ tests really measure". Psychological Bulletin 101, 171-191.

Fuerst, J., Fuerst, D. (1993). "Chicago experience with an early childhood program: The special case of the child parent center program". Urban Education 28 (1), 69-96.

Garber, H.L. (1988). The Milwaukee Project: Preventing Mental Retardation in Children at Risk. American Association on Mental Retardation, Washington, DC.

Garces, E., Thomas, D., Currie, J. (2002). "Longer-term effects of head start". American Economic Review 92 (4), 999-1012.

Gomby, D.S., Larson, C.S., Lewit, E.M., Behrman, R.E. (1999). "Home visiting: Recent program evaluations - analysis and recommendations". The Future of Children 9 (1), 4-26.

Gormley, W., Gayer, T., Phillips, D., Dawson, B. (2004). "The effect of universal pre-K on cognitive development". Unpublished manuscript. Georgetown University.

Gray, S.W., Ramsey, B.K., Klaus, R.A. (1982). From 3 to 20: The Early Training Project. University Park Press, Baltimore, MD.

Griliches, Z. (1977). "Estimating the returns to schooling: Some econometric problems". Econometrica 45 (1), 1-22.

Grogger, J., Neal, D. (2000). "Further evidence of the effects of catholic secondary schooling". BrookingsWharton Papers on Urban Affairs, 151-193.

Hansen, K.T., Heckman, J.J., Mullen, K.J. (2004). "The effect of schooling and ability on achievement test scores". Journal of Econometrics 121 (1-2), 39-98.

Hanushek, E., Leung, C.K.Y., Yilmaz, K. (2004). "Borrowing constraints, college aid, and intergenerational mobility". Technical Report 10711, NBER.

Hayek, F.A.V (1941). The Pure Theory of Capital. University of Chicago Press, Chicago.

Heckman, J.J. (1995). "Lessons from the bell curve". Journal of Political Economy 103 (5), 1091.

Heckman, J.J. (1999). "Doing it right: Job training and education". The Public Interest 135, 86-107.

Heckman, J.J. (2000). "Policies to foster human capital". Research in Economics 54 (1), 3-56. With discussion.

Heckman, J.J. (2005). "Invited comments". In: Schweinhart, L.J., Montie, J., Xiang, Z., Barnett, W.S., Belfield, C.R., Nores, M. (Eds.), Lifetime Effects: The High/Scope Perry Preschool Study Through Age 40. Monographs of the High/Scope Educational Research Foundation, vol. 14. High/Scope, Ypsilanti, MI, pp. 229-233.

Heckman, J.J., LaFontaine, P. (2007). America's Dropout Problem: The GED and the Importance of Social and Emotional Skills. University of Chicago Press, Chicago. In press.

Heckman, J.J., LaLonde, R.J., Smith, J.A. (1999). "The economics and econometrics of active labor market programs". In: Ashenfelter, O., Card, D. (Eds.), Handbook of Labor Economics, vol. 3A. North-Holland, New York. Chapter 31, pp. 1865-2097.

Heckman, J.J., Larenas, M.I., Urzua, S. (2004). "Accounting for the effect of schooling and abilities in the analysis of racial and ethnic disparities in achievement test scores". Unpublished manuscript. University of Chicago, Department of Economics.

Heckman, J.J., Lochner, L.J. (2000). "Rethinking myths about education and training: Understanding the sources of skill formation in a modern economy”. In: Danziger, S., Waldfogel, J. (Eds.), Securing the Future: Investing in Children from Birth to College. Russell Sage Foundation, New York.

Heckman, J.J., Lochner, L.J., Smith, J., Taber, C. (1997). "The effects of government policy on human capital investment and wage inequality". Chicago Policy Review 1 (2), 1-40.

Heckman, J.J., Lochner, L.J., Taber, C. (1998). "Explaining rising wage inequality: explorations with a dynamic general equilibrium model of labor earnings with heterogeneous agents". Review of Economic Dynamics 1 (1), 1-58. 
Heckman, J.J., Lochner, L.J., Todd, P.E. (2006). "Earnings equations and rates of return: The Mincer equation and beyond". In: Hanushek, E.A., Welch, F. (Eds.), Handbook of the Economics of Education. Elsevier, Amsterdam. In this Handbook.

Heckman, J.J., Rubinstein, Y. (2001). "The importance of noncognitive skills: Lessons from the GED testing program". American Economic Review 91 (2), 145-149.

Heckman, J.J., Savelyev, P., Yavitz, A. (2006). "The Perry preschool project: A reanalysis". Unpublished manuscript, University of Chicago, Department of Economics.

Heckman, J.J., Stixrud, J., Urzua, S. (2006). "The effects of cognitive and noncognitive abilities on labor market outcomes and social behavior". Journal of Labor Economics 24 (3), 411-482.

Heckman, J.J., Vytlacil, E.J. (2005). "Structural equations, treatment effects and econometric policy evaluation". Econometrica 73 (3), 669-738.

Heckman, J.J., Vytlacil, E.J. (2007a). "Econometric evaluation of social programs, part I: Causal models, structural models and econometric policy evaluation". In: Heckman, J., Leamer, E. (Eds.), Handbook of Econometrics, vol. 6. Elsevier, Amsterdam. In press.

Heckman, J.J., Vytlacil, E.J. (2007b). "Econometric evaluation of social programs, part II: Using the marginal treatment effect to organize alternative economic estimators to evaluate social programs and to forecast their effects in new environments". In: Heckman, J., Leamer, E. (Eds.), Handbook of Econometrics, vol. 6. Elsevier, Amsterdam. In press.

Herrera, C., Sipe, C.L., McClanahan, W.S. (2000). Mentoring School-Age Children: Relationship Development in Community-Based and School-Based Programs. Public/Private Ventures, Philadelphia, PA.

Herrnstein, R.J., Murray, C.A. (1994). The Bell Curve: Intelligence and Class Structure in American Life. Free Press, New York.

Huggett, M. (1993). "The risk-free rate in heterogeneous-agent incomplete-insurance economies". Journal of Economic Dynamics and Control 17 (5-6), 953-969.

Jensen, A.R. (1980). Bias in Mental Testing. Free Press, New York.

Johnson, A.W. (1996). An Evaluation of the Long-Term Impacts of the Sponsor-A-Scholar Program on Student Performance. Mathematica Policy Research, Princeton, NJ.

Johnson, D.L. (1988). "Primary prevention of behavior problems in young children: The Houston parentchild development center". In: Cowen, E., Price, R., Ramos-McKay, J., Lorion, R. (Eds.), 14 Ounces of Prevention: A Casebook for Practitioners. American Psychological Association, Washington, DC, pp. 4452. Chapter 4.

Judd, K.L. (2000). "Is education as good as gold? A portfolio analysis of human capital investment." Unpublished working paper. Hoover Institution, Stanford University.

Kane, T.J. (1994). "College entry by blacks since 1970: The role of college costs, family background, and the returns to education". Journal of Political Economy 102 (5), 878-911.

Kane, T.J. (1996). "College cost, borrowing constraints and the timing of college entry”. Eastern Economic Journal 22 (2), 181-194.

Kane, T.J. (1999). The Price of Admission: Rethinking How Americans Pay for College. Brookings Institution, Washington, DC.

Karoly, L.A. (2001). "Investing in the future: Reducing poverty through human capital investments". In: Danziger, S., Haveman, R. (Eds.), Understanding Poverty. Russell Sage Foundation, New York, pp. 314356.

Karoly, L.A., Greenwood, P.W., Everingham, S.S., Hoube, J., Kilburn, M.R., Rydell, C.P., Sanders, M., Chiesa, J. (1998). Investing in Our Children: What We Know and Don't Know About the Costs and Benefits of Early Childhood Interventions. RAND, Santa Monica, CA.

Keane, M.P., Wolpin, K.I. (2001). "The effect of parental transfers and borrowing constraints on educational attainment". International Economic Review 42 (4), 1051-1103.

Keating, D.P., Hertzman, C. (1999). Developmental Health and the Wealth of Nations: Social, Biological, and Educational Dynamics. Guilford Press, New York.

Klein, R., Spady, R., Weiss, A. (1991). "Factors affecting the output and quit propensities of production workers". Review of Economic Studies 58 (5), 929-953. 
Knight, F.H. (1944). "Diminishing returns from investment”. Journal of Political Economy 52 (1), $26-47$.

Knudsen, E.I. (2004). "Sensitive periods in the development of the brain and behavior". Journal of Cognitive Neuroscience 16 (1), 1412-1425.

Knudsen, E.I., Heckman, J.J., Cameron, J., Shonkoff, J.P. (2006). "Economic, neurobiological, and behavioral perspectives on building America's future workforce". Proceedings of the National Academy of Sciences 103 (27), 10155-10162.

Laitner, J. (1979). "Household bequest behaviour and the national distribution of wealth". Review of Economic Studies 46 (3), 467-483.

Laitner, J. (1992). "Random earnings differences, lifetime liquidity constraints, and altruistic intergenerational transfers". Journal of Economic Theory 58 (2), 135-170.

Lally, J.R., Manggione, P.L., Honig, A.S. (1988). "Syracuse university family development research program: Long-range impact of an early intervention with low-income children and their families". In: Powell, D.R. (Ed.), Parent Education as Early Childhood Intervention: Emerging Directions in Theory, Research, and Practice. Ablex Publishing Company, Norwood, NJ, pp. 79-104.

Levenstein, P., O'Hara, J., Madden, J. (1983). "The mother-child program of the verbal interaction project." In: Consortium for Longitudinal Studies (Ed.), As the Twig is Bent: Lasting Effects of Preschool Programs. Erlbaum, Hillsdale, NJ.

Levy, D., Duncan, G.J. (2000). "Using sibling samples to assess the effect of childhood family income on completed schooling." Working paper, JCPR.

Lochner, L.J., Monge, A. (2004). "Education default incentives with government student loan programs". Unpublished manuscript. University of Western Ontario, Department of Economics.

Long, D.A., Mallar, C.D., Thornton, C.V. (1981). "Evaluating the benefits and costs of the job corps". Journal of Policy Analysis and Management 1 (1), 55-76.

Love J.M., Eliason-Kisker, E., Ross C.M., Schochet, P.Z., Brooks-Gunn, J. Paulsell, D., Boller, K. Constantine, J., Vogel, C. Sidle Fuligni, A., Brady-Smith, C. (2002). "Making a difference in the lives of infants and toddlers and their families: The impacts of early head start". Technical Report PR02-30a, Mathematica Policy Research Report.

Magnuson, K.A., Meyers, M., Ruhm, C.J., Waldfogel, J. (2004). "Inequality in preschool education and school readiness". American Educational Research Journal 41 (1), 115-157.

Magnuson, K.A., Ruhm, C.J., Waldfogel, J. (2004). "Does prekindergarten improve school preparation and performance?” Technical Report 10452, NBER.

Marshall, A. (1890). Principles of Economics. Macmillan, New York.

Maxfield, M., Schirm, A., Rodriguez-Planas, N. (2003). "The quantum opportunity program demonstration: Implementation and short-term impacts”. Technical Report, MPR reference No. 8279-093, Mathematica Policy Research, Washington, DC.

McCarton, C.M., Brooks-Gunn, J., Wallace, I.F., Bauer, C., Bennett, F.C., Bernbaum, J.C., Broyles, R.S., Casey, P.H., McCormick, M.C., Scott, D.T., Tyson, J., Tonascia, J., Meinert, C.L. (1997). "Age 8 years of early intervention for low-birth-weight premature infants: The infant health and development program". Journal of the American Medical Association 277 (2), 126-132.

Meaney, M.J. (2001). "Maternal care, gene expression, and the transmission of individual differences in stress reactivity across generations". Annual Review of Neuroscience 24 (1), 1161-1192.

Meghir, C., Palme, M. (1999). "Assessing the effect of schooling on earnings using a social experiment." Technical Report W99/10, IFS.

Monroe, E., McDonald, M.S. (1981). "Follow up study of the 1966 Head Start program, Rome city schools, Rome, Georgia.” Unpublished manuscript, Georgia Public Schools.

Morris, P., Duncan, G.J., Clark-Kauffman, E. (2005). "Child well-being in an era of welfare reform: The sensitivity of transitions in development to policy change". Developmental Psychology 41 (6), 919-932.

Moskoff, W. (1980). "Pronatalist policies in Romania". Economic Development and Cultural Change 28 (3), 597-614.

Mulligan, C.B. (1997). Parental Priorities and Economic Inequality. University of Chicago Press, Chicago, IL. 
Navarro, S. (2005). "Understanding schooling: Using observed choices to infer agent's information in a dynamic model of schooling choice when consumption allocation is subject to borrowing constraints". Ph.D. dissertation, University of Chicago, Chicago, IL.

Newport, E.L. (2002). “Critical periods in language development”. In: Nadel, L. (Ed.), Encyclopedia of Cognitive Science. Macmillan/Nature Publishing Group, London, pp. 737-740.

O’Connor, T.G., Rutter, M., Beckett, C., Keaveney, L., Kreppner, J.M., The English and Romanian Adoptees Study Team (2000). "The effects of global severe privation on cognitive competence: Extension and longitudinal follow-up". Child Development 71 (2), 376-390.

Olds, D.L. (2002). "Prenatal and infancy home visiting by nurses: From randomized trials to community replication". Prevention Science 3 (2), 153-172.

Orfield, G. (1992). "Money, equity, and college access". Harvard Educational Review 62 (3), 337-372.

Palmer, F. (1983). "The Harlem study: Effects by type of training, age of training and social class." In: Consortium for Longitudinal Studies (Ed.), As the Twig is Bent: Lasting Effects of Preschool Programs. Lawrence Erlbaum, Hillsdale, NJ.

Pinker, S. (1994). The Language Instinct: How the Mind Creates Language. W. Morrow, New York.

Ramey, C.T., Bryant, D.M., Wasik, B.H., Sparling, J.J., Campbell, F.A. (1988). "Early intervention for highrisk children: The Carolina early intervention program”. In: Price, R.H. (Ed.), 14 Ounces of Prevention: A Casebook for Practitioners. American Psychological Association, Washington, DC.

Reynolds, A.J., Ou, S.-R., Topitzes, J.W. (2004). "Paths of effects of early childhood interventions on educational attainment and deliquency: A confirmatory analysis of the Chicago parent-child centers". Child Development 75 (5), 1299-1328.

Robinson, G.E., Grozinger, C.M., Whitfield, C.W. (2005). "Sociogenomics: Social life in molecular terms". Nature Review Genetics 6 (4), 257-270.

Rolnick, A., Grunewald, R. (2003). "Early childhood development: Economic development with a high public return.” Technical Report. Federal Reserve Bank of Minneapolis, Minneapolis, MN.

Rosapepe, J.C. (2001). "Half way home: Romania's abandoned children ten years after the revolution". Report of the US Ambassador to Romania, accessed on 12/05/2004.

Rutter, M.A., The English and Romanian Adoptees Study Team (1998). "Developmental catch-up, and deficit, following adoption after severe global early privation". Journal of Child Psychology and Psychiatry 39 (4), 465-476.

Samuelson, P.A. (1974). "Complementarity: An essay on the 40th anniversary of the Hicks-Allen revolution in demand theory". Journal of Economic Literature 12 (4), 1255-1289.

Schechtman, J. (1976). "An income fluctuation problem". Journal of Economic Theory 12 (2), 218-241.

Schweinhart, L.J., Barnes, H.V., Weikart, D. (1993). Significant Benefits: The High-Scope Perry Preschool Study Through Age 27. High/Scope Press, Ypsilanti, MI.

Seitz, V. (1990). "Intervention programs for impoverished children: A comparison of educational and family support models". In: Vasta, R. (Ed.), Annals of Child Development: A Research Annual, vol. 7. Jessica Kingsley, London, pp. 73-103.

Seshadri, A., Yuki, K. (2004). "Equity and efficiency effects of redistributive policies". Journal of Monetary Economics 51 (7), 1415-1447.

Shonkoff, J.P., Phillips, D. (2000). From Neurons to Neighborhoods: The Science of Early Child Development. National Academy Press, Washington, DC.

Spence, A.M. (1973). “Job market signaling”. Quarterly Journal of Economics 87 (3), 355-374.

Stanley, M. (2003). "College education and the midcentury GI bills". Quarterly Journal of Economics 118 (2), 671-708.

Sternberg, R.J. (1985). Beyond IQ: A Triarchic Theory of Human Intelligence. Cambridge University Press, New York.

Stiglitz, J.E. (1975). "The theory of 'screening', education, and the distribution of income". American Economic Review 65 (3), 283-300.

Stinebrickner, R., Stinebrickner, T.R. (2004). “Time-use and college outcomes”. Journal of Econometrics 121 (1-2), 243-269. 
$\mathrm{Su}, \mathrm{X}$. (2004). "The allocation of public funds in a hierarchical educational system". Journal of Economic Dynamics and Control 28 (12), 2485-2510.

Suomi, S.J. (1999). "Developmental trajectories, early experiences, and community consequences: Lessons from studies with rhesus monkeys". In: Keating, D.P., Hertzman, C. (Eds.), Developmental Health and the Wealth of Nations: Social, Biological, and Educational Dynamics. Guilford Press, New York, pp. 185200 .

Taber, C.R. (2001). "The rising college premium in the eighties: Return to college or return to unobserved ability?" Review of Economic Studies 68 (3), 665-691.

Taggart, R. (1995). Quantum Opportunity Program. Opportunities Industrialization Centers of America, Philadelphia, PA.

Terman, L.M., Merrill, M.A. (1960). Stanford-Binet Intelligence Scale: Manual for the Third Revision Form L-M. Houghton Mifflin, Boston.

Tiegs, E.W., Clark, W.W. (1970). Examiner's Manual and Test Coordinator's Handbook: California Achievement Tests. McGraw-Hill.

Tierney, J.P., Grossman, J.B., Resch, N.L. (1995). Making a Difference: An Impact Study of Big Brothers/Big Sisters. Public/Private Ventures, Philadelphia, PA.

Turkheimer, E., Haley, A., Waldron, M., D’Onofrio, B., Gottesman, I.I. (2003). “Socioeconomic status modifies heritability of IQ in young children". Psychological Science 14 (6), 623-628.

Urzua, S. (2006). "The effects of cognitive and noncognitive skills on racial and ethnic wage gaps." Unpublished manuscript. University of Chicago, Department of Economics.

Walker, G.C., Vilella-Velez, F. (1992). Anatomy of a Demonstration: The Summer Training and Education Program (STEP) from Pilot Through Replication and Postprogram Impacts. Public/Private Ventures, Philadelphia, PA.

Weinberg, B.A. (2001). "An incentive model of the effect of parental income on children". Journal of Political Economy 109 (2), 266-280.

Willis, R.J. (1986). "Wage determinants: A survey and reinterpretation of human capital earnings functions". In: Ashenfelter, O., Layard, R. (Eds.), Handbook of Labor Economics. North-Holland, New York, pp. 525-602. 